\title{
Estudo dos fatores associados à capacidade para o trabalho em trabalhadores do Setor Elétrico
}

Maria Carmen Martinez

Tese apresentada ao Programa de PósGraduação em Saúde Pública da Faculdade de Saúde Pública da Universidade de São Paulo para obtenção do título de Doutor em Saúde Pública

Área de concentração: Epidemiologia

Orientador: Profa. Dra. Maria do Rosário Dias de Oliveira Latorre

São Paulo

2006 
É expressamente proibida a comercialização deste documento tanto na sua forma impressa como eletrônica. Sua reprodução total ou parcial é permitida exclusivamente para fins acadêmicos e científicos, desde que na reprodução figure a identificação do autor, título, instituição e ano da tese/dissertação. 


\section{AGRADECIMENTOS}

A Deus, por me sustentar e guiar em meus caminhos.

Ao meu companheiro William e às minhas amigas Elza, Paula e Tereza que estiveram ao meu lado nos momentos mais difíceis.

A duas pessoas que foram fundamentais e quem sem elas esta pesquisa não teria sido possível: Luiz Carlos de Miranda Junior, Gerente de Segurança do trabalho, Saúde e Qualidade de Vida, e Artur Jaques Goldfeder, Epidemiologista.

À minha querida orientadora, Profa. Dra. Maria do Rosário Dias de Oliveira Latorre, que desde muito antes deste doutorado vem sendo um incentivo e um exemplo.

Às minhas colegas na Faculdade de Saúde Pública, Aline, Luciana, Márcia, Maria, Stela e Tatiana, pela alegria e companheirismo.

E, em especial, aos trabalhadores da empresa onde ocorreu a pesquisa, pela simpatia com que me acolheram e pela colaboração e disposição em participarem do estudo. 
“Algumas vezes, digo que estou bem porque necessito dizer ou seja para manter o meu emprego, ou para manter a minha família ao qual depende do meu emprego, não digo que não estou cansado porque minha família me espera em casa meus filhos para brincar minha esposa para lhe dar atenção e com eles dispor de carinhos. Infelizmente no Brasil, isto é que acontece com muitos trabalhadores brasileiros, principalmente ele sendo homem omitindo algumas vezes a verdade como, questões de saúde como dar um exemplo por vários motivos financeiros e outros e o caso de muitos pais de família, estou bem sou forte eu consigo com isto, deixa comigo. Isto são coisas reais e já vi muitos exemplos. Porém nesta pesquisa meus dados são verdadeiros. Desejo que esta pesquisa você vai da melhor forma.

Boa sorte. Obrigado.”

(Mensagem deixada por um trabalhador da população de estudo) 
Martinez MC. Estudo dos fatores associados à capacidade para o trabalho em trabalhadores do Setor Elétrico [Tese de Doutorado]. São Paulo: Faculdade de Saúde Pública da USP; 2006.

\section{RESUMO}

Introdução - A capacidade para o trabalho é influenciada por vários fatores, incluindo a condição de saúde, características sócio-demográficas, estilo de vida e fatores relacionados ao trabalho. Objetivo - Analisar os fatores associados à capacidade para o trabalho em uma população de eletricitários. Métodos - Estudo transversal onde foram analisados 475 trabalhadores, voluntários, de uma empresa privada no setor eletricitário do Estado de São Paulo, Brasil. Os dados foram coletados por meio de questionários auto-preenchidos (Índice de Capacidade para o Trabalho - ICT, Escala Estresse no Trabalho - EET, Medical Outcomes Study 36 Item short form health survey - SF-36, Questionário de Baecke, Questionário de tolerância de Fagerström e Questionário AUDIT). A relação entre as variáveis foi analisada por meio do coeficiente de correlação de Spearman, e para comparação das médias foram utilizados os testes Mann-Whitney e Kruskal-Wallis. A análise conjunta das variáveis foi feita por meio de regressão linear múltipla. Resultados Foi identificada uma diminuição progressiva do valor do ICT significativamente associada aos aumentos da idade $(\mathrm{r}=-0,16, \mathrm{p}<0,001)$, do índice de massa corporal $(\mathrm{r}=-0,17, \mathrm{p}<0,001)$, do consumo de álcool $(\mathrm{r}=-0,11, \mathrm{p}=0,019)$, do tempo na empresa $(\mathrm{r}=-0,17, \mathrm{p}<0,001)$ e da intensidade do estresse no trabalho $(\mathrm{r}=-0,37, \mathrm{p}<0,001)$. O valor do ICT apresentou elevação associada ao incremento da prática de atividade física $(\mathrm{r}=0,19, \mathrm{p}<0,001)$. A média do valor do ICT esteve associada à unidade de trabalho $(\mathrm{p}=0,043)$. O ICT esteve associado significativamente com as diversas dimensões do estado de saúde físico e mental ( $p<0,001$ em todas as dimensões). A análise múltipla, ajustada por sexo e tempo na empresa, evidenciou que os fatores que melhor explicaram a variação do ICT foram o estresse no trabalho e as dimensões da saúde física. Uma segunda análise, excluídas as dimensões da saúde, 
mostrou que o estresse no trabalho, a unidade de trabalho e características do estilo de vida foram os fatores que melhor explicaram a variação do ICT. Conclusões - A pesquisa evidenciou que o estresse decorrente de fatores psicossociais do trabalho, a elevação do índice de massa corporal, o consumo de bebida alcoólica e o local de trabalho podem contribuir para a diminuição da capacidade para o trabalho, e que uma boa qualidade do estado da saúde física e a prática de atividade física podem contribuir para a manutenção da capacidade para o trabalho dos eletricitários.

Descritores: capacidade para o trabalho, saúde do trabalhador, fatores psicossociais no trabalho, trabalhadores, ambiente de trabalho, condições de trabalho, eletricidade. 
Martinez MC. Study of the factors associated with work ability in electric sector workers [Thesis]. São Paulo: Faculdade de Saúde Pública da USP; 2006.

\begin{abstract}
Introduction - The work ability receives influence of several factors, including the health state, social and demographic characteristics, the lifestyle, and factors related to work. Aim - To analyze the factors associated with work ability in a population of electric sector workers. Methods - This is a cross-sectional study. There have been analyzed 475 volunteers workers of a private company of the electric sector of São Paulo, Brazil. They answered the questionnaires: Work Ability Index - WAI, Work Stress Scale - WSS, Medical Outcomes Study 36 - Item short form health survey SF-36, Baecke Questionnaire, Fagerström Tolerance Questionnaire and AUDIT test. These questionnaires got information regarding work ability, stress related to psychosocial factors at work, health state, smoking, alcohol intake and practice of physical activities. The statistical analyses were done using Spearman correlation coefficient, Mann-Whitney test, Kruskal-Wallis test, and multiple linear regression models. Results - There was a significant progressive decrease of the WAI value associated to the increase of the age $(r=-0,16, p<0,001)$, body mass index $(r=-0,17$, $\mathrm{p}<0,001)$, alcohol intake $(\mathrm{r}=-0,11, \mathrm{p}=0,019)$, time at company $(\mathrm{r}=-0,17, \mathrm{p}<0,001)$ and intensity of work stress $(\mathrm{r}=-0,37, \mathrm{p}<0,001)$. The WAI value presented elevation associated to the increment of the practice of physical activities $(r=0,19, p<0,001)$. The mean of WAI was associated to workplace $(p=0,043)$. The WAI had significant association with the several dimensions of the physical and mental health state ( $\mathrm{p}<0,001$ in all dimensions). The multiple analyses, adjusted for sex and time at company, showed that the factors that better explained the variability of WAI were work stress and the physical health dimensions. Another analysis, excluded the health dimensions, showed that work stress, local of work and lifestyle characteristics were those that better explained the variability of WAI. Conclusions - The stress related to psychosocial factors of the work, the body mass increase, the
\end{abstract}


alcohol intake and the workplace can contribute to the decrease of work ability, and a good physical health state and the practice of physical activity can contribute to the maintenance of the work ability of the electric sector workers.

Key words: work ability, worker's health, psychosocial factors at work, workers, working environment, working conditions, electricity. 


\section{ÍNDICE}

1 - INTRODUÇÃO

Pág.

1.1 - Determinantes e fatores associados à capacidade para o trabalho 5

1.2 - Justificativa do estudo 14

1.3 - O trabalho no Setor Elétrico 17

2 - OBJETIVOS 26

2.1 - Geral 26

2.2 - Específicos 26

3 - MATERIAIS E MÉTODOS 27

3.1 - Tipo de estudo 27

3.2 - Local de estudo 27

3.3 - População de estudo 27

3.4 - Metodologia 31

3.5 - Análise estatística 40

3.6 - Programas de computador $\quad 42$

3.7 - Aspectos éticos $\quad 42$

4 - RESULTADOS 44

4.1 - Análise das perdas 44

4.2 - Confiabilidade dos questionários 46

4.3 - Caracterização da população de estudo $\quad 47$

4.4 - Análise do Índice de capacidade para o trabalho $\quad 54$

4.5 - Análise dos fatores associados à capacidade para o trabalho 57

4.6 - Análise de regressão linear múltipla (análise conjunta dos fatores associados) $\quad 62$

5 - DISCUSSÃO 78

5.1 - Aspectos metodológicos 78

5.2 - Perfil da população de estudo $\quad 88$

5.3 - Fatores associados à capacidade para o trabalho 95

5.4 - Considerações finais 112 


\section{Pág.}

6 - CONCLUSÕES 115

7 - REFERÊNCIAS 117

ANEXOS 139

Anexo 01: Termo de Consentimento Livre e Esclarecido 140

Anexo 02: Cronograma de trabalho 141

Anexo 03: Informações demográficas e funcionais 142

Anexo 04: Índice de capacidade para o trabalho 143

Anexo 05: Escala estresse no trabalho 146

Anexo 06: Estado de saúde: Medical Outcomes Study 36 - Item short form 147 health survey - SF-36

Anexo 07: Prática de atividade física - Questionário de Baecke 153

Anexo 08: Tabagismo - Questionário de tolerância de Fagerström 155

Anexo 09: Consumo de bebida alcoólica - Questionário AUDIT 156

Anexo 10: Parecer do Comitê de Ética de aprovação da pesquisa 158

Anexo 11: Análise da confiabilidade dos questionários 159

Anexo 12: Análise de resíduos dos modelos estatísticos 163

Anexo 13: Comparação do perfil de saúde e de capacidade para o trabalho 164 com outro grupo de trabalhadores 


\section{LISTA DE TABELAS, GRÁFICOS E FIGURAS}

Figura 1 - Modelo teórico do estresse-desgaste

Pg.

Figura 2 - Fatores associados à capacidade para o trabalho 5

$\begin{array}{ll}\text { Figura } 3 \text { - Campos de atuação do Setor Elétrico } & 18\end{array}$

Tabela 1 - Análise comparativa entre perdas e participantes segundo características demográficas e funcionais, variáveis qualitativas, Campinas e região, 2005.

Tabela 2 - Análise comparativa entre perdas e participantes segundo características demográficas e funcionais, variáveis quantitativas, Campinas e região, 2005.

Tabela 3 - Valores do alpha de Cronbach por dimensão do ICT, Campinas e região, 2005.

Tabela 4 - Distribuição da população de estudo (nº e \%) segundo variáveis demográficas, Campinas e região, 2005.

Tabela 5 - Distribuição da população de estudo (nº e \%) segundo variáveis qualitativas relativas ao estilo de vida, Campinas e região, 2005.

Gráfico 1 - Distribuição dos trabalhadores tabagistas (\%) segundo grau de dependência ao tabaco, Campinas e região, 2005.

Tabela 6 - Estatística descritiva das variáveis quantitativas relativas ao estilo de vida, Campinas e região, 2005.

Tabela 7 - Distribuição da população de estudo (nº e \%) segundo variáveis funcionais qualitativas, Campinas e região, 2005.

Tabela 8 - Estatística descritiva dos componentes do estresse no trabalho, Campinas e região, 2005.

Tabela 9 - Estatística descritiva das variáveis relativas ao estado de saúde, Campinas e região, 2005.

Tabela 10 - Distribuição da população de estudo ( $n^{\circ}$ e \%) segundo pontuação das dimensões do Índice de Capacidade para o Trabalho, Campinas e região, 2005. 
Tabela 11 - Distribuição da população segundo doenças auto-referidas $\left(n^{\circ}\right.$ e \%), Campinas e região, 2005.

Tabela 12 - Estatística descritiva do escore de capacidade para o trabalho segundo características demográficas, Campinas e região, 2005.

Tabela 13 - Estatística descritiva do escore de capacidade para o trabalho segundo as características qualitativas do estilo de vida, Campinas e região, 2005.

Tabela 14-Coeficientes de correlação entre variáveis quantitativas relacionadas ao estilo de vida e capacidade para o trabalho, Campinas e região, 2005.

Tabela 15 - Estatística descritiva do escore de capacidade para o trabalho segundo variáveis qualitativas relacionadas ao trabalho, Campinas e região, 2005.

Tabela 16 - Coeficientes de correlação entre variáveis relacionadas ao estado de saúde e capacidade para o trabalho, Campinas e região, 2005.

Tabela 17 - Relação de variáveis selecionadas para a análise de regressão linear múltipla, Campinas e região, 2005.

Tabela 18 - Descrição das etapas de modelagem múltipla dos fatores associados à capacidade para $\mathrm{o}$ trabalho, $1^{\mathrm{a}}$ modelagem (incluídas as dimensões do estado de saúde), Campinas e região, 2005.

Tabela 19 - Coeficientes de correlação entre as dimensões da saúde e capacidade para o trabalho, Campinas e região, 2005.

Tabela 20 - Descrição das etapas de modelagem múltipla dos fatores associados à capacidade para o trabalho, $2^{\mathrm{a}}$ modelagem (excluídas as dimensões do estado de saúde), Campinas e região, 2005. 


\section{1 - INTRODUÇÃO}

No mundo ocidental tem sido observado, principalmente a partir dos anos 80, o envelhecimento da população trabalhadora. Esse processo foi acompanhado de declínio da proporção de trabalhadores com idade entre 50 e 54 anos, aumento da proporção daqueles com idade entre 55 e 64 anos e elevação da razão de dependência, definida como o número de pessoas dependentes em relação ao número de pessoas trabalhando em uma população (ILMARINEN et al. 1991a, ILMARINEN 1997, 2001). Com isso, questões referentes à idade de aposentadoria, capacidade para o trabalho e saúde do trabalhador em fase de envelhecimento passaram a ser objeto de estudo na área de saúde do trabalhador. O estudo que representou o primeiro marco teórico importante neste campo de conhecimento foi realizado pelo Finnish Institute of Occupational Health (FIOH). Este estudo analisou uma coorte no período de 1981 a 1992, com o objetivo de avaliar se o critério de aposentadoria por idade vinculada ao tipo de trabalho continuava sendo adequado e, também, de verificar como fatores do trabalho, saúde, capacidade física, capacidade para o trabalho e esforço percebido, influenciariam o trabalhador em fase de envelhecimento (ILMARINEN et al. 1991a, 1991b).

Além de embasar modificações no sistema de aposentadorias finlandês, os estudos do FIOH possibilitaram consolidar a base teórica sobre os principais determinantes da capacidade para o trabalho, as conseqüências positivas de uma boa qualidade da capacidade para o trabalho e, ainda, recomendar medidas de intervenção válidas para promover e proteger a capacidade para o trabalho (ILMARINEN et al. 1991a; ILMARINEN e RANTANEN 1999; ILMARINEN 2001). Além disso, propuseram o Índice de Capacidade para o Trabalho - ICT, que é um questionário que possibilita a avaliação da capacidade para o trabalho considerando a percepção do próprio trabalhador. 
Os estudos do FIOH sobre envelhecimento e capacidade para o trabalho tomaram como base o modelo teórico estresse-desgaste (stress-strain) de Rutenfranz (ILMARINEN et al. 1991a), que está apresentado na Figura 1.

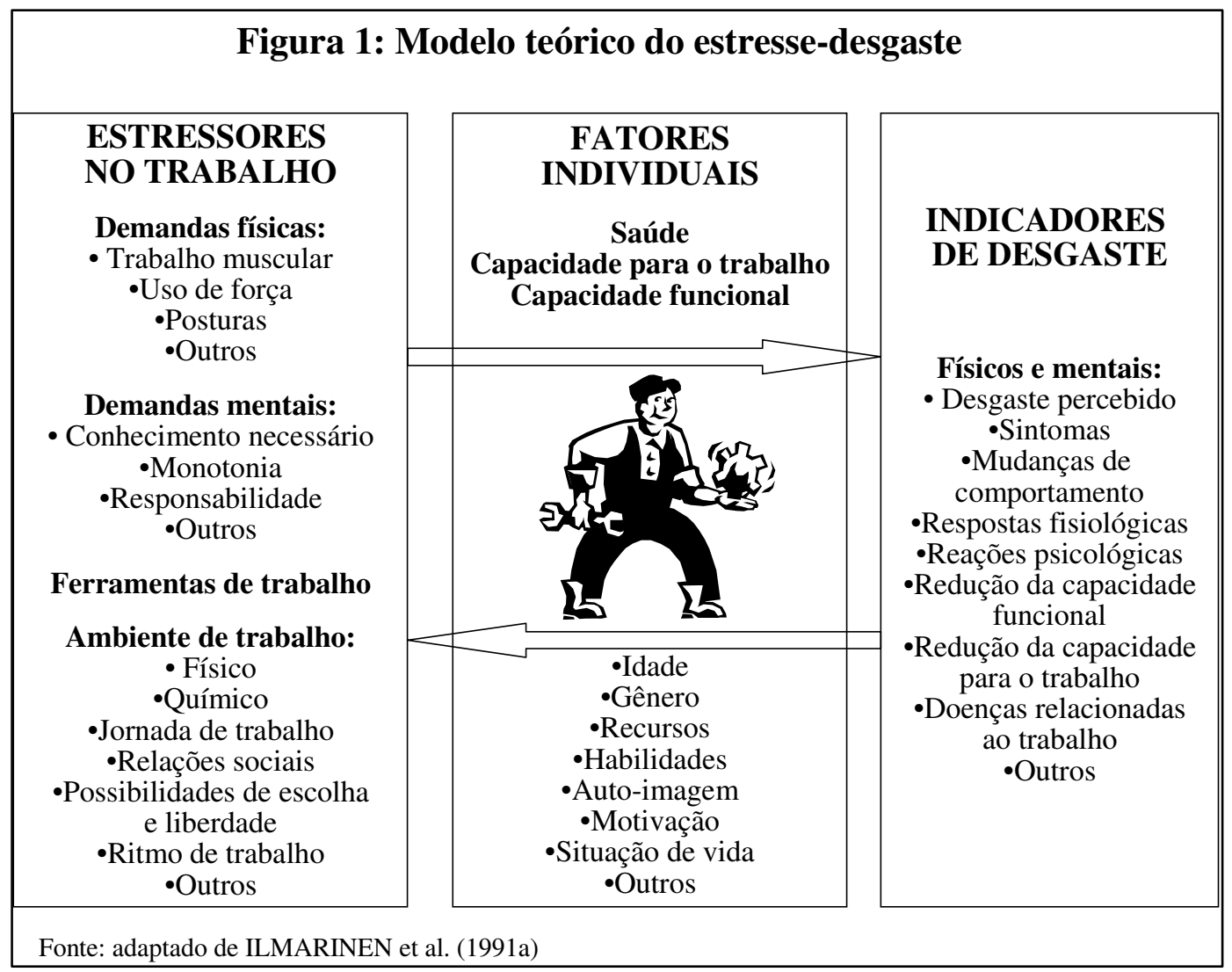

Segundo este modelo, o desgaste que o trabalhador vivencia depende tanto de estressores relacionados ao trabalho como de características e habilidades do trabalhador (COLQUHOUN e RUTENFRANZ 1980; ILMARINEN et al. 1991a; TUOMI et al. 1991a). Os estressores podem ser decorrentes das cargas física e mental do trabalho, e do ambiente e das ferramentas do trabalho. Esse processo é influenciado por características do indivíduo que vão condicionar sua capacidade de enfrentamento, podendo haver diferentes respostas ao estresse, com diferentes manifestações físicas e/ou mentais ao esforço realizado (COLQUHOUN e RUTENFRANZ 1980; ILMARINEN et al. 1991a; TUOMI et al. 1991a). 
Os pesquisadores do FIOH partiram da concepção que a capacidade para o trabalho diz respeito às qualificações do trabalhador para lidar com as exigências do trabalho, sendo baseada em sua capacidade física, mental e social. Situações em que as exigências são superiores ou inferiores aos recursos do trabalhador podem ser resultantes tanto de um trabalho não adequado às características do trabalhador, como de uma condição na qual o trabalho não é percebido como significativo e respeitado (ILMARINEN et al. 1991a).

O desgaste decorrente das exigências do trabalho pode desencadear respostas fisiológicas crônicas e agudas, reações psicológicas e mudanças comportamentais, com possibilidade de diminuição da capacidade funcional e da capacidade para o trabalho e desencadeamento de doenças relacionadas ao trabalho. Por outro lado, exigências que se caracterizem como positivas podem promover e proteger a saúde, a capacidade para o trabalho e a capacidade funcional, qualquer que seja a idade do trabalhador (ILMARINEN et al. 1991a; TUOMI et al. 1997a).

Cabe ressaltar que o conceito de desgaste aqui adotado difere do apresentado por LAURELL e NORIEGA (1989, p.111), entendido como "a perda da capacidade potencial e/ou efetiva corporal e psíquica". Para estes autores, o desgaste resultante do processo de adaptação decorrente da interação dinâmica entre os diversos elementos do processo de trabalho e o corpo do trabalhador, deve ser entendido em um contexto de problematização da saúde-doença enquanto processo social, devendo revelar as dinâmicas dos processos biopsíquicos (LAURELL e NORIEGA 1989; SELIGMANN-SILVA 1994).

A noção de desgaste adotada nesta pesquisa tem raízes na vertente teórica que adota o conceito de estresse no trabalho e que se desenvolveu em modelos mais complexos, incorporando a análise de aspectos sociais e antropológicos, incluindo o exame de aspectos referentes ao âmbito da empresa, à organização do trabalho e ao contexto social (SELIGMANN-SILVA 1994, 1999). Esse modelo contempla uma 
abordagem psicossocial que, sem correr ao exame da dinâmica intrapsíquica, abriu uma nova linha para os estudos sobre estresse (SELIGMANN-SILVA 1999).

Ao referencial teórico que embasou os estudos do FIOH, foi incorporada, ainda na década de 90, a concepção de envelhecimento e capacidade para o trabalho da Organização Mundial da Saúde que integra trabalho, estilo de vida, envelhecimento e saúde como condicionantes do envelhecimento funcional (OMS 1993; TUOMI et al. 1997a). TUOMI et al. (1997a) salientam que, quando se objetiva a promoção da saúde, avaliar saúde somente por meio da presença de doenças ou pela capacidade funcional torna-se um método limitado que deve ser substituído por uma avaliação mais abrangente e integral, contemplando os diferentes aspectos da saúde. Por esta razão, o referencial teórico que embasou os estudos do FIOH e avaliava saúde por meio da capacidade funcional e da presença de doenças, foi expandido integrando trabalho, estilo de vida, envelhecimento e uma visão global de saúde (TUOMI et al. 1997a).

O conceito de capacidade para o trabalho, proposto a partir dos estudos do FIOH, enfatiza que esta é a condição resultante da combinação entre recursos humanos em relação às demandas físicas, mentais e sociais do trabalho, gerenciamento e comunidade do trabalho, cultura organizacional e ambiente de trabalho (ILMARINEN 2001, 2002). Este conceito foi expresso com "quão bem está, ou estará, um (a) trabalhador (a) presentemente ou num futuro próximo, e quão capaz ele ou ela podem executar seu trabalho em função das exigências, de seu estado de saúde e capacidades físicas e mentais" (FISCHER 2005, p.9).

Pode-se inferir, portanto, que a capacidade para o trabalho pode ser influenciada por um processo multifatorial em que os diversos elementos interagem entre si, muitas vezes de maneira complexa (ILMARINEN 2001; COSTA et al 2005; ILMARINEN et al. 2005; ILMARINEN 2006). A seguir, serão descritos os fatores considerados como determinantes ou associados à capacidade para o trabalho. 


\section{1 - Determinantes e fatores associados à capacidade para o trabalho:}

A capacidade para o trabalho, considerada como resultante de um processo dinâmico entre recursos do indivíduo em relação ao seu trabalho, sofre modificações em função de vários fatores, entre eles a condição de saúde, as características sóciodemográficas, o estilo de vida, o envelhecimento e os fatores relacionados ao trabalho (OMS 1993; TUOMI et al. 1997a; ILMARINEN 1997, 2001; POHJONEN 1999). Estes fatores estão ilustrados de forma esquemática na Figura 2, que não pretende ser um modelo estrutural e hierárquico de determinação, mas expressa o sentido de causalidade em um modelo funcionalista.

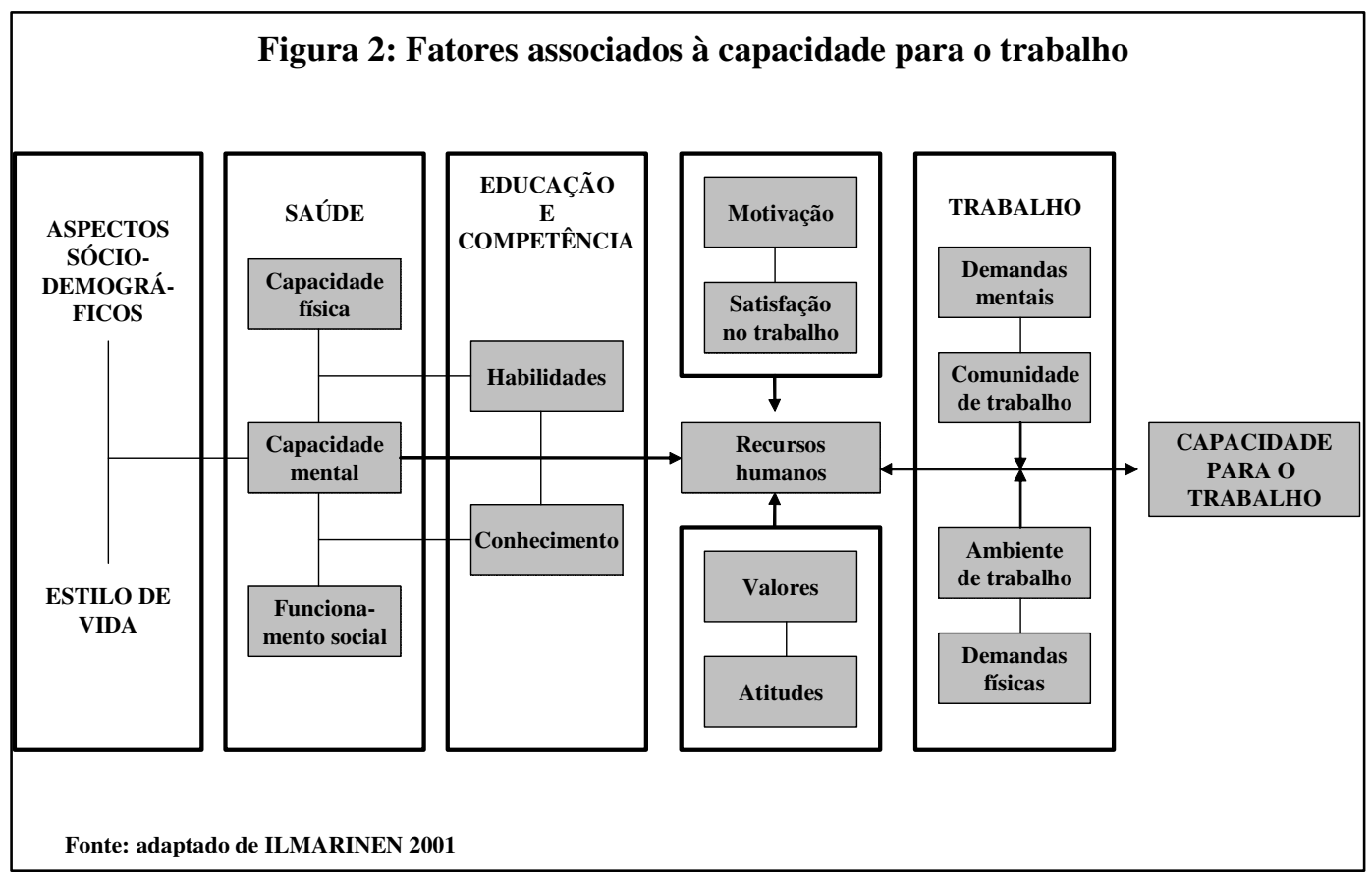

\section{Aspectos sócio-demográficos:}

A idade é identificada como um fator determinante da capacidade para o trabalho. Para a Organização Mundial da Saúde, a categoria "trabalhador em envelhecimento" começa a partir da idade de 45 anos quando a capacidade funcional 
necessária à execução de determinadas tarefas começa a diminuir (OMS 1993). Além disso, o envelhecimento cronológico tende a ser acompanhado pelo aparecimento e/ou agravamento de diversos tipos de doenças, favorecendo a deterioração da capacidade funcional física e mental (ILMARINEN et al. 1997; SEITSAMO e KLOCKARS 1997; TUOMI et al. 1997a, 1997b; KISS et al. 2002; SÖGRENRÖNKÄ et al. 2002).

Entretanto, é importante destacar que estudos junto a trabalhadores finlandeses (ILMARINEN e TUOMI 1992) e brasileiros (MONTEIRO 1999; BELLUSCI 2003) identificaram que esta associação não é linear ou pode estar ausente, evidenciando a interferência de outros fatores nesta relação.

O sexo é apontado como fator associado à capacidade para o trabalho. A pior condição de saúde entre as mulheres é conhecida e influenciada pela inserção da mulher no mercado de trabalho, inserção esta caracterizada por piores condições de trabalho e salariais quando comparadas aos homens e, ainda, pela dupla jornada de trabalho (emprego/casa) (SALIM 2003).

Estudos como o de PERKIÖ-MÄKELÄ (2000), na Finlândia, e os de BELLUSCI (2003) e de WALSH et al. (2004), no Brasil, evidenciaram que o sexo feminino tem maior risco para diminuição da capacidade para o trabalho.

Melhores condições sócio-econômicas são apontadas como associadas a uma melhor condição da capacidade para o trabalho (AITTOMÄKI et al. 2003). Em estudos como os de TUOMI et al. (1991a), MONTEIRO (1999), METZNER (2000) e AITTOMÄKI et al. (2003), observa-se que nível sócio-econômico é representado por meio de diferentes critérios, podendo ser citados a escolaridade, a renda e as condições de vida e de trabalho determinadas pela inserção profissional. Entretanto, os padrões de associação entre condições sócio-econômicas e capacidade para o trabalho são complexos, recebendo influência de fatores relacionados ao trabalho, às condições de vida e aos hábitos de saúde (AITTOMÄKI et al. 2003). 
O nível educacional e a competência profissional também são considerados fatores associados à capacidade para o trabalho. Segundo POHJONEN (1999) e ILMARINEN (2002), a capacidade para o trabalho pode ser promovida por meio do aumento da competência, entendida como as habilidades e conhecimentos que o trabalhador dispõe para executar seu trabalho, em especial frente às mudanças nos processos de trabalho demandando maior ênfase em habilidades psicológicas e cognitivas.

TUOMI et al. (2001) verificaram que o hábito de estudar e a possibilidade de desenvolvimento e de influenciar o trabalho apresentaram forte associação positiva com capacidade para o trabalho. No mesmo estudo, o treinamento mostrou ser um fator preditivo para boa capacidade para o trabalho entre aqueles cuja capacidade havia sido pobre ou moderada antes do treinamento. $\mathrm{O}$ treinamento também mostrou melhores resultados para os trabalhadores envolvidos com trabalho físico, com poucas possibilidades de desenvolvimento.

\section{Estilo de vida:}

$\mathrm{O}$ estudo longitudinal do FIOH evidenciou que a prática regular de atividade física e a satisfação com a vida são preditores de boa capacidade para o trabalho (TUOMI et al. 1991a, 1991b; SEITSAMO e ILMARINEN 1997). O papel protetor da atividade física é explicado pelo seu efeito na preservação da capacidade músculo-esquelética e cardiorrespiratória e no controle do peso corporal, bem como pelo seu efeito reduzindo as reações emocionais ao estresse e aumentando a autoestima (OMS 1993; TUOMI et al. 1997b; POHJONEN 2001a; POHJONEN e RANTA 2001).

A obesidade também está associada à diminuição da capacidade para o trabalho. POHJONEN (2001a) e POHJONEN e RANTA (2001), estudando os efeitos da prática de atividade física sobre a capacidade para o trabalho em mulheres com atuação em assistência de saúde domiciliar na Finlândia, identificaram que, após 
seguimento de 5 anos, houve aumento do risco para perda da capacidade para o trabalho entre as pessoas obesas. $\mathrm{O}$ excesso de peso pode exercer impacto negativo sobre a capacidade para o trabalho por afetar a capacidade cardiorrespiratória e músculo-esquelética e por favorecer o aumento da morbidade por doenças crônicas (ILMARINEN 2006).

O tabagismo e o consumo de álcool também têm sido incluídos em estudos sobre capacidade para o trabalho. Entretanto, SEITSAMO e ILMARINEN (1997) salientam que os efeitos destes fatores nem sempre são lineares e que indivíduos que praticam atividade física também podem ser de tabagistas ou etilistas, o que poderia favorecer a confusão dos resultados.

De maneira geral, os estudos que contemplam as questões do estilo de vida em relação à capacidade para o trabalho, privilegiam uma concepção de estilo de vida compatível com a da Organização Mundial da Saúde. Nessa concepção, um estilo de vida saudável diz respeito a um comportamento individual de adoção de hábitos que podem reduzir o risco de afetar a saúde, com ênfase em questões como prática de atividade física, consumo de álcool, tabagismo e obesidade (WHO 1999).

\section{Saúde:}

A saúde é apontada como o fator que exerce o maior impacto sobre a capacidade para o trabalho (POHJONEN 1999; TUOMI et al. 2001; ILMARINEN 2002, 2006; ILMARINEN et al. 1997, 2005). Nos estudos que abordam as relações entre capacidade para o trabalho e saúde, esta tem sido avaliada por meio de indicadores da capacidade funcional, da quantidade e do tipo de doenças físicas e mentais com diagnóstico médico referido ou, ainda, da percepção do estado geral de saúde.

A capacidade funcional é apontada como condição essencial para uma boa qualidade de saúde (ILMARINEN et al. 1997; POHJONEN 1999). A capacidade 
cardiorrespiratória e o funcionamento músculo-esquelético são considerados como os componentes da capacidade funcional que maior impacto exercem sobre a capacidade física (ILMARINEN et al.1991b; MATSUDO et al. 2001).

NYGÅRD et al. (1991) investigaram as relações entre capacidade física e capacidade para o trabalho no estudo longitudinal do FIOH. A capacidade física foi avaliada por meio do consumo máximo de oxigênio e da freqüência cardíaca como indicadores da capacidade cardiorrespiratória e por meio de testes de resistência e flexibilidade músculo-esquelética. A capacidade mental foi avaliada por meio de testes das funções visual, verbal, motora, memória e raciocínio. Os resultados mostraram associação da capacidade para o trabalho com resistência músculoesquelética e com velocidade visual e, embora as associações tenham sido significativas, as correlações não foram altas. Os autores consideraram que as medidas objetivas da capacidade física são úteis, mas não suficientes, para embasar decisões pertinentes à capacidade para o trabalho. Também consideraram que a capacidade mental demonstrou limitada relevância porque a avaliação da capacidade para o trabalho reflete primariamente características físicas.

ESKELINEN et al. (1991), analisando as relações entre avaliação clínica e auto-avaliação de saúde entre 174 trabalhadores finlandeses, concluíram que as respostas ao questionário sobre percepção do estado de saúde apresentaram boa correlação com fatores avaliados clinicamente.

BELLUSCI (2003) identificou que, entre as 14 doenças mais freqüentemente referidas entre os trabalhadores brasileiros que participaram de avaliações realizadas em 1997 e 2001, 10 apresentaram associação estatisticamente significativa com capacidade para o trabalho moderada ou fraca, sendo que entre elas estavam as lesões nas costas, lesões nos braços e pernas, doenças da coluna cervical, dor ciática, distúrbio emocional leve e gastrite ou duodenite. 


\section{Trabalho:}

Quando as demandas físicas e mentais do trabalho não estão adequadas aos recursos do trabalhador para lidar com elas, surgem exigências que podem desencadear respostas fisiológicas e psicológicas com repercussões negativas sobre a capacidade para o trabalho (ILMARINEN et al. 1991a). Nos estudos sobre capacidade para o trabalho, o mesmo tem sido contemplado sob diferentes aspectos, tais como conteúdo do trabalho (predominância de exigências físicas ou mentais), condições de trabalho, fatores psicossociais e/ou organização do trabalho e, ainda, satisfação no trabalho.

As condições de trabalho dizem respeito às condições físicas, químicas e biológicas do ambiente de trabalho, e repercutem sobre as condições físicas do trabalhador (COHN e MARSIGLIA 1994). Entre estas condições que podem configurar cargas físicas inadequadas podem ser citadas: riscos de acidentes, trabalho muscular estático, levantamento e transporte de peso, uso de força muscular, esforço intenso repentino, movimentos repetitivos, posturas simultâneas de flexão e torção, sujeira, umidade, calor, frio, ruído, mudanças de temperatura, equipamentos e ferramentas inadequados (ILMARINEN et al. 1991b; TUOMI et al. 1991a, 1997c, 2001).

Para a International Labour Organization (Organização Internacional do Trabalho), fatores psicossociais no trabalho são aqueles que "referem-se à interação entre e no meio ambiente de trabalho, conteúdo do trabalho, condições organizacionais e habilidades do trabalhador, necessidades, cultura, causas pessoais extra-trabalho que podem, por meio de percepções e experiência, influenciar a saúde, o desempenho no trabalho e a satisfação no trabalho" (ILO 1984, p.3). O conceito de fatores psicossociais inclui uma ampla variedade de condições e um grande número de fatores, sendo que a ação da interação desses elementos constitui o que tem sido chamado de "processo de estresse" e cujos resultados exercem impactos sobre a condição de saúde e o desempenho no trabalho (KALIMO 1987; SAUTER et al. 1998; LEVI 1998, 1999). 
Entre os diversos fatores psicossociais do ambiente de trabalho que podem configurar cargas mentais inadequadas para o trabalhador estão: conflito de papéis, conflito com chefias, tipo de atitude da chefia, medo de errar ou falhar, pressão de tempo, volume de trabalho, restrição no uso de habilidades e conhecimentos, limitação no controle sobre o próprio trabalho, falta de liberdade no trabalho, nível de responsabilidade, limitação no desenvolvimento profissional, falta de reconhecimento e de valorização, jornada e turnos de trabalho, monotonia, e conteúdo do trabalho (TUOMI et al. 1991a, 2001; AITTOMÄKI et al. 2003; BUGAJSKA e ŁASTOWIECKA 2005; ESTRYN-BEHAR et al. 2005; ILMARINEN et al. 2005; LINDBERG et al. 2005).

TUOMI et al. (1997c) verificaram que a análise conjunta de variáveis referentes ao estilo de vida e trabalho demonstrou que os fatores que apresentaram o melhor ajuste para explicar o aumento do nível da capacidade para o trabalho foram a melhoria das atitudes da chefia, a diminuição de movimentos repetitivos no trabalho e o aumento de atividade física vigorosa no tempo livre. Os fatores que apresentaram melhor ajuste para explicar a deterioração da qualidade da capacidade para o trabalho foram a diminuição no reconhecimento e na valorização do trabalho, a piora dos postos de trabalho, o aumento do trabalho em pé e a diminuição da atividade física vigorosa no tempo livre.

POHJONEN (2001b) observou que condições insatisfatórias do ponto de vista da ergonomia, como posturas inadequadas, transporte manual de objetos, uso de força e movimentos ou deambulação freqüente, foram as principais características determinantes de diminuição da capacidade para o trabalho entre mulheres que prestam serviços de saúde no domicílio, executando um trabalho caracterizado por elevadas exigências físicas. O estudo também demonstrou que condições adequadas do ponto de vista da ergonomia, como a possibilidade de controle sobre o trabalho e o suporte e as atitudes satisfatórias da liderança, estiveram associados à boa condição da capacidade para o trabalho em todas as faixas etárias estudadas. A autora concluiu que o foco de ações de promoção da capacidade para o trabalho deve ser direcionado 
prioritariamente para melhorias nas condições, no ambiente e na comunidade de trabalho.

Em outro estudo, TUOMI et al. (2001) verificaram que a boa qualidade das condições de trabalho esteve fortemente associada à boa qualidade da capacidade para o trabalho. As variáveis referentes às demandas e ambiente do trabalho (posturas, conteúdo do trabalho, uso de conhecimento, ambiente e ferramentas, ambiente físico, modificações nas tarefas, no ambiente e ferramentas e na carga mental) foram os fatores que melhor explicaram a capacidade para o trabalho. Em seguida, foram as variáveis referentes à comunidade e organização do trabalho (gerenciamento, liberdade, desafios no trabalho, jornada de trabalho e uso da experiência).

No Brasil, BELLUSCI (2003) verificou que as características da organização do trabalho que representaram fatores de risco para a capacidade para o trabalho foram a impossibilidade de exercer influência sobre o ritmo de trabalho, sobre o uso do tempo no trabalho, sobre o planejamento de pausas e sobre o planejamento de férias. Ainda na organização do trabalho, a impossibilidade de interação com colegas durante o desenvolvimento das tarefas e a impossibilidade de interação com colegas fora do ambiente de trabalho também representaram risco para a capacidade para o trabalho. As características do ambiente físico do trabalho que representaram fatores de risco para perda da capacidade para o trabalho foram o levantamento e transporte de pesos, o sentimento de exposição a acidentes de trabalho, a percepção de exposição ao frio e a percepção de exposição ao calor no ambiente de trabalho.

Além das condições físicas e da organização do trabalho, a satisfação no trabalho também pode estar associada à capacidade para o trabalho. A satisfação no trabalho é um estado emocional agradável resultante da avaliação que o indivíduo faz de seu trabalho e decorre da percepção da pessoa sobre como o trabalho satisfaz ou permite satisfação dos seus valores importantes em relação a este trabalho (LOCKE 1969). 
TUOMI et al. (1991a) consideraram a satisfação no trabalho como um indicador de estresse no trabalho, apresentando efeito positivo sobre a capacidade para o trabalho. A experiência e a satisfação com a vida e o histórico de trabalho condicionam os papéis, expectativas e valores associados a cada estágio da carreira dos trabalhadores, definindo diferenças entre as pessoas quanto à atitude em relação ao trabalho e à satisfação no trabalho, podendo gerar efeitos sobre a capacidade para o trabalho (TUOMI 1999; ILMARINEN 2001).

POHJONEN (1999) salienta o papel da satisfação com aspectos psicossociais no trabalho citando, entre outros, a satisfação com o planejamento, o conteúdo do trabalho, a utilização das capacidades, a variedade no trabalho e o suporte social.

MARTINEZ (2002), estudando a associação entre satisfação com aspectos psicossociais no trabalho e a saúde entre trabalhadores de área administrativa no Município de São Paulo, verificou que a satisfação no trabalho esteve associada à capacidade para o trabalho e esta associação foi independente de características sócio-demográficas e funcionais.

Considerando a necessidade de conhecer o papel dos diferentes fatores, no sentido de manter e promover a capacidade para o trabalho, ILMARINEN et al. (2005) acompanharam uma amostra representativa de trabalhadores finlandeses no período de 2000 a 2001. Os resultados mostraram que as condições psicofísicas de saúde e o desgaste mental decorrente de fatores do ambiente de trabalho foram os fatores que explicaram melhor o nível do índice de capacidade para o trabalho. $\mathrm{O}$ papel de características e recursos individuais, tais como competência, valores, atitudes, padrões familiares e de sociabilidade, foram menos significativos e sua importância diminuiu com a idade (ILMARINEN et al. 2005).

DELLVE et al. (2006) assinalam a necessidade de desenvolver estudos com uma abordagem mais ampla. Estes autores consideram que os estudos dos fatores relacionados ao trabalho e ao indivíduo não são suficientes para dar suporte a esforços e programas preventivos uma vez que os fatores macro-organizacionais são 
pré-requisitos na determinação da organização do trabalho e das características individuais. Para os autores, apesar da dificuldade em mensurar fatores contextuais, os estudos sobre capacidade para o trabalho devem contemplar questões relativas à estrutura sócio-econômica, tais como inserção no mercado de trabalho, setor de trabalho, condições de vida, recursos econômicos, localização geográfica e acesso a serviços de reabilitação, dada a necessidade de implementar teorias, conceitos e medidas sobre fatores contextuais que exercem impactos sobre a capacidade para o trabalho.

A preocupação de ILMARINEN et al. (2005) e DELLVE et al. (2006) em ampliar e aprofundar o escopo dos estudos sobre os determinantes e os fatores associados à capacidade para o trabalho ilustra o aumento na produção de estudos de qualidade sobre o tema. COSTA et al. (2005), atestam o crescente interesse e importância desta questão em função de suas implicações nas perspectivas sociais e econômicas, com benefícios para os indivíduos, empresas e sociedade como um todo.

\section{2 - Justificativa do estudo}

O processo de transição demográfica no Brasil vem sendo caracterizado pelo envelhecimento populacional, onde as mudanças na estrutura etária da população com aumento do peso relativo das pessoas com idade mais elevada são conseqüentes ao rápido e generalizado declínio da fecundidade que teve início na década de 60 (PATARRA 1995; CARVALHO e GARCIA 2003). A partir dos anos 80 o país apresenta uma elevação progressiva na participação proporcional das pessoas com idade a partir de 30 anos (IBGE 2004). Essas alterações na estrutura etária populacional condicionam o envelhecimento da força de trabalho e têm reflexos importantes na composição da população economicamente ativa e na razão de dependência da população. 
Os estudos sobre capacidade para o trabalho e envelhecimento funcional no Brasil iniciaram-se no final da década de 90 com a tradução e adaptação do ICT para a língua portuguesa.

MONTEIRO (1999), analisando a associação entre capacidade para o trabalho e algumas características demográficas, do estilo de vida e do trabalho, verificou que ter idade mais elevada (50 a 57 anos), ter menor número de doenças com diagnóstico médico, ser do sexo masculino e ter maior nível de escolaridade eram características associadas a uma melhor condição da capacidade para o trabalho.

BORGES (2002) verificou correlações estatisticamente significativas entre capacidade para o trabalho e fadiga em 34 trabalhadores de enfermagem de um hospital público da cidade de São Paulo, onde quanto maior a perda da capacidade para o trabalho, maior a projeção da fadiga sobre o corpo.

O estudo de MARTINEZ (2002) encontrou associações positivas estatisticamente significativas entre todas as dimensões da saúde analisadas e o ICT de 224 trabalhadores de área administrativa de empresa de auto-gestão em saúde e previdência privada no Município de São Paulo, sendo que estas associações foram independentes de características demográficas e funcionais.

BELLUSCI $(1998,2003)$ realizou estudo com desenho longitudinal, avaliando o índice de capacidade para o trabalho nos anos de 1997 e de 2001, entre servidores forenses na cidade de São Paulo. A autora buscou verificar se características demográficas, presença de doenças e características organizacionais e psicossociais do trabalho estavam associadas à capacidade para o trabalho. Os resultados evidenciaram que as características associadas à diminuição da capacidade para o trabalho foram: ser do sexo feminino, ser separado, divorciado ou viúvo e ser portador de alguns tipos de agravos (lesões nas costas, lesões nos braços e pernas, doenças da coluna cervical, dor ciática, distúrbio emocional leve e gastrite ou duodenite). Características da organização do trabalho (impossibilidade de exercer influência sobre o ritmo de trabalho, sobre o uso do tempo, sobre o planejamento de 
pausas e sobre o planejamento de férias, impossibilidade de interação com colegas durante o desenvolvimento das tarefas e impossibilidade de interação com colegas fora do ambiente laboral) também representaram fatores de risco para a capacidade para o trabalho. Finalmente, características do ambiente físico do trabalho (levantamento e transporte de pesos, sentir-se exposto a acidentes de trabalho, percepção de exposição ao frio e percepção de exposição ao calor no ambiente de trabalho) também foram identificadas como fatores de risco para a capacidade para o trabalho.

MARQUEZE (2005) identificou correlação entre o nível de satisfação geral no trabalho e a capacidade para o trabalho de 154 docentes de uma instituição privada de ensino superior no sul do país. Também observou que a satisfação com 9 dos 22 aspectos psicossociais do trabalho analisados esteve correlacionada com a capacidade para o trabalho. Estes aspectos foram: satisfação com a segurança no emprego, estilo da supervisão, tipo tarefas desempenhadas, possibilidade de crescimento na carreira, possibilidade de atingir aspirações, participação na tomada de decisão, liberdade no trabalho, clima psicológico e volume de trabalho.

Além dos estudos citados, foram identificados outros avaliando a distribuição da capacidade para o trabalho em algumas populações específicas: BELLUSCI et al. (1999), FISCHER et al. (1999) e FISCHER e BELLUSCI (2000) em trabalhadores de setor hospitalar; FISCHER (2000), FISCHER et al. (2000), MARTINS (2002), CHILLIDA e COCCO (2003), DURAN e COCCO (2004) e RAFFONE e HENNINGTON (2005) em trabalhadores de enfermagem; METZNER (2000) em trabalhadores de indústria têxtil; CANTERO et al. (2001) em trabalhadores da área de Recursos Humanos de uma empresa de papel e celulose; BOLDORI (2001) junto a bombeiros do Estado de Santa Catarina; e WALSH (2004) com trabalhadores de linha de produção de empresa produtora de materiais escolares e de escritório.

Esse panorama evidencia que o campo dos fatores associados à capacidade para o trabalho entre trabalhadores brasileiros, apesar de relevante no atual contexto de transição demográfica e de modificação das relações de produção e de trabalho, 
ainda não está amplamente investigado. Assim, esta pesquisa pretende analisar a associação entre capacidade para o trabalho e as características do trabalhador, de seu estado de saúde e do ambiente psicossocial do trabalho em trabalhadores do Setor Elétrico.

\section{3 - O trabalho no Setor Elétrico}

O Setor Elétrico, também chamado de setor eletricitário ou de energia elétrica, contempla o conjunto de processos, instrumentos e equipamentos destinados à geração, transmissão, distribuição e comercialização de energia elétrica (NOGUEIRA 1999; MTE 2002). Ele é organizado em três grandes campos de atividades (Figura 3):

- Geração de energia: ocorre em instalações e usinas hidrelétricas onde, por meio de processos termelétricos, hidrelétricos ou outros, a energia mecânica proveniente de quedas d'água é convertida em energia elétrica (NOGUEIRA 1999; MTE 2002).

- Transmissão de energia: a energia elétrica produzida é conduzida para subestações elevatórias, onde transformadores aumentam a tensão elétrica a níveis elevados de 138 a $500 \mathrm{kV}$. Em seguida a energia é transportada das subestações elevatórias em corrente alternada (60hz) através de cabos elétricos, até estações rebaixadoras próximas aos centros de consumo, onde a tensão será rebaixada para níveis de 67 a $138 \mathrm{kV}$ para ser distribuída aos consumidores (NOGUEIRA 1999; MTE 2002).

- Distribuição de energia: a partir das estações rebaixadoras, a energia elétrica é distribuída e comercializada aos consumidores finais através de redes elétricas aéreas ou subterrâneas, compostas por postes, torres, dutos subterrâneos, cabos e transformadores para novos rebaixamentos da tensão elétrica. Os grandes consumidores (indústrias e construções de grande porte) são abastecidos com 
tensões de 67 a $88 \mathrm{kV}$, os médios consumidores são abastecidos com potência de $13,8 \mathrm{kV}$, e os pequenos consumidores (residências, comércio e pequenas indústrias) são abastecidos com potência de 75 kVA (110, 220 e 380 V) (NOGUEIRA 1999; MTE 2002).

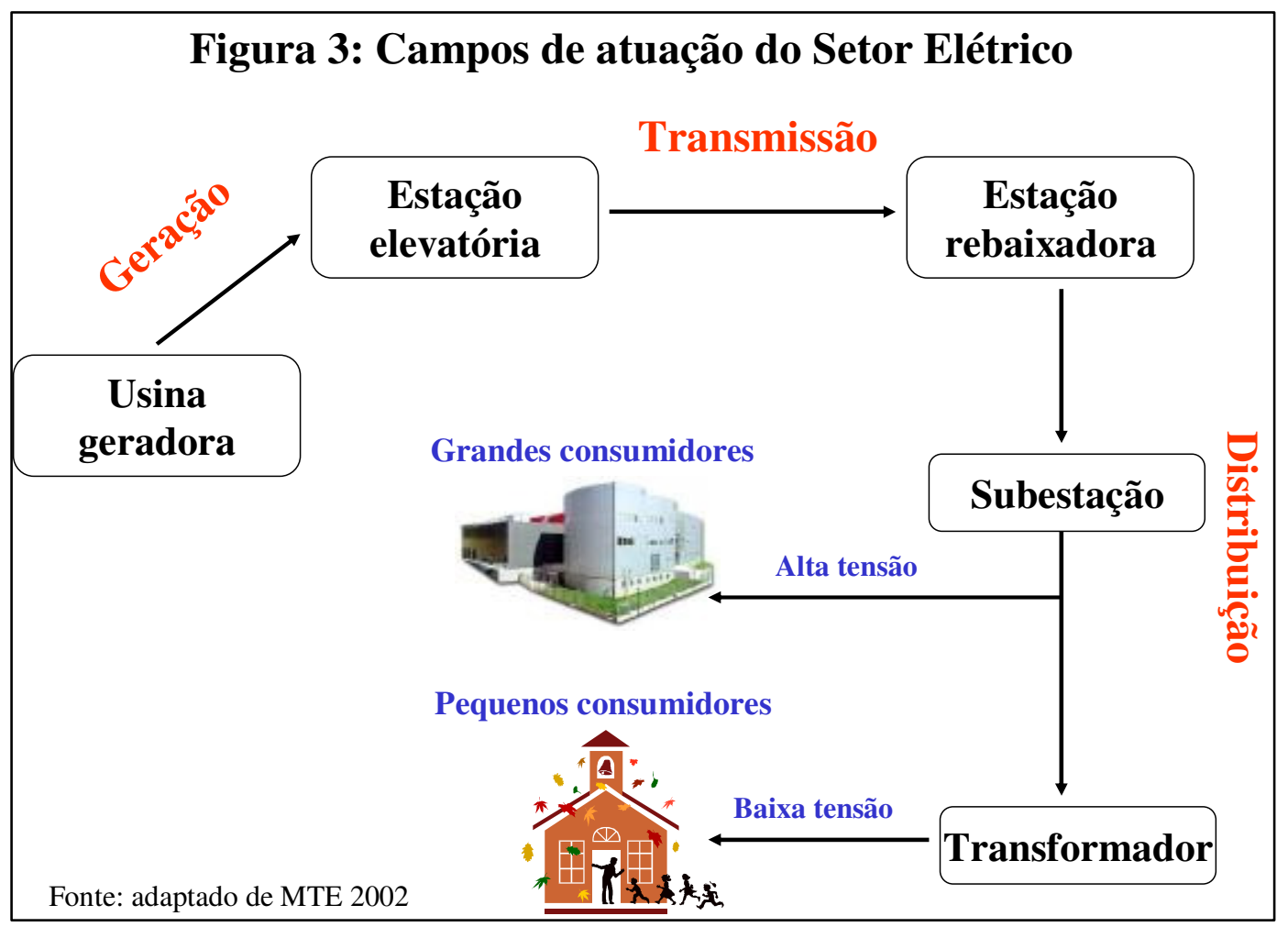

Originalmente sob controle estatal, o Setor Elétrico passou por processo de reestruturação que foi caracterizado pela privatização com transferência do controle estatal para a iniciativa privada nacional e estrangeira. Atualmente o Setor é regulado pela Agência Nacional de Energia Elétrica - ANEEL, autarquia criada pela Lei 9.427 de 26/12/1996 e que disciplina o regime das concessões de Serviços Públicos de Energia Elétrica (BRASIL 1996). O processo de reestruturação do Setor no país iniciou em 1992, sendo que no Estado de São Paulo o início ocorreu em 1996 (FUNDAÇÃO SEADE 2005).

No bojo deste processo, foram recorrentes as situações de terceirização de atividades, a redução do efetivo de trabalhadores por meio de demissões e de 
programas de aposentadoria e de demissão incentivada, a substituição de mão de obra por outra de menor qualificação, a fragmentação da classe com enfraquecimento da representatividade sindical, e as mudanças nos processos e equipamentos de trabalho visando racionalização produtiva e econômica (NOGUEIRA 1999; GUIMARÃES et al. 2002; MTE 2002).

Esse contexto trouxe profundas modificações nas condições e na organização do trabalho, nas relações de trabalho e na inserção do trabalhador no mercado de trabalho. Algumas das situações apontadas como origem de conseqüências negativas para a saúde e bem-estar dos trabalhadores das empresas do Setor Elétrico são: aumento da jornada de trabalho e do volume de trabalho, pressões de prazos e de responsabilidades, medo do desemprego, exigência de maior qualificação para o trabalhador remanescente, aumento da competitividade com deterioração nas relações interpessoais, introdução ou intensificação da informatização e de novas tecnologias, e precarização dos equipamentos, das instalações e das viaturas de trabalho (NOGUEIRA 1999; GUIMARÃES et al. 2002; MTE 2002).

As atividades executadas pelos trabalhadores na geração de energia elétrica estão relacionadas à instalação e manutenção de equipamentos e de maquinário, manutenção de instalações, operação de painéis de controle, supervisão dos processos de geração, transformação, e medição da energia elétrica (MTE 2002).

O trabalho executado na transmissão de energia elétrica compreende atividades relacionadas à inspeção, manutenção e construção de linhas de transmissão. A manutenção inclui a limpeza e substituição de dispositivos, de equipamentos e de estruturas, e o desmatamento e limpeza de faixas de servidão. A construção de linhas de transmissão inclui estudos de viabilidade, relatórios de impacto, desmatamentos, escavações, montagem de estruturas, instalação e lançamento de cabos e acessórios, e realização de testes (MTE 2002).

A distribuição de energia é considerada como o segmento com maior quantidade e diversidade de atividades, destacando-se: recebimento e medição de 
energia elétrica nas estações, rebaixamento do potencial de energia elétrica, construção de redes de distribuição e de estruturas e obras civis, montagem de estações de transformação e distribuição, montagem de painéis e centros de controle, manutenção das redes de distribuição, poda de árvores, limpeza de isoladores, de pára-raios e de estruturas da rede, limpeza e desmatamento das faixas de servidão, medição de energia elétrica nos consumidores, e operação dos centros de controle e supervisão da distribuição (MTE 2002). Essas atividades podem ser realizadas em sistemas energizados (linha viva) ou desenergizados (MTE 2002).

O trabalho no Setor Elétrico é caracterizado pela presença de demandas físicas e mentais importantes, e os riscos à saúde e segurança dos trabalhadores são considerados elevados, com possibilidade de agravos de grande gravidade, condicionados pelas especificidades do setor, pelas condições e pela organização do trabalho (NOGUEIRA 1999; GUIMARÃES et al. 2002; MTE 2002).

No que diz respeito aos acidentes de trabalho, dados do Ministério da Previdência Social (MPS 2003) mostram que, em 2003, houve uma incidência de 15,4 novos casos de acidentes de trabalho registrados para cada 1.000 trabalhadores cobertos pelo Seguro Acidente do Trabalho - SAT no setor de produção e distribuição de energia elétrica no Brasil. A taxa de incapacidade foi de 11,6 acidentes para cada 1.000 trabalhadores cobertos pelo SAT. Esses números, quando observados em uma classificação de 555 categorias de atividades econômicas, representam o $294^{\circ}$ posto em termos de incidência e o $331^{\circ}$ em termos de incapacidade, sugerindo que a ocorrência de acidentes é relativamente baixa.

Quando se observam as taxas de mortalidade e de letalidade, o panorama é mais preocupante evidenciando a gravidade dos acidentes ocorridos e refletindo os riscos existentes no exercício desta atividade. A taxa de mortalidade de 31,8 óbitos por acidente de trabalho para cada 100.000 empregados cobertos pelo SAT representa o $64^{\circ}$ posto em termos de mortalidade, e a taxa de letalidade de 20,6 óbitos por acidente de trabalho para cada 1.000 acidentes de trabalho registrados representa o $58^{\circ}$ posto em termos de letalidade (MPS 2003). 
A seguir, são relacionados os principais riscos à saúde apontados como presentes no desempenho das atividades dos trabalhadores do Setor Elétrico.

\section{- Riscos de origem elétrica:}

Os riscos de origem elétrica, inerentes ao trabalho no Setor, são considerados os principais agentes de risco do trabalhador na geração, transmissão e distribuição de energia elétrica (MTE 2002).

- Choque elétrico: é a resposta involuntária de um corpo à passagem de uma corrente elétrica através dele (WHSC 2003). Os efeitos do choque elétrico dependem da intensidade, frequiência e tipo de corrente elétrica, da tensão elétrica, do tempo de exposição à corrente e do trajeto da corrente pelo corpo humano (SILVA 1996; MTE 2002; WHSC 2003). Os efeitos diretos do choque elétrico podem ser queimaduras, contrações musculares, tetania, parada cardíaca, parada respiratória, destruição de tecidos e hemorragias internas. Também podem ocorrer efeitos indiretos resultantes de quedas e batidas (SILVA 1996; MTE 2002; WHSC 2003).

- Arco voltaico: consiste em um fluxo de corrente elétrica através de um meio isolante como o ar, emitindo vapores de material ionizado e raios ultravioleta, e produzindo calor capaz que provocar queimaduras e incêndios (MTE 2002).

- Campo eletromagnético: um campo eletromagnético - CEM é gerado quando ocorre a presença (campo elétrico) e a movimentação (campo magnético) de carga elétrica. A exposição a CEM de baixa freqüência, dependendo de sua intensidade, pode induzir circulação de correntes elétricas no organismo humano causando estimulação de nervos e músculos ou outros efeitos biológicos (WHO 2005a). Entretanto, os estudos disponíveis não mostram evidências consistentes de correlação entre exposição ocupacional a CEM de baixa freqüência (50-60 HZ) e riscos à saúde (ANATEL 1999; WHO 2005a). 
Uma das questões mais controversas diz respeito à relação causal entre exposição a CEM e câncer. O National Institute of Environmental Health Sciences (Instituto Nacional das Ciências da Saúde Ambiental) nos Estados Unidos da América, em revisão de literatura, verificou que alguns estudos demonstraram um padrão pouco consistente de aumento do risco para leucemia em crianças e em trabalhadores expostos a CEM (NIEHS 2002). JOHANSEN (2004), também realizando revisão de literatura, concluiu que não há evidências de associação entre exposição ocupacional a CEM de baixa freqüência $(50 \mathrm{~Hz})$ e aumento de risco para câncer e outras doenças neurodegenerativas ou cardiovasculares.

\section{- Riscos mecânicos:}

- Quedas: no trabalho em alturas, as quedas podem ser conseqüências de choques elétricos, uso de equipamentos em condições inadequadas (cestos, escadas, plataformas, equipamentos de proteção individual), falta de treinamento, e delimitação e sinalização inadequadas nos pontos de serviços (SEGOVIA HERRERA 1988; MTE 2002).

- Acidentes de transporte: relacionados à movimentação diária que os trabalhadores fazem entre os diversos pontos de prestação de serviços (SEGOVIA HERRERA 1988; MTE 2002).

\section{- Riscos biológicos:}

- Ataque de animais: como o trabalho ocorre em ambiente externo, com execução de atividades em ruas, subestações, domicílios, áreas silvícolas e florestais, não é raro o ataque de insetos, de animais peçonhentos e de animais domésticos (SEGOVIA HERRERA 1988; MTE 2002; LEYVA et al. 2005). 
- Contaminação biológica: no trabalho em redes de distribuição subterrâneas existe a proximidade com redes de esgoto e locais encharcados (MTE 2002).

\section{- Riscos químicos:}

- Contaminantes químicos: em ambientes fechados, como caixas subterrâneas e estações de transformação, pode existir a presença de gases asfixiantes (monóxido e dióxido de carbono) e/ou explosivos (metano e vapores de combustíveis) provenientes de vazamentos ou de reações químicas em esgotos (MTE 2002; LEYVA et al. 2005).

- Bifenilas policloradas: hidrocarboneto carcinogênico utilizado em transformadores que, embora de uso proibido no Brasil desde 1981, ainda pode ser encontrado em equipamentos obsoletos (MATTOS et al. 2002; MTE 2002).

\section{- Riscos físicos:}

- Calor: no trabalho ao ar livre ou próximo a transformadores e capacitores ou em ambientes confinados, os trabalhadores estão expostos às radiações solares e/ou aos efeitos diretos do calor com possibilidade de ocorrência de queimaduras, câimbras por calos, síncope por calor, exaustão por calor, intermação, insolação, catarata e câncer de pele (ALMEIDA 1995; MTE 2002; LEYVA et al. 2005)

- Frio e chuva: no trabalho ao ar livre com exposição ao frio, chuva ou umidade, podem ocorrer infecções de vias aéreas superiores, pneumonias e dores articulares, além do risco de acidentes relacionados ao solo e estruturas escorregadias, dificuldade de visualização e presença de raios e faíscas elétricas (SEGOVIA HERRERA 1988; ALMEIDA 1995). 
- Ruído: pode ocorrer hipoacusia resultante de exposição ao ruído presente em estações e subestações de energia (MTE 2002; LEYVA et al. 2005). Também deve ser considerada a exposição ao ruído relacionado ao trânsito.

\section{- Riscos biomecânicos:}

- O trabalho no Setor Elétrico contempla uma grande variedade de atividades que, se por um lado possibilitam a diversidade e pouca monotonia, por outro lado, condicionam situações onde os aspectos biomecânicos são desfavoráveis: trabalho em alturas com necessidade de alcance em pontos distantes ou de difícil acesso, falta de apoio, equipamentos inadequados, ambientes restritos, área de visão restrita e cargas volumosas e/ou pesadas, entre outras, geram movimentos e posturas inadequadas e necessidade de esforço estático e dinâmico intenso (NOGUEIRA 1999; MTE 2002; LEYVA et al. 2005). Deve ser lembrado, também, o desconforto ocasionado pela exposição aos fatores de risco anteriormente citados (GUIMARÃES et al. 2002; MTE 2002).

\section{- Fatores psicossociais:}

- Os riscos inerentes aos fatores psicossociais e à organização do trabalho do no Setor Elétrico foram potencializados pela já citada reestruturação do setor no país e podem configurar elevadas demandas mentais no trabalho. Entre esses fatores são citados: pressão de prazos e de tempo para execução das atividades rotineiras e de atendimento de emergências, realização de horasextras, grande volume de trabalho, responsabilidade pela execução (prazos e qualidade) do trabalho, análise e solução de problemas, necessidade de tomada de decisões em situações rotineiras e emergenciais, pouca autonomia, sentimento de desvalorização profissional, percepção de presença de riscos à saúde e integridade física, necessidade de adaptação a novas tecnologias, pressão de chefias, pressão de clientes, pouca perspectiva de carreira, insegurança quanto ao futuro na empresa (SEGOVIA HERRERA 1988; 
NOGUEIRA 1999; GUIMARÃES et al. 2002; MTE 2002; LEYVA et al. 2005).

Pelo exposto, verifica-se que o trabalhador no Setor Elétrico potencialmente executa suas atividades em contato com diversos riscos que podem levar a um comprometimento de sua saúde e diminuição de sua capacidade para o trabalho. Apesar disso, há carência de estudos que contemplem questões pertinentes à saúde deste grupo de profissionais no Brasil. Na revisão de literatura encontraram-se os trabalhos de MATTOS e KOIFMAN (1996) e de MATTOS et al. (2002) que avaliaram a mortalidade por câncer neste grupo de profissionais, os de CIÓRLIA (1997) e de CIÓRLIA e GODOY (2005) que estudaram os fatores de risco cardiovascular, e os de SEGOVIA HERRERA (1988), NOGUEIRA (1999) e GUIMARÃES et al. (2002) que avaliaram condições e organização do trabalho. No que diz respeito à capacidade para o trabalho, não foram identificados estudos abordando este tema entre os eletricitários no país. Assim, considera-se oportuno iniciar estudos nesta temática a fim de contribuir com as políticas que enfoquem estes trabalhadores. 


\section{2 - OBJETIVOS}

\section{1 - Geral}

Analisar os fatores associados à capacidade para o trabalho em trabalhadores do Setor Elétrico no Estado de São Paulo.

\section{2 - Específicos}

- Verificar se as características dos trabalhadores (aspectos demográficos e do estilo de vida) estão associadas à capacidade para o trabalho.

- Verificar quais as dimensões da saúde auto-referida estão associados à capacidade para o trabalho.

- Verificar se as características do trabalho (características funcionais, conteúdo do trabalho e estresse decorrente do ambiente psicossocial do trabalho) estão associadas à capacidade para o trabalho.

- Verificar quais as características dos trabalhadores, das dimensões da saúde e do trabalho são fatores independentes associados à capacidade para o trabalho. 


\section{3 - MATERIAL E MÉTODOS}

\section{1 - Tipo de estudo}

Este é um estudo de corte transversal.

\section{2 - Local de estudo}

Este estudo foi realizado junto aos trabalhadores de uma empresa do Setor Elétrico do Estado de São Paulo com atuação nas áreas de geração, distribuição e comercialização de energia elétrica. A empresa passou por processo de privatização e reestruturação produtiva que teve início em 1997 e foi concluído recentemente. Esse processo foi acompanhado pela ampliação do mercado de atuação da empresa, pela adoção de novas práticas de gestão e operação e de normas internacionais de qualidade com a respectiva certificação, pela implementação de programas de sustentabilidade e responsabilidade corporativa, e pela implementação de programas nas áreas ambiental, cultural, social e de saúde voltados aos trabalhadores e à comunidade.

Atualmente a empresa tem $100 \%$ de capital nacional, atendendo o mercado das macrorregiões de Campinas, Ribeirão Preto, Franca, Bauru, São José do Rio Preto, Araçatuba, Araraquara, Piracicaba, Americana, São Carlos, Marília e Jaú.

\section{3 - População de estudo}

Esta pesquisa foi direcionada aos trabalhadores dos setores de transmissão e de distribuição de energia elétrica da Empresa. Esta escolha considerou que, de acordo com NOGUEIRA (1999), GUIMARÃES et al. (2002) e MTE (2002), estes são os trabalhadores do Setor Elétrico expostos a maior intensidade e variedade de fatores 
de risco. Optou-se, também, por incluir trabalhadores do setor administrativo de forma a possibilitar comparações por diferentes tipos e graus de exposição.

A população alvo do estudo foi composta pelos 582 trabalhadores que compunham o quadro dos setores Transmissão de Energia, Distribuição de Energia (Estações Avançadas) e Administrativo (Recursos Humanos e Contabilidade). Os trabalhadores estavam distribuídos na Sede da Empresa na cidade de Campinas e em 08 Estações Avançadas em Campinas e municípios da Região.

Os critérios de exclusão foram estar em férias ou afastado do trabalho (por doença, acidente de trabalho ou licenças) no período da coleta de dados. Foram consideradas perdas as seguintes situações: trabalhadores ausentes em cursos externos ou em viagem a serviço, recusa em participar, respostas incompletas e não localização do trabalhador.

Todos os trabalhadores da população alvo que não se enquadravam nos critérios de exclusão foram convidados a participar voluntariamente do estudo.

Os trabalhadores que compuseram a população do estudo ocupam os cargos sumariamente descritos a seguir:

\section{- Setor de Transmissão de Energia:}

- Técnico de transmissão: técnicos que elaboram estudos de atendimento de novos clientes; elaboram e analisam projetos e orçamentos; coordenam a inspeção, medicação e fiscalização de obras; desempenham e/ou supervisionam tarefas especializadas e complexas em escritório.

- Eletricista de transmissão: técnicos que executam inspeções em subestações e sítios troncalizados; executam serviços e manobras programadas e emergenciais em subestações de distribuição, transmissão e em linhas de 
transmissão; realizam pequenas manutenções nas instalações das subestações; informam sobre as ocorrências, manobras e manutenções.

- Eletricista de linha viva de transmissão: técnicos que ligam, desligam e religam unidades com rede energizada; orientam consumidores sobre normas e serviços; efetuam manobras na rede, equipamentos e subestações; realizam inspeção e manutenção de redes, equipamentos e iluminação.

O cargo de Técnico de Transmissão é caracterizado por atividades realizadas em escritório, com exigências que são predominantemente mentais. Para o cargo de Eletricista, as exigências são físicas e mentais. As exigências físicas requerem diferentes graus de esforço físico, estático ou dinâmico, às vezes de grande intensidade, como nas tarefas executadas em manobras e manutenção de rede. As demandas físicas são alternadas e/ou mescladas com demandas cognitivas e de atenção, relativas à necessidade de análise de problemas e de tomada de decisão, pressão de prazos, de relacionamentos interpessoais e de responsabilidades, entre outras exigências mentais.

\section{- Setor de Distribuição de Energia:}

- Liderança: técnicos que supervisionam a operação elétrica; coordenam as equipes das Estações Avançadas; programam e despacham as ordens de serviços; acompanham e supervisionam as equipes de campo; realizam o controle de veículos, ferramentas, equipamentos e materiais; gerenciam indicadores técnicos e comerciais; supervisionam contratos.

- Eletricista de distribuição: técnicos responsáveis pela manutenção elétrica da rede. Realizam inspeção, medição e recebimento de obras executadas por empreiteiras; planejam, programam e executam as inspeções e manutenção de linhas; executam manutenção preventiva e corretiva em equipamentos e instalações. 
- Eletricista de linha viva de distribuição: técnicos responsáveis pela instalação de linhas elétricas. Ligam, desligam e religam unidades com rede energizada; orientam consumidores sobre normas e serviços; efetuam manobras na rede, equipamentos e subestações; realizam inspeção e manutenção de redes, equipamentos e iluminação.

O cargo de Liderança é caracterizado por atividades em escritório e de campo, com exigências predominantemente mentais. Para os cargos de Eletricista e Eletricista de linha viva do Setor de Distribuição de Energia, as exigências são mistas, da mesma forma que para os Eletricistas do Setor de Transmissão.

\section{- Setor administrativo (contabilidade e recursos humanos):}

O grupo do Setor Administrativo foi composto por profissionais das áreas de Contabilidade e Recursos Humanos e, também, pelos cargos de Auxiliar de Escritório e Assistente Administrativo da Distribuição.

- Contabilidade: os profissionais da área de Contabilidade ocupam cargos de economista, contador, supervisor de orçamento e secretariado. As atividades executadas por estes profissionais dizem respeito à administração de fluxo de caixa, de contas a pagar e de arrecadação e contas a receber; controle de custos; análise de lançamentos contábeis e ajustes de contas; apuração de impostos federais e registro de operações fiscais.

- Recursos humanos: os profissionais da área de Recursos Humanos executam atividades com foco na melhoria da produtividade e satisfação das pessoas e na redução de custos equilibrada com qualidade e eficiência. As atividades incluem aquelas pertinentes à formulação, implantação, gerenciamento e execução de políticas, diretrizes e procedimentos de administração de recursos humanos; gestão, administração e implementação dos procedimentos relativos aos planos de benefícios, folha de pagamentos, e 
demais questões trabalhistas; elaboração, implementação, execução e avaliação de programas e ações em saúde e segurança do trabalho.

- Auxiliar de escritório: executam serviços gerais de apoio administrativo.

- Assistente administrativo: desempenham atividades administrativas gerais de apoio.

As atividades são realizadas em escritório, com exigências predominantemente mentais, com demandas cognitivas e de atenção, necessidade de análise de problemas e de tomada de decisão, pressão de prazos, de relacionamentos interpessoais e de responsabilidades, entre outras.

\section{4 - Metodologia}

A realização desta pesquisa seguiu as seguintes etapas:

a. Negociação do campo de estudo: inicialmente foi feita apresentação do projeto de pesquisa à Gerência de Segurança do Trabalho, Saúde e Qualidade de Vida. A seguir, o projeto foi apresentado à Gerência do Departamento de Recursos Humanos e à Diretoria de Recursos Humanos para obtenção de autorização para realização da mesma. Foram apresentados os objetivos da pesquisa, a metodologia para coleta de dados, os aspectos éticos inerentes ao processo, e a forma de divulgação dos resultados.

b. Divulgação do estudo junto às chefias: a apresentação do projeto de pesquisa foi feita por meio de reuniões com as chefias e lideranças. Nestas reuniões foi abordado o mesmo conteúdo citado no item acima, foi solicitada a colaboração no sentido de facilitar o acesso aos trabalhadores e, também, foram discutidos e planejados detalhes da operacionalização da coleta de dados. 
c. Pré-teste: foi realizado pré-teste dos questionários junto a 17 trabalhadores de um setor da Empresa que não fazia parte da população de estudo. Esses trabalhadores foram informados quantos aos objetivos do pré-teste e da pesquisa, foram orientados quanto à confidencialidade dos dados obtidos e assinaram o Termo de Consentimento Livre e Esclarecido (Anexo 01). Com base nos resultados do préteste foram feitas alterações e adequações nos instrumentos de coleta de dados.

d. Divulgação do estudo junto aos trabalhadores: as chefias e lideranças dos setores forneceram informações iniciais sobre o estudo aos trabalhadores sob sua responsabilidade. Esta divulgação foi feita verbalmente, por meio de informativos e/ou por correio eletrônico.

e. Coleta de dados: a partir de cronograma previamente definido, as chefias e lideranças organizaram reuniões para realização da coleta de dados. O cronograma e os horários das reuniões, bem como o número de trabalhadores em cada reunião variaram em função do efetivo de cada setor/unidade, das escalas de trabalho, da rotina de trabalho e de demandas imprevistas. O Anexo 02 apresenta o cronograma de trabalho, incluindo o período de coleta de dados. Rotineiramente, as reuniões foram realizadas nos locais de trabalho, em salas reservadas para tais reuniões, e contaram com a presença das chefias/lideranças realizando a abertura da reunião, apresentando a pesquisadora (Maria Carmen Martinez, autora desta tese) e introduzindo alguns aspectos da pesquisa. Em seguida, a pesquisadora fornecia informações referentes à confidencialidade dos dados, ao caráter voluntário da participação, ao tema, objetivos e metodologia da pesquisa, à forma de preenchimento dos questionários, e à assinatura do termo de consentimento livre e esclarecido. Os trabalhadores eram informados que os resultados individuais seriam tratados com confidencialidade, sendo de conhecimento e acesso apenas por parte da própria pesquisadora. Também foi apresentado o compromisso de devolutiva dos resultados individuais aos trabalhadores e de divulgação pública dos resultados coletivos. Por fim, foram distribuídos os questionários que deveriam ser preenchidos naquela ocasião na sala onde estava sendo feita a reunião ou em outra área que fosse da preferência 
do empregado. A pesquisadora permanecia no local esclarecendo dúvidas e dando orientações, quando solicitado. Terminado o preenchimento, os questionários eram entregues à pesquisadora em envelope individual lacrado. Trabalhadores que não tiveram interesse ou não quiseram participar da pesquisa também entregavam seu envelope lacrado. Toda a coleta de dados foi feita pela própria autora desta tese.

\subsection{1 - Instrumentos para coleta de dados:}

O levantamento de dados foi feito por meio da aplicação de questionários para obtenção de dados referentes à capacidade para o trabalho, características demográficas, estilo de vida, características funcionais, estresse no trabalho e estado de saúde. Os questionários estão descritos a seguir.

\section{- Identificação:}

Questões objetivas sobre características demográficas (sexo, idade, estado conjugal, escolaridade) e funcionais (turno de trabalho, setor de trabalho, tempo na empresa, cargo, e faixa salarial). Esta parte do questionário está apresentada no Anexo 03.

\section{- Capacidade para o trabalho:}

A capacidade para o trabalho foi medida por meio do Índice de Capacidade para o Trabalho - ICT, o qual possibilita avaliar e detectar precocemente alterações, além de ter valor preditivo e poder ser usado como instrumento para subsidiar informações para direcionamento de medidas preventivas (TUOMI et al. 2005). O ICT oferece as facilidades de ser um instrumento de preenchimento rápido e simples, com baixo custo, e auto-aplicável desde que a escolaridade mínima seja a $4^{\mathrm{a}}$ série do Ensino Fundamental (FISCHER 2005). Optou-se por utilizar a auto-aplicação mesmo junto aos trabalhadores com escolaridade abaixo da preconizada, pois se 
sabia previamente que trabalhadores nestas condições eram em pequeno número, e utilizar outra forma de aplicação poderia gerar algum tipo de constrangimento. Além disso, estes trabalhadores lidam rotineiramente com atividades envolvendo leitura, escrita e uso de raciocínio.

O ICT (Anexo 04) foi traduzido para o português e testado por um grupo de pesquisadores da Faculdade de Saúde Pública da Universidade de São Paulo e profissionais de outras universidades e instituições (públicas e privadas) do Brasil (FISCHER 2005).

O ICT fornece um escore que varia de 07 a 49 pontos, e é composto por 7 dimensões:

- Capacidade para o trabalho atual, comparada com a melhor de toda a vida: escore de 0 a 10 pontos.

- Capacidade para o trabalho em relação às exigências do trabalho: número de pontos ponderados de acordo com a natureza do trabalho compondo um escore de 0 a 10 pontos.

- Número atual de doenças diagnosticadas por médico: a partir de uma lista de 51 doenças, é composto um escore variando de 1 a 7 pontos.

- Perda estimada para o trabalho devido a doenças: escore de 1 a 6 pontos.

- Faltas ao trabalho por doenças: escore de 1 a 5 pontos.

- Prognóstico próprio sobre a capacidade para o trabalho: pontuação com valor de 1,4 ou 7 pontos.

- Recursos mentais: número de pontos a partir de três questões pertinentes à vida em geral que, ponderadas, compõem um escore de 1 a 4 pontos.

As instruções para cálculo do escore estão disponíveis em TUOMI et al. (2005).

\section{- Estresse no trabalho:}

Atualmente, está disponível para uso no Brasil a Escala Estresse no Trabalho EET (Anexo 05), que é um questionário construído e validado por PASCHOAL e TAMAYO (2004). Tem a finalidade de proporcionar uma medida geral de estresse 
no trabalho, podendo ser utilizada como instrumento de diagnóstico do ambiente psicossocial do trabalho. Nesta pesquisa, optou-se pelo uso da EET porque ela possibilita avaliar 23 diferentes aspectos do trabalho a partir da percepção dos próprios trabalhadores, e obter uma medida genérica de estresse, apresentando as vantagens de ser de aplicação rápida e de fácil entendimento.

A EET fornece um escore que varia de 1,0 a 5,0 pontos, cujas instruções para cálculo estão disponíveis em PASCHOAL e TAMAYO (2004).

\section{- Estado de saúde:}

Nesta pesquisa foi usado o Medical Outcomes Study 36 - Item short form health survey - SF-36 (Anexo 06). Este questionário foi criado com a finalidade de ser um questionário genérico de avaliação de saúde e, portanto, seus conceitos não são específicos para uma determinada idade, doença ou grupo de tratamento (CICONELLI 1997; WARE 2000). O SF-36 é formado por 36 itens, englobados em 8 dimensões que foram escolhidas por representar os conceitos mais freqüentemente mensurados nos inquéritos de saúde (CICONELLI 1997; WARE 2000). Estas dimensões são:

- Capacidade funcional: avalia presença e extensão de limitações relacionadas à capacidade física.

- Aspecto físico: avalia as limitações no tipo e na quantidade do trabalho e das atividades de vida diária em conseqüência de problemas físicos.

- Dor: avalia a extensão da dor e a interferência nas atividades de vida diária.

- Estado geral de saúde: avalia as percepções referentes ao estado de saúde geral.

- Vitalidade: considera o nível de energia e de fadiga.

- Aspecto social: avalia a limitação da participação do indivíduo em atividades sociais, decorrente de problemas com a saúde.

- Aspecto emocional: avalia as limitações no tipo e na quantidade do trabalho e das atividades de vida diária em conseqüência de problemas emocionais. 
- Saúde mental: avalia as percepções em relação a 4 principais dimensões da saúde mental: ansiedade, depressão, alterações do comportamento e bem-estar psicológico.

Para avaliação dos resultados é dado um escore para cada questão que, posteriormente, é transformado em uma dimensão que varia de 0 a 100, onde 0 (zero) corresponde a um pior estado de saúde e 100 a um melhor estado de saúde, sendo que cada dimensão é analisada em separado (CICONELLI 1997). A pontuação das questões e instruções para cálculo dos escores é encontrada em CICONELLI (1997).

\section{- Estilo de vida:}

A avaliação do estilo de vida foi realizada considerando a prática de atividade física, o estado nutricional, o tabagismo e o consumo de bebida alcoólica.

A avaliação da prática da atividade física deve abranger as diversas características da atividade considerando a modalidade, a frequiência, a intensidade e a duração dos exercícios realizados. FLORINDO e LATORRE (2003) traduziram o questionário de Baecke que investiga a atividade física habitual dos últimos 12 meses por meio de 16 questões, compondo escores referentes às atividades físicas ocupacionais (AFO), aos exercícios e atividades físicas praticados durante o tempo de lazer (EFL), às atividades físicas de locomoção (ALL) e, ainda, um escore de atividade física total (ET).

A versão validada para a população brasileira foi padronizada para ser autoadministrada (FLORINDO e LATORRE 2003; FLORINDO et al. 2004). Esta versão está apresentada no Anexo 07 e a metodologia para o cálculo dos escores é encontrada em FLORINDO e LATORRE (2003) e em FLORINDO et al. (2004).

Para avaliar o estado nutricional foi utilizado o Índice de Massa Corporal (IMC), que é calculado dividindo-se a massa corporal (em quilogramas) pelo 
quadrado da altura (em metros) (SBEM 2004). Tanto a massa (peso) como a altura foram auto-referidos.

O tabagismo pode ser avaliado pelo número de cigarros que a pessoa fuma por dia ou, alternativamente, pelo grau de dependência à nicotina. O Questionário de Tolerância de Fagerström tem como objetivos identificar e medir a dependência nicotínica e é utilizado em avaliações e pesquisas em saúde, sendo seu uso recomendado pela Sociedade Brasileira de Cardiologia (SBC 2001) e pela Associação Brasileira de Psiquiatria (MARQUES e RIBEIRO 2002b).

O Questionário de Tolerância de Fagerström foi composto originalmente por 8 questões e, posteriormente, reduzido para seis, sendo que a versão reduzida apresenta consistência interna satisfatória e correlação significativa com níveis de monóxido de carbono no ar expirado, níveis séricos, urinários ou na saliva de nicotina e cotinina que são marcadores bioquímicos de elevada sensibilidade e especificidade para dependência nicotínica (HEATHERTON et al. 1991). O questionário é composto de três questões que avaliam fumo matinal considerando-o como indicador de síndrome de abstinência, e por três questões que avaliam o consumo de cigarros (HALTY et al. 2002). Duas questões têm 4 alternativas para resposta com pontuação variando de 0 a 3 , e quatro questões têm 2 alternativas para resposta com pontuação variando de 0 a 1, com um escore final que varia de 0 a 10 pontos, que pode ser categorizado em 4 graus de dependência. $\mathrm{O}$ questionário está apresentado no 08 e a metodologia para o cálculo dos escores é encontrada em HALTY et al. (2002) e em MARQUES e RIBEIRO (2002b).

O padrão de consumo de álcool pode ser avaliado por meio de questionários, como o Cut down, Annoyed by criticism, Guilty e Eye-opener (CAGE) e o Alcohol Use Disorders Identification Test (AUDIT), que possibilitam o rastreamento do uso e dependência alcoólica (MARQUES e RIBEIRO 2002a; SILVA et al. 2004).

O AUDIT foi desenvolvido pela Organização Mundial da Saúde em 1980, sendo composto por 10 questões que avaliam consumo de risco de álcool (freqüência 
de consumo, quantidade típica e frequiência de consumo elevado), sintomas de dependência (perda de controle sobre o consumo, aumento da relevância do consumo e consumo matutino), e problemas relacionados ao uso do álcool (sentimento de culpa decorrente do consumo, falhas de memória, lesões relacionadas com o álcool e preocupação de outros pelo seu consumo) (BABOR et al. 2001; WHO 2003; SILVA et al. 2004). O questionário, que está apresentado no Anexo 09, oferece um escore que vai de 0 a 40 pontos, sendo que um valor a partir de 8 indica a necessidade de uma investigação diagnóstica mais detalhada (BABOR et al. 2001; WHO 2003; SILVA et al. 2004).

\subsection{2 - Variáveis de estudo:}

\section{Variável dependente:}

\section{- Capacidade para o trabalho:}

Escore do Índice de Capacidade para o Trabalho - ICT, variando de 7 a 49 pontos.

\section{Variáveis independentes:}

\section{- Características demográficas:}

- Sexo: variável categorizada em feminino ou masculino.

- Idade: variável quantitativa contínua, em anos.

- Estado conjugal: os trabalhadores foram categorizados em: solteiro, casado/companheiro, separado/divorciado e viúvo.

- Escolaridade: foram usadas as categorias: Ensino Fundamental incompleto, $4^{\mathrm{a}}$ série do Ensino Fundamental completa, $8^{\mathrm{a}}$ série do Ensino Fundamental completa, Ensino Médio completo, Ensino Superior completo.

\section{- Características funcionais:}

- Unidade de trabalho: esta variável foi categorizada de acordo com o setor e/ou localização geográfica de atuação do trabalho, a saber: Valinhos/Itatiba, 
Americana, Sumaré, Itapira, Piracicaba, Centro, Trevo, Transmissão de Energia, Contabilidade, Recursos Humanos.

- Setor de trabalho: esta variável foi categorizada de acordo com o setor de atuação do empregado, a saber: Administrativo, Transmissão de Energia e Distribuição de Energia (Estações Avançadas).

- Cargo: para categorização desta variável, os trabalhadores foram agrupados de acordo com o cargo/ função que exercem, a saber: administrativo, liderança da Distribuição, Eletricista da Distribuição, Eletricista de Linha Viva da Distribuição, Técnico da Distribuição, Eletricista da Transmissão, Eletricista de Linha Viva da Transmissão, Técnico da Transmissão.

- Turno de trabalho: variável categorizada em diurno integral, manhã, tarde, noturno.

- Conteúdo do trabalho: variável categorizada em mental (predominância de exigências mentais) e mista (exigências físicas e mentais).

- Faixa salarial: esta variável foi categorizada a partir da quantidade de salários mínimos (SM) dos trabalhadores, considerando o valor do salário mínimo em vigor em de maio de 2005, de $\mathrm{R} \$ 300,00$. As categorias utilizadas foram: menos que 4 SM, 4 a 6,9 SM, 7 a 10,9 SM, 11 a 15,9 SM, 16 a 20,9 SM, 21 a $25,9 \mathrm{SM}$ e 26 ou mais SM.

- Tempo na empresa: variável quantitativa contínua, em anos, que expressa o tempo de vínculo empregatício do trabalhador na empresa.

\section{- Estresse no trabalho:}

Escore variando de 1,0 a 5,0 pontos, composto a partir de 23 questões relativas ao ambiente psicossocial do trabalho.

\section{- Características do estilo de vida:}

- Prática de atividade física: escore variando de 0 a 15 pontos, composto a partir de escores ponderados de 0 a 5 pontos referentes às atividades físicas ocupacionais (AFO), exercícios físicos no lazer (EFL) e atividades físicas de lazer e locomoção (AFL). 
- Índice de massa corporal (IMC): para descrição da população e tendo como base os parâmetros apresentados pela sociedade Brasileira de Endocrinologia e Metabologia (SBEM 2004), o escore do IMC foi categorizado em: desnutrido (abaixo de $18,5 \mathrm{Kg} / \mathrm{m}^{2}$ ), peso adequado $\left(18,5 \mathrm{a} 24,9 \mathrm{Kg} / \mathrm{m}^{2}\right)$, sobrepeso (25,0 a $\left.29,9 \mathrm{Kg} / \mathrm{m}^{2}\right)$, obesidade grau I (30,0 a $\left.34,9 \mathrm{Kg} / \mathrm{m}^{2}\right)$, obesidade grau II (35,0 a $\left.39,9 \mathrm{Kg} / \mathrm{m}^{2}\right)$, e obesidade grau III $\left(40,0 \mathrm{Kg} / \mathrm{m}^{2}\right.$ e acima). Para análise das associações, o IMC foi utilizado como variável quantitativa contínua expressa em $\mathrm{Kg} / \mathrm{m}^{2}$.

- Tabagismo: foram utilizadas as variáveis tempo de tabagismo em anos e quantidade de cigarros por dia, como variáveis quantitativas contínuas. Também foi utilizado o grau de dependência ao tabaco na forma de escore variando de 0 a 10 pontos para análise das associações. Para descrição da população de estudo, este escore foi categorizado em graus de dependência: muito baixo ( 0 a 2 pontos), baixo ( 3 a 4 pontos), médio (5 pontos), elevado (6 a 7 pontos) e muito elevado ( 8 a 10 pontos).

- Consumo de álcool: escore variando de 0 a 40 pontos.

\section{- Estado de saúde:}

- Saúde física: representada por 4 dimensões variando de 0 a 100 pontos: capacidade funcional, aspecto físico, dor, estado geral de saúde.

- Saúde mental: representada por 4 dimensões variando de 0 a 100 pontos: vitalidade, aspecto social, aspecto emocional, saúde mental.

\section{5 - Análise estatística}

\subsection{1 - Análise das perdas:}

Foi feita a comparação entre a população participante no estudo e as perdas segundo sexo, idade, tempo na empresa, unidade de trabalho e setor de trabalho, utilizando o teste de associação pelo Qui-Quadrado para as variáveis categóricas e o teste t-Student para as variáveis quantitativas. 


\subsection{2 - Análise da confiabilidade dos questionários:}

A análise da confiabilidade dos questionários utilizados foi feita por meio do coeficiente alpha de Cronbach.

\subsection{3 - Caracterização da população de estudo:}

Foi feita a análise descritiva por meio das médias, desvios-padrão, valores mínimos e máximos dos escores das variáveis quantitativas e proporções para as variáveis qualitativas.

Para o ICT, foi realizado o teste de Kolmogorov-Smirnov para verificar a aderência do escore ICT à distribuição normal, determinando os tipos de testes estatísticos a serem utilizados.

\subsection{4 - Análise dos fatores associados à capacidade para o trabalho:}

Para a análise da correlação entre o ICT e as variáveis quantitativas foi usado do coeficiente de correlação de Spearman.

Para comparação das médias do ICT segundo as categorias das variáveis qualitativas dicotômicas sem variância constante, foi utilizado o teste MannWhitney. Para comparação das médias entre as variáveis qualitativas com 3 ou mais categorias, foi utilizado o teste de Kruskal-Wallis. Havendo diferença estatisticamente significativa entre as médias, foi realizado o teste post hoc de Tukey para múltiplas comparações. A homogeneidade das variâncias foi avaliada pelo teste de Levene. 


\subsection{5 - Análise de regressão linear múltipla:}

Foi realizada a modelagem múltipla com todas as variáveis que apresentaram $\mathrm{p}<0,20$ na análise descrita no item 3.5.4. O valor do " $\mathrm{p}$ " determinou a ordem de entrada no modelo múltiplo. O processo de modelagem foi o stepwise forward. A variável independente permanecia no modelo múltiplo se $\mathrm{p}<0,05$ e/ou se fosse variável de ajuste. As variáveis qualitativas foram transformadas em variáveis indicadoras (Dummy) tomando como referência a categoria com maior média no escore do ICT.

\subsection{6 - Nível de significância:}

Em todas as análises realizadas foi utilizado o nível de significância de 5\%.

\section{6 - Programas de computador}

Para realização de dupla digitação, validação e verificação da consistência dos dados, foi utilizado o programa Epi-info versão 6.04 para DOS. Para a realização das análises descritivas e de todos os testes estatísticos, foi utilizado o SPSS para Windows versão 10 .

\section{7 - Aspectos éticos}

O projeto de pesquisa foi submetido à apreciação e aprovado pelo Comitê de Ética da Faculdade de Saúde Pública da USP (Anexo 10). O estudo seguiu as diretrizes e normas regulamentadoras de pesquisas envolvendo seres humanos definidas na Resolução n 196/96 do CNS - Conselho Nacional de Saúde. 
A empresa onde o estudo foi desenvolvido forneceu autorização formal para realização do mesmo. A participação dos trabalhadores foi voluntária e mediante assinatura do Termo de Consentimento Livre e Esclarecido apresentado no 01. Os resultados individuais foram tratados com confidencialidade e serão apresentados aos trabalhadores por meio de cartas individualizadas. Os resultados coletivos serão apresentados à diretoria da empresa, às chefias e aos trabalhadores por meio de reuniões e palestras. As circunstâncias para convite e aceite de participação estão descritas no item 3.4. 


\section{4 - RESULTADOS}

\section{1 - Análise das perdas}

A população alvo do estudo foi composta pelos 582 trabalhadores que compunham o quadro dos setores Transmissão de Energia, Distribuição de Energia (Estações Avançadas) e Administrativo (Recursos Humanos, Contabilidade).

Foram excluídos 39 (6,7\%) trabalhadores por estarem afastados, em mudança de função ou de férias no período da coleta de dados. Das 543 pessoas que se enquadravam nos critérios do estudo, 22 estavam em cursos externos, em viagem a serviço ou não foi possível localizá-las, restando 521 (89,5\%) trabalhadores contatados. Dos 521 trabalhadores, 21 não responderam ou não quiseram participar do estudo, determinando uma taxa de recusa de 4,0\%. Houve, ainda, perda de 25 pessoas que responderam o questionário de forma incompleta, resultando em um total de 68 perdas. Restaram 475 trabalhadores que correspondem a 87,5\% dos 543 trabalhadores da população que preencheram os critérios de inclusão.

A análise das perdas demonstrou que não houve diferença em relação ao sexo ( $8,5 \%$ de perdas entre as mulheres e $12,9 \%$ de perdas entre os homens; $p=0,385$ ), ao setor de trabalho (14,6\% de perdas no Setor Administrativo; $12,5 \%$ no Setor de Distribuição de Energia e 10,5\% no setor de Transmissão de Energia; p=0,703), e ao tempo na empresa (média de 12,9 anos na empresa entre os participantes, e média de 12,4 anos entre as perdas; $\mathrm{p}=0,548$ ). Houve diferença estatisticamente significativa na porcentagem de perdas entre as unidades de trabalho, com maior percentual de perdas nas unidades Americana, Trevo, Contabilidade e Itapira (respectivamente $24,1 \%, 18,9 \%, 18,6 \%$ e $18,5 \% ; \mathrm{p}=0,038)$. Também houve diferença em relação à idade, sendo a média de 37,5 anos entre os participantes e 39,7 anos entre as perdas $(\mathrm{p}=0,030)$. Os dados estão apresentados nas Tabelas 1 e 2 . 
Tabela 1: Análise comparativa entre perdas e participantes segundo características demográficas e funcionais, variáveis qualitativas, Campinas e região, 2005.

\begin{tabular}{|c|c|c|c|c|c|c|}
\hline \multirow[t]{2}{*}{ Variável } & \multicolumn{2}{|c|}{ Participação } & \multicolumn{2}{|c|}{ Perdas } & \multirow{2}{*}{$\begin{array}{c}\text { Total } \\
n^{\circ}\end{array}$} & \multirow[t]{2}{*}{$\mathbf{p}^{*}$} \\
\hline & $n^{0}$ & $\%$ & $n^{0}$ & $\%$ & & \\
\hline \multicolumn{7}{|l|}{ Sexo } \\
\hline Feminino & 43 & 91,5 & 4 & 8,5 & 47 & 0,385 \\
\hline Masculino & 432 & 87,1 & 64 & 12,9 & 496 & \\
\hline \multicolumn{7}{|l|}{ Unidade } \\
\hline Valinhos & 9 & 100,0 & -- & -- & 9 & 0,038 \\
\hline Itatiba & 14 & 100,0 & -- & -- & 14 & \\
\hline Americana & 41 & 75,9 & 13 & 24,1 & 54 & \\
\hline Sumaré & 50 & 92,6 & 4 & 7,4 & 54 & \\
\hline Itapira & 44 & 81,5 & 10 & 18,5 & 54 & \\
\hline Piracicaba & 72 & 93,5 & 5 & 6,5 & 77 & \\
\hline Trevo & 30 & 81,1 & 7 & 18,9 & 37 & \\
\hline Centro & 56 & 90,3 & 6 & 9,7 & 62 & \\
\hline Transmissão & 77 & 89,5 & 9 & 10,5 & 86 & \\
\hline Contabilidade & 35 & 81,4 & 8 & 18,6 & 43 & \\
\hline Recursos Humanos & 47 & 88,7 & 6 & 11,3 & 53 & \\
\hline \multicolumn{7}{|l|}{ Setor } \\
\hline Administrativo & 82 & 85,4 & 14 & 14,6 & 96 & 0,703 \\
\hline Distribuição de energia & 316 & 87,5 & 45 & 12,5 & 361 & \\
\hline Transmissão de energia & 77 & 89,5 & 9 & 10,5 & 86 & \\
\hline Total & 475 & $\mathbf{8 7 , 5}$ & 68 & 12,5 & 543 & \\
\hline
\end{tabular}

Tabela 2: Análise comparativa entre perdas e participantes segundo características demográficas e funcionais, variáveis quantitativas, Campinas e região, 2005.

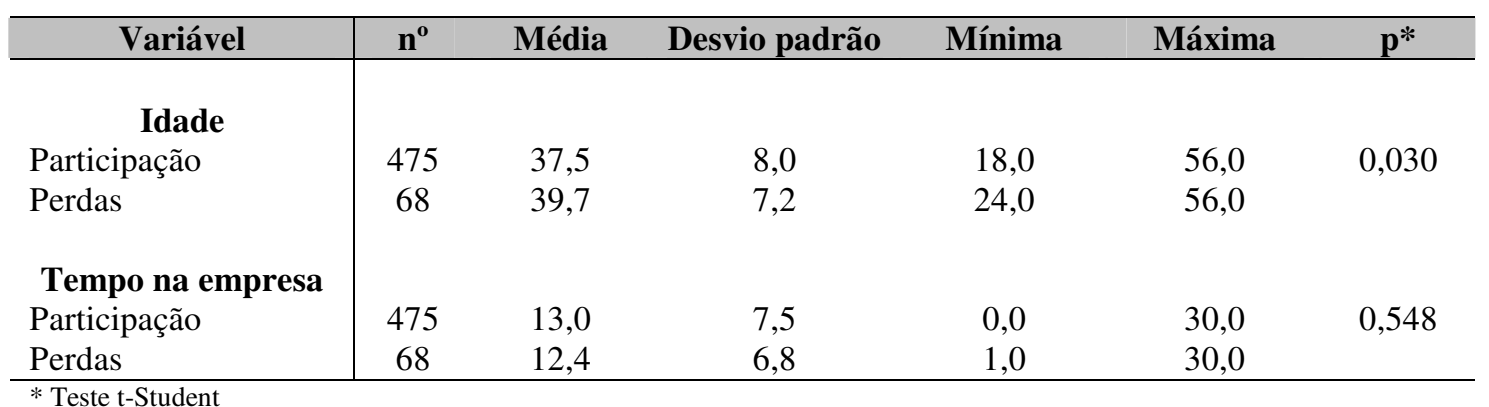




\section{2 - Confiabilidade dos questionários}

\subsection{1 - Confiabilidade do índice de capacidade para o trabalho (ICT)}

O ICT, utilizado para mensurar a variável dependente, apresentou coeficiente alpha de Cronbach de 0,68 (Tabela 3). A exclusão de alguma das dimensões não alterou o resultado, mostrando que houve boa confiabilidade no índice.

Tabela 3: Valores do alpha de Cronbach por dimensão do ICT, Campinas e região, 2005.

\begin{tabular}{l|c}
\hline \multicolumn{1}{c|}{ Questão } & $\begin{array}{r}\text { Alpha de Crombach } \\
\text { se a questão for } \\
\text { excluída }\end{array}$ \\
\hline Capacidade para o trabalho atual comparada com a melhor de toda a vida & 0,68 \\
Capacidade para o trabalho em relação às exigências físicas do trabalho & 0,69 \\
Capacidade para o trabalho em relação às exigências mentais do trabalho & 0,71 \\
Número atual de doenças diagnosticadas pelo médico (pontos) & 0,74 \\
Perda estimada para o trabalho devido às doenças & 0,68 \\
Faltas ao trabalho por doenças nos últimos 12 meses & 0,71 \\
Prognóstico próprio sobre a capacidade para o trabalho daqui a dois anos & 0,72 \\
Apreciação das atividades diárias & 0,70 \\
Sentir-se ativo e alerta & 0,70 \\
Esperança para o futuro & 0,70 \\
\hline ICT (com todas as dimensões) & $\mathbf{0 , 7 2}$ \\
\hline * Itens ponderados de acordo com as instruções para cálculo do escore disponíveis em TUOMI et al. (2005).
\end{tabular}

\subsection{2 - Confiabilidade dos demais questionários}

Os resultados das análises da confiabilidade de todos os questionários, incluindo os valores do alpha de Cronbach para cada questão excluída estão apresentados nas Tabelas de A até E do Anexo 11. 
Entre os questionários utilizados para avaliar características do estilo de vida, o Questionário de Tolerância de Fagerström para avaliar dependência ao tabagismo, o Questionário AUDIT para avaliar dependência ao álcool e o Questionário de Baecke para avaliar prática de atividade física apresentaram coeficiente alpha de Cronbach respectivamente de 0,69,0,79 e 0,66. A exclusão de alguma das questões que compõem os instrumentos não proporcionou melhorias importantes nos resultados.

A Escala Estresse no Trabalho apresentou coeficiente alpha de Cronbach de 0,94 e a exclusão de alguma das dimensões não alterou o resultado.

As 8 dimensões que compõem o questionário SF-36, utilizado para avaliar o estado de saúde, apresentaram coeficiente alpha de Cronbach com valores acima de 0,70. A saber: capacidade funcional $=0,85$, aspecto físico $=0,76$, dor $=0,88$, estado geral de saúde $=0,72$, vitalidade $=0,86$, aspecto social $=0,74$, aspecto emocional $=$ 0,73 , e saúde mental $=0,86$. A exclusão de alguma das questões que compõem as dimensões analisadas não proporcionou melhorias importantes nos resultados.

\section{3 - Caracterização da população de estudo}

\subsection{1 - Características demográficas}

$\mathrm{Na}$ Tabela 4 se observa que a população de estudo foi predominantemente masculina (90,9\%), casada ou com companheiro(a) $(75,2 \%)$ e com escolaridade com Ensino Médio completo (64,6\%) ou ensino superior completo (26,7\%). A média da idade dos trabalhadores foi de 36,8 anos ( $\mathrm{dp}=8,0$ anos), variando de 18,0 a 56,0 anos, com mediana de 37,0 anos. 
Tabela 4: Distribuição da população de estudo (nº \% ) segundo variáveis demográficas, Campinas e região, 2005.

\begin{tabular}{|c|c|c|}
\hline Variável & $\mathrm{n}^{\mathbf{0}}$ & $\%$ \\
\hline Sexo & & \\
\hline Mulheres & 43 & 9,1 \\
\hline Homens & 432 & 90,9 \\
\hline Estado civil & & \\
\hline Solteiro & 87 & 18,3 \\
\hline Casado / companheiro & 357 & 75,2 \\
\hline Separado / divorciado & 27 & 5,7 \\
\hline Viúvo & 2 & 0,4 \\
\hline Sem resposta & 2 & 0,4 \\
\hline Escolaridade & & \\
\hline Ensino Fundamental incompleto & 2 & 0,4 \\
\hline $4^{\mathrm{a}}$ série do Ensino Fundamental completa & 7 & 1,5 \\
\hline $8^{\mathrm{a}}$ série do Ensino Fundamental completa & 32 & 6,7 \\
\hline Ensino Médio completo & 307 & 64,6 \\
\hline Ensino Superior completo & 127 & 26,7 \\
\hline Total & 475 & 100,0 \\
\hline
\end{tabular}

\subsection{2 - Características do estilo de vida}

Na Tabela 5 observa-se que 42,9\% dos trabalhadores apresentaram sobrepeso e $16,8 \%$ apresentaram obesidade.

Entre os $14,5 \%$ de trabalhadores informaram ser tabagistas (Tabela 4), 36,2\% apresentaram dependência ao tabaco elevada ou muito elevada (Gráfico 1). Estas pessoas fumavam, em média, há 18,3 anos $(\mathrm{dp}=8,5)$, variando de 2 a 40 anos, com mediana de 20 anos, e com um padrão de consumo de, em média, 14,9 cigarros por dia $(\mathrm{dp}=7,6)$, variando de 1 a 30 cigarros, com mediana de 15 cigarros (Tabela 6).

Entre os trabalhadores, 373 pessoas $(79,0 \%)$ informaram algum tipo de consumo de bebida alcoólica. A média do escore de dependência ao álcool foi de 4,8 pontos $(\mathrm{dp}=4,3)$, e o mesmo escore variou de 0,0 a 23,0 pontos, com mediana de 4,0 pontos (Tabela 6). Considerando que um valor a partir de 8 sugere a indicação de uma investigação diagnóstica mais detalhada, existiam 105 pessoas (22,2\% dos trabalhadores que responderam esta questão) nesta situação. 
Entre os trabalhadores, $71,6 \%$ informaram praticar algum tipo de atividade física. A média do escore da prática de atividade física foi de 8,5 pontos $(\mathrm{dp}=1,3)$, variando de 4,0 a 12,0 pontos, com mediana de 8,5 pontos. A dimensão referente às atividades físicas ocupacionais foi a que apresentou maior média entre as três dimensões que compõem o escore (Tabela 6).

Tabela 5: Distribuição da população de estudo (nº e \%) segundo variáveis qualitativas relativas ao estilo de vida, Campinas e região, 2005.

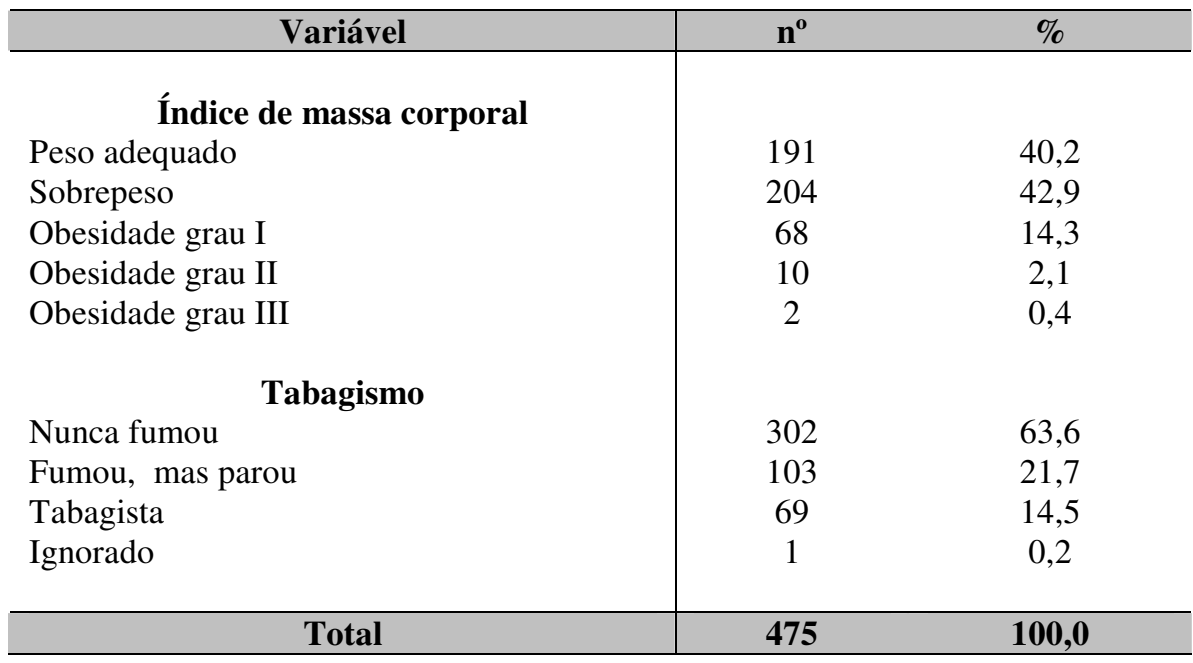

Gráfico 1: Distribuição dos 64 trabalhadores tabagistas (\% ) segundo grau de dependência ao tabaco, Empresa, 2005.

Baixo $23,2 \%$

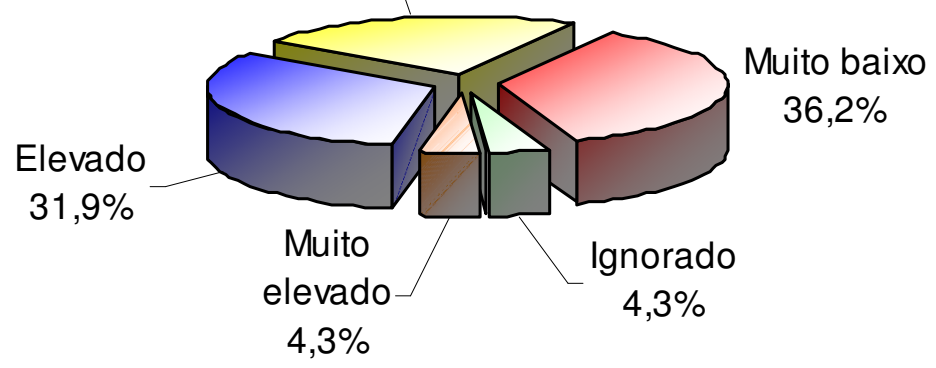


Tabela 6: Estatística descritiva das variáveis quantitativas relativas ao estilo de vida, Campinas e região, 2005.

\begin{tabular}{|c|c|c|c|c|c|c|}
\hline Variável & $\mathbf{n}^{0}$ & Média & $\begin{array}{l}\text { Desvio } \\
\text { padrão }\end{array}$ & $\begin{array}{c}\text { Míni- } \\
\text { ma }\end{array}$ & $\begin{array}{c}\text { Máxi- } \\
\text { ma }\end{array}$ & $\begin{array}{c}\text { Media- } \\
\text { na }\end{array}$ \\
\hline Tempo de tabagismo (anos) & 69 & 18,3 & 8,5 & 2,0 & 40,0 & 20,0 \\
\hline Quantidade de cigarros (dia) & 69 & 14,9 & 7,6 & 1,0 & 30,0 & 15,0 \\
\hline Consumo de álcool (pontos) & 472 & 4,8 & 4,3 & 0,0 & 23,0 & 4,0 \\
\hline Prática de atividade física & & & & & & \\
\hline Atividades físicas ocupacionais (AFO) & 474 & 3,1 & 0,5 & 2,0 & 4,0 & 3,1 \\
\hline Exercícios físicos no lazer (EFL) & 468 & 2,8 & 0,7 & 1,0 & 5,0 & 2,8 \\
\hline $\begin{array}{l}\text { Atividades físicas de lazer e locomoção } \\
\text { (AFL) }\end{array}$ & 472 & 2,6 & 0,6 & 1,0 & 5,0 & 2,5 \\
\hline Atividade física (escore total) (AF) & 466 & 8,5 & 1,3 & 4,0 & 12,0 & 8,5 \\
\hline
\end{tabular}

Consumo de álcool: escore de 0 a 40 pontos

AFO, EFL e AFL: escore de 0 a 5 pontos

AF: escore de 0 a 15 pontos

\subsection{3 - Características funcionais e estresse no trabalho}

Os trabalhadores estavam distribuídos em 10 unidades de trabalho, sendo que as maiores concentrações estavam na Transmissão de Energia (16,2\%), em Piracicaba $(15,2 \%)$ e no Centro $(11,8 \%)$. O maior percentual de trabalhadores estava no Setor de Distribuição de Energia $(66,5 \%)$ e a predominância dos cargos foi de Eletricistas de Distribuição (50,5\%). Os dados estão apresentados na Tabela 7.

Na mesma na Tabela 7 observa-se que a maioria dos trabalhadores atuava em horário diurno integral $(72,8 \%)$ e recebia menos que 11 salários mínimos mensais $(82,1 \%)$. Eles tinham, em média, 12,8 anos de tempo de serviço na empresa ( $d p=7,5$ anos), variando de menos de 1,0 a 31,0 anos, com mediana de 11,0 anos.

Quanto ao conteúdo do trabalho, 22,1\% dos trabalhadores exercia atividades com conteúdo com predominância de exigências mentais e 77,9\% com conteúdo com exigências físicas e mentais, não havendo trabalhadores com atividades com predominância de exigências físicas (Tabela 7). 
Tabela 7: Distribuição da população de estudo (nº e \%) segundo variáveis funcionais qualitativas, Campinas e região, 2005.

\begin{tabular}{|c|c|c|}
\hline Variável & $n^{0}$ & $\%$ \\
\hline $\begin{array}{l}\text { Unidade de trabalho } \\
\text { Valinhos/Itatiba } \\
\text { Americana } \\
\text { Sumaré } \\
\text { Itapira } \\
\text { Piracicaba } \\
\text { Trevo } \\
\text { Centro } \\
\text { Transmissão } \\
\text { Contabilidade } \\
\text { Recursos Humanos }\end{array}$ & $\begin{array}{l}23 \\
41 \\
50 \\
44 \\
72 \\
30 \\
56 \\
77 \\
35 \\
47\end{array}$ & $\begin{array}{c}4,8 \\
8,6 \\
10,5 \\
9,3 \\
15,2 \\
6,3 \\
11,8 \\
16,2 \\
7,4 \\
9,9\end{array}$ \\
\hline $\begin{array}{l}\quad \text { Setor } \\
\text { Administrativo } \\
\text { Distribuição de energia } \\
\text { Transmissão de energia }\end{array}$ & $\begin{array}{c}82 \\
316 \\
77\end{array}$ & $\begin{array}{l}17,3 \\
66,5 \\
16,2\end{array}$ \\
\hline $\begin{array}{l}\text { Cargo } \\
\text { Administrativo } \\
\text { Liderança da Distribuição } \\
\text { Eletricista de Distribuição } \\
\text { Eletricista de Linha Vida da Distribuição } \\
\text { Técnico da Distribuição } \\
\text { Eletricista da Transmissão } \\
\text { Eletricista de Linha Viva da Transmissão } \\
\text { Técnico da Transmissão }\end{array}$ & $\begin{array}{c}90 \\
15 \\
240 \\
39 \\
18 \\
5 \\
11 \\
57\end{array}$ & $\begin{array}{c}18,9 \\
3,2 \\
50,5 \\
8,2 \\
3,8 \\
1,1 \\
2,3 \\
12,0\end{array}$ \\
\hline $\begin{array}{ll} & \text { Turno } \\
\text { Diurno integral } & \\
\text { Manhã } & \\
\text { Tarde } & \\
\text { Noturno } & \end{array}$ & $\begin{array}{l}346 \\
38 \\
64 \\
27\end{array}$ & $\begin{array}{c}72,8 \\
8,0 \\
13,5 \\
5,7\end{array}$ \\
\hline $\begin{array}{l}\text { Conteúdo do trabalho } \\
\text { Mental } \\
\text { Misto }\end{array}$ & $\begin{array}{l}105 \\
370\end{array}$ & $\begin{array}{l}22,1 \\
77,9\end{array}$ \\
\hline $\begin{array}{l}\quad \text { Faixa salarial (salários mínimos) } \\
<4 \\
4,0-6,9 \\
7,0-10,9 \\
11-15,9 \\
16-20,9 \\
21-25,9 \\
26 \text { e }+\end{array}$ & $\begin{array}{c}29 \\
218 \\
143 \\
36 \\
34 \\
9 \\
6\end{array}$ & $\begin{array}{c}6,1 \\
45,9 \\
30,1 \\
7,6 \\
7,2 \\
1,9 \\
1,3\end{array}$ \\
\hline Total & 475 & 100,0 \\
\hline
\end{tabular}


O escore de estresse no trabalho apresentou média de 2,3 pontos $(\mathrm{dp}=0,7)$, variando de 1,0 a 5,0 pontos, com mediana de 2,3 pontos (Tabela 8 ).

Tabela 8: Estatística descritiva dos componentes do estresse no trabalho, Campinas e região, 2005.

\begin{tabular}{|c|c|c|c|c|c|c|c|}
\hline 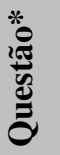 & 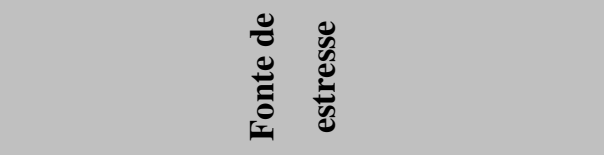 & $\because$ & 葛 & 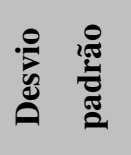 & 㞼 & 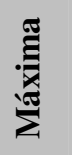 & 苞 \\
\hline 12 & Discriminação/favoritismo & 474 & 3,0 & 1,4 & 1,0 & 5,0 & 3,0 \\
\hline 15 & Falta de valorização & 474 & 2,8 & 1,3 & 1,0 & 5,0 & 3,0 \\
\hline 16 & Perspectivas de crescimento & 474 & 2,8 & 1,2 & 1,0 & 5,0 & 3,0 \\
\hline 5 & Informações organizacionais & 474 & 2,6 & 1,1 & 1,0 & 5,0 & 2,0 \\
\hline 1 & Distribuição das tarefas & 474 & 2,6 & 1,0 & 1,0 & 5,0 & 3,0 \\
\hline 17 & Tarefas abaixo da habilidade & 474 & 2,4 & 1,2 & 1,0 & 5,0 & 2,0 \\
\hline 2 & Tipo de controle & 474 & 2,4 & 1,1 & 1,0 & 5,0 & 2,0 \\
\hline 13 & Falta de treinamentos & 474 & 2,4 & 1,1 & 1,0 & 5,0 & 2,0 \\
\hline 6 & Informações sobre tarefas & 474 & 2,4 & 1,0 & 1,0 & 5,0 & 2,0 \\
\hline 21 & Trabalho bem feito é encoberto & 474 & 2,3 & 1,2 & 1,0 & 5,0 & 2,0 \\
\hline 18 & Competição no ambiente & 474 & 2,3 & 1,1 & 1,0 & 5,0 & 2,0 \\
\hline 22 & Tempo insuficiente & 474 & 2,3 & 1,1 & 1,0 & 5,0 & 2,0 \\
\hline 4 & Falta de confiança do superior & 474 & 2,2 & 1,2 & 1,0 & 5,0 & 2,0 \\
\hline 11 & Comunicação com supervisor & 474 & 2,2 & 1,1 & 1,0 & 5,0 & 2,0 \\
\hline 23 & Responsabilidades sem importância & 474 & 2,2 & 1,1 & 1,0 & 5,0 & 2,0 \\
\hline 3 & Falta de autonomia & 474 & 2,2 & 1,0 & 1,0 & 5,0 & 2,0 \\
\hline 19 & Incompreensão quanto responsabilidades & 474 & 2,2 & 1,0 & 1,0 & 5,0 & 2,0 \\
\hline 8 & Mau tratamento pelo supervisor & 474 & 2,1 & 1,3 & 1,0 & 5,0 & 2,0 \\
\hline 7 & Comunicação entre colegas & 474 & 2,1 & 1,0 & 1,0 & 5,0 & 2,0 \\
\hline 20 & Ordens contraditórias & 474 & 2,1 & 1,0 & 1,0 & 5,0 & 2,0 \\
\hline 10 & Trabalho durante horas seguidas & 474 & 2,0 & 1,0 & 1,0 & 5,0 & 2,0 \\
\hline 14 & Isolamento na organização & 474 & 2,0 & 1,0 & 1,0 & 5,0 & 2,0 \\
\hline 9 & Tarefas além da capacidade & 474 & 1,9 & 1,0 & 1,0 & 5,0 & 2,0 \\
\hline & Estresse no trabalho (escore total) & 474 & 2,3 & 0,7 & 1,0 & 5,0 & 2,3 \\
\hline
\end{tabular}


Os aspectos do trabalho que representaram as principais fontes de estresse foram discriminação/favoritismo no ambiente de trabalho, a pouca valorização pelos superiores, as poucas perspectivas de crescimento na carreira, a deficiência na divulgação de informações sobre decisões organizacionais, e a forma como as tarefas são distribuídas. Os aspectos que representaram as menores fontes de estresse foram a necessidade de realizar tarefas que estão além da capacidade do trabalhador, o sentimento de isolamento na organização, e a necessidade de trabalhar durante muitas horas seguidas. Os dados estão apresentados na Tabela 8.

\subsection{4 - Características relativas ao estado de saúde}

As dimensões relativas ao estado de saúde com os maiores escores foram capacidade funcional, aspecto físico e aspecto emocional (com médias respectivamente de 91,2, 88,3 e 85,0). As dimensões com as piores avaliações foram vitalidade, presença de dor e saúde mental (com médias respectivamente de 72,8, 75,0 e 76,6). Os dados estão apresentados na Tabela 9.

Tabela 9: Estatística descritiva das variáveis relativas ao estado de saúde, Campinas e região, 2005.

\begin{tabular}{l|cccccc}
\hline \multicolumn{1}{c|}{ Dimensão } & $\mathbf{n}^{\mathbf{0}}$ & Média & $\begin{array}{c}\text { Desvio } \\
\text { padrão }\end{array}$ & Mínima & Máxima & Mediana \\
\hline Capacidade funcional & 470 & 91,2 & 13,3 & 0,0 & 100,0 & 95,0 \\
Aspecto físico & 474 & 88,3 & 24,4 & 0,0 & 100,0 & 100,0 \\
Dor & 474 & 75,0 & 20,8 & 12,0 & 100,0 & 74,0 \\
Estado geral de saúde & 473 & 80,7 & 16,1 & 15,0 & 100,0 & 82,0 \\
Vitalidade & 475 & 72,8 & 17,0 & 0,0 & 100,0 & 75,0 \\
Aspecto social & 475 & 82,4 & 20,2 & 0,0 & 100,0 & 87,5 \\
Aspecto emocional & 474 & 85,0 & 28,6 & 0,0 & 100,0 & 100,0 \\
Saúde mental & 475 & 76,6 & 17,1 & 0,0 & 100,0 & 80,0 \\
\hline Escores variando de 0,0 a 100,0 & & & & &
\end{tabular}




\section{4 - Análise do índice de capacidade para o trabalho}

\subsection{1 - Análise descritiva do índice de capacidade para o trabalho}

O índice de capacidade para o trabalho médio observado foi de 41,8 pontos (dp=5,1), variando de 13,0 a 49,0 pontos e mediana de 43,0 pontos. Esta variável não apresentou aderência à distribuição normal $(\mathrm{p}<0,0001$ no teste de KolmogorovSmirnov), determinando o uso de testes não paramétricos para realização dos testes estatísticos. Vale destacar que $25,1 \%$ dos trabalhadores apresentaram valores do ICT entre 46 e 49 pontos nesta escala que vai de 7 a 49 pontos.

Na Tabela 10 observa-se que as dimensões que compõem o índice de capacidade para o trabalho apresentaram os seguintes resultados:

- Capacidade para o trabalho atual comparada com a melhor de toda a vida: $83,6 \%$ dos trabalhadores ocuparam as 3 pontuações superiores da dimensão.

- Capacidade para o trabalho em relação às exigências do trabalho: $86,1 \%$ dos trabalhadores ocuparam as 3 pontuações superiores da dimensão.

- Número atual de doenças diagnosticadas pelo médico: 36,6\% dos trabalhadores não referiram presença de doenças (pontuação $=7$ ) e $8,4 \%$ informaram 5 ou mais doenças (pontuação $=1$ ).

- Perda estimada para o trabalho devido às doenças: 57,5\% dos trabalhadores informaram que não têm nenhum impedimento/doença para realizar seu trabalho (pontuação = 6).

- Faltas ao trabalho por doenças nos últimos 12 meses: 59,8\% dos trabalhadores negaram afastamento do trabalho por doenças nos últimos 12 meses (pontuação = 5). 
- Prognóstico próprio sobre a capacidade para o trabalho: 89,1\% dos trabalhadores consideraram que é bastante provável que daqui a 2 anos serão capazes de fazer o trabalho atual (pontuação =7).

- Recursos mentais: $65,1 \%$ dos trabalhadores ocuparam a pontuação mais elevada em termos de recursos mentais (capacidade para apreciar as atividades diárias, percepção de estar ativo e alerta, sentimento de esperança para o futuro).

Com isso, percebe-se que a população de estudo apresentou altos valores nas diversas dimensões do ICT.

\subsection{2 - Doenças auto-referidas no questionário ICT}

Na Tabela 11 estão apresentadas as prevalências das doenças que o trabalhador referiu ter tanto em sua própria opinião como por diagnóstico médico, ressaltando que estão apresentadas somente aquelas com prevalência acima de 5,0\%. Observa-se que as doenças mais prevalentes foram aquelas relacionadas a distúrbios músculoesqueléticos (costas, pescoço, membros inferiores e superiores), distúrbios emocionais leves, obesidade e gastrite/irritação duodenal.

Cabe ressaltar que, exceção feita à hipertensão arterial e à outra doença da pele, as prevalências apresentadas na opinião própria do trabalhador foram mais elevadas que aquelas com história referida de diagnóstico médico. Outra exceção diz respeito aos problemas auditivos onde a prevalência da opinião própria foi igual àquela do diagnóstico médico informado. 
Tabela 10: Distribuição da população de estudo (nº \% ) segundo pontuação das dimensões do Índice de Capacidade para o

Trabalho, Campinas e região, 2005.

\begin{tabular}{|c|c|c|c|c|c|c|c|c|c|c|c|c|}
\hline \multirow[t]{2}{*}{ Dimensão } & \multicolumn{12}{|c|}{ Pontuação } \\
\hline & $\mathbf{0}$ & 1 & 2 & 3 & 4 & 5 & 6 & 7 & 8 & 9 & 10 & Total \\
\hline $\begin{array}{l}\text { Capacidade para o trabalho atual comparada com a melhor } \\
\qquad \text { de toda a vida }\end{array}$ & $\begin{array}{c}1 \\
(0,2)\end{array}$ & $\begin{array}{c}-- \\
(--)\end{array}$ & $\begin{array}{l}-- \\
(--)\end{array}$ & $\begin{array}{c}3 \\
(0,6)\end{array}$ & $\begin{array}{c}2 \\
(0,4)\end{array}$ & $\begin{array}{c}9 \\
(1,9)\end{array}$ & $\begin{array}{c}10 \\
(2,1)\end{array}$ & $\begin{array}{c}53 \\
(11,2)\end{array}$ & $\begin{array}{c}158 \\
(33,3)\end{array}$ & $\begin{array}{c}136 \\
(28,6)\end{array}$ & $\begin{array}{c}103 \\
(21,7)\end{array}$ & $\begin{array}{c}475 \\
(100,0)\end{array}$ \\
\hline $\begin{array}{l}\text { Capacidade para o trabalho em relação às exigências do } \\
\text { trabalho }\end{array}$ & $\begin{array}{l}-- \\
(--)\end{array}$ & $\begin{array}{l}-- \\
(--)\end{array}$ & $\begin{array}{l}-- \\
(--)\end{array}$ & $(--)$ & $\begin{array}{c}2 \\
(0,4)\end{array}$ & $\begin{array}{c}2 \\
(0,4)\end{array}$ & $\begin{array}{c}21 \\
(4,4)\end{array}$ & $\begin{array}{c}41 \\
(8,6)\end{array}$ & $\begin{array}{c}143 \\
(30,1)\end{array}$ & $\begin{array}{c}113 \\
(23,8)\end{array}$ & $\begin{array}{c}153 \\
(32,2)\end{array}$ & $\begin{array}{c}475 \\
(100,0)\end{array}$ \\
\hline $\begin{array}{l}\text { Número atual de doenças diagnosticadas pelo médico } \\
\text { (pontos) }\end{array}$ & & $\begin{array}{c}40 \\
(8,4)\end{array}$ & $\begin{array}{c}30 \\
(6,3)\end{array}$ & $\begin{array}{c}51 \\
(10,7)\end{array}$ & $\begin{array}{c}64 \\
(13,5)\end{array}$ & $\begin{array}{c}116 \\
(24,4)\end{array}$ & & $\begin{array}{c}174 \\
(36,6)\end{array}$ & & & & $\begin{array}{c}475 \\
(100,0)\end{array}$ \\
\hline Perda estimada para o trabalho devido às doenças & & $\begin{array}{c}3 \\
(0,6)\end{array}$ & $\begin{array}{c}3 \\
(0,6)\end{array}$ & $\begin{array}{c}13 \\
(2,7)\end{array}$ & $\begin{array}{c}79 \\
(16,6)\end{array}$ & $\begin{array}{c}104 \\
(21,9)\end{array}$ & $\begin{array}{c}273 \\
(57,5)\end{array}$ & & & & & $\begin{array}{c}475 \\
(100,0)\end{array}$ \\
\hline Faltas ao trabalho por doenças nos últimos 12 meses & & $\begin{array}{c}8 \\
(1,7)\end{array}$ & $\begin{array}{c}11 \\
(2,3)\end{array}$ & $\begin{array}{c}27 \\
(5,7)\end{array}$ & $\begin{array}{c}145 \\
(30,5)\end{array}$ & $\begin{array}{c}284 \\
(59,8)\end{array}$ & & & & & & $\begin{array}{c}475 \\
(100,0)\end{array}$ \\
\hline $\begin{array}{l}\text { Prognóstico próprio sobre a capacidade para o trabalho } \\
\qquad \text { daqui a dois anos }\end{array}$ & & $\begin{array}{c}21 \\
(4,4)\end{array}$ & & & $\begin{array}{c}31 \\
(6,5)\end{array}$ & & & $\begin{array}{c}423 \\
(89,1)\end{array}$ & & & & $\begin{array}{c}475 \\
(100,0)\end{array}$ \\
\hline Recursos mentais & & $\begin{array}{c}5 \\
(1,1)\end{array}$ & $\begin{array}{c}25 \\
(5,3)\end{array}$ & $\begin{array}{c}136 \\
(28,6)\end{array}$ & $\begin{array}{c}309 \\
(65,1)\end{array}$ & & & & & & & $\begin{array}{c}475 \\
(100,0)\end{array}$ \\
\hline
\end{tabular}


Tabela 11: Distribuição da população segundo doenças auto-referidas (no e \%),

Campinas e região, 2005.

\begin{tabular}{l|cc|cc}
\hline \multicolumn{1}{c|}{ Doença } & \multicolumn{3}{c|}{ Opinião própria } & \multicolumn{3}{c}{ Diagnóstico médico } \\
& $\mathbf{n}^{\mathbf{0}}$ & $\mathbf{\%}$ & $\mathbf{n}^{\mathbf{0}}$ & $\mathbf{\%}$ \\
\hline Lesão nas costas & 127 & 26,7 & 65 & 13,7 \\
\hline Distúrbio emocional leve & 102 & 22,1 & 38 & 8,0 \\
\hline $\begin{array}{l}\text { Doença na parte superior das costas ou região do } \\
\text { pesç̧o }\end{array}$ & & & & \\
Lesão nos braços / mãos & 95 & 20,0 & 23 & 4,8 \\
\hline Dor nas costas que se irradia para a perna & 63 & 19,2 & 53 & 11,2 \\
\hline Obesidade & 62 & 13,3 & 32 & 6,7 \\
\hline Doença na parte inferior das costas & 60 & 12,6 & 31 & 6,5 \\
\hline Gastrite ou irritação duodenal & 60 & 12,6 & 37 & 5,7 \\
\hline Doença ou lesão na visão & 49 & 10,3 & 43 & 7,8 \\
\hline Lesão nas pernas / pés & 47 & 9,9 & 33 & 6,1 \\
\hline Problema ou diminuição na audição & 43 & 9,1 & 43 & 9,1 \\
\hline Infecções repetidas no trato respiratório & 41 & 8,6 & 32 & 6,7 \\
\hline Alergia, eczema & 41 & 8,6 & 28 & 5,9 \\
\hline Hipertensão arterial & 36 & 7,6 & 40 & 8,4 \\
\hline $\begin{array}{l}\text { Doenças músculo-esquelética afetando } \\
\text { pernas }\end{array}$ & & & & \\
\hline Lesão em outras partes do corpo & 34 & 7,2 & 15 & 3,2 \\
\hline Sinusite crônica & 28 & 5,9 & 23 & 4,8 \\
\hline Outra doença da pele & 26 & 5,5 & 17 & 3,6 \\
\hline \multicolumn{1}{|c|}{ Total } & 22 & 4,6 & 25 & 5,3 \\
\hline
\end{tabular}

\section{5 - Análise dos fatores associados à capacidade para o trabalho}

\subsection{1 - Características demográficas}

$\mathrm{Na}$ Tabela 12 observa-se que não houve diferenças estatisticamente significativas entre as médias do escore capacidade para o trabalho $\mathrm{e}$ as características demográficas sexo, estado civil e escolaridade $(\mathrm{p}=0,283 ; \mathrm{p}=0,260$ e $\mathrm{p}=0,563$, respectivamente).

A única característica demográfica que esteve significativamemte associada à capacidade para o trabalho foi idade, sendo que quanto mais elevada a idade, menor o valor do ICT $(\mathrm{p}<0,001, \mathrm{r}=-0,16)$. 
Tabela 12: Estatística descritiva do escore de capacidade para o trabalho segundo características demográficas, Campinas e região, 2005.

\begin{tabular}{ll|ccc}
\multicolumn{1}{c|}{ Variável } & \multicolumn{1}{c}{ Categoria } & $\mathbf{n}^{\mathbf{0}}$ & $\begin{array}{c}\text { Média (Desvio } \\
\text { padrão) }\end{array}$ & p \\
\hline \multirow{2}{*}{ Sexo } & Mulheres & 43 & $41,1(4,9)$ & $0,283^{(\mathrm{M})}$ \\
& Homens & 432 & $41,9(5,2)$ & \\
Estado civil & Casado(a) / com companheira(o) & 357 & $41,8(4,9)$ & $0,260^{(\mathrm{M})}$ \\
& Não casado(a) & 116 & $41,9(6,0)$ & \\
Escolaridade & Sem ensino superior completo & 348 & $41,7(5,3)$ & $0,563^{(\mathrm{M})}$ \\
& Com ensino superior completo & 127 & $42,2(4,6)$ & \\
\hline
\end{tabular}

$(\mathrm{M})=$ Teste Mann-Whitney

Das características demográficas, a idade e o sexo foram selecionadas para a análise múltipla. A variável sexo foi selecionada, pois é potencial fator de confusão nesta análise.

\subsection{2 - Características do estilo de vida}

$\mathrm{Na}$ Tabela 13 observa-se que não houve diferenças estatisticamente significativas entre as médias do escore de capacidade para o trabalho e as variáveis tabagismo $(\mathrm{p}=0,731)$, tempo de tabagismo $(\mathrm{p}=0,538)$ e grau de dependência ao tabaco $(\mathrm{p}=0,369)$. 
Tabela 13: Estatística descritiva do escore de capacidade para o trabalho segundo características qualitativas do estilo de vida, Campinas e região, 2005.

\begin{tabular}{|c|c|c|c|c|}
\hline Variável & Categoria & $n^{0}$ & Média (Desvio padrão) & $\mathbf{p}$ \\
\hline Tabagismo & $\begin{array}{l}\text { Nunca fumou } \\
\text { Fumou, mas parou } \\
\text { Menos que } 10 \text { cigarros / dia } \\
10 \text { a } 19 \text { cigarros /dia } \\
20 \text { ou mais cigarros por dia }\end{array}$ & $\begin{array}{c}302 \\
103 \\
16 \\
21 \\
32\end{array}$ & $\begin{array}{l}42,0(5,1) \\
41,6(4,9) \\
40,9(7,0) \\
41,9(6,0) \\
41,3(4,8)\end{array}$ & $0,731^{(\mathrm{K})}$ \\
\hline $\begin{array}{l}\text { Tempo de } \\
\text { tabagismo }\end{array}$ & $\begin{array}{l}\text { Nunca fumou } \\
\text { Fumou, mas parou } \\
\text { Menos que } 10 \text { anos } \\
10 \text { a } 19 \text { anos } \\
20 \text { ou mais cigarros por dia }\end{array}$ & $\begin{array}{c}302 \\
103 \\
12 \\
20 \\
37\end{array}$ & $\begin{array}{l}42,0(5,1) \\
41,6(4,9) \\
42,4(5,9) \\
41,6(6,2) \\
41,0(5,3)\end{array}$ & $0,538^{(\mathrm{K})}$ \\
\hline $\begin{array}{l}\text { Dependência } \\
\text { ao tabaco }\end{array}$ & $\begin{array}{l}\text { Não fuma } \\
\text { Muito baixa, baixa ou média } \\
\text { Elevada ou muito elevada }\end{array}$ & $\begin{array}{c}405 \\
57 \\
9\end{array}$ & $\begin{array}{c}41,9(5,1) \\
41,6(5,5) \\
39(6,9)\end{array}$ & $0,369^{(\mathrm{K})}$ \\
\hline
\end{tabular}

Na Tabela 14 observa-se que houve correlação estatisticamente significativa entre índice de massa corporal e capacidade para o trabalho, sendo que quanto maior o IMC, menor o valor do ICT ( $\mathrm{p}<0,001, \mathrm{r}=-0,17)$. Também se observou correlação estatisticamente significativa entre grau de dependência ao álcool e capacidade para o trabalho, sendo que quanto maior o grau de dependência, menor o valor do ICT ( $\mathrm{p}=0,019, \mathrm{r}=-0,11)$. Ainda na Tabela 14 observa-se que houve correlação estatisticamente significativa entre prática de atividade física e capacidade para o trabalho, sendo que quanto maior o escore relacionado à atividade física, maior o valor do ICT $(\mathrm{p}<0,001, \mathrm{r}=0,19)$.

Tabela 14: Coeficientes de correlação entre variáveis quantitativas relacionadas ao estilo de vida e capacidade para o trabalho, Campinas e região, 2005.

\begin{tabular}{l|ccc}
\hline \multicolumn{1}{c|}{ Variável } & $\mathbf{n}^{\mathbf{0}}$ & $\mathbf{r}^{(\mathrm{SP})}$ & $\mathbf{p}$ \\
\hline & & & \\
Índice de massa corporal & 475 & $-0,17$ & $<0,001$ \\
Dependência ao álcool & 472 & $-0,11$ & 0,019 \\
Prática de atividade física & 466 & 0,19 & $<0,001$ \\
\hline
\end{tabular}


Das variáveis relacionadas ao estilo de vida, foram selecionadas o índice de massa corporal, a dependência química ao álcool e a prática de atividade física para a análise múltipla.

\subsection{3 - Características relacionadas ao trabalho}

Na Tabela 15 observa-se que não ocorreram diferenças estatisticamente significativas entre as médias do escore de capacidade para o trabalho e o setor de trabalho $(p=0,085)$, cargo $(p=0,257)$, turno de trabalho $(p=0,931)$, conteúdo do trabalho $(\mathrm{p}=0,796)$ e faixa salarial $(\mathrm{p}=0,145)$.

A unidade de trabalho esteve significativamente associada à capacidade para o trabalho, sendo que o teste Tukey post hoc demonstrou que as unidades Itapira e Transmissão apresentaram médias do ICT superiores à média da unidade Centro, com $\mathrm{p}=0,043$ (Tabela 15).

Identificou-se correlação estatisticamente significativa entre tempo na empresa e capacidade para o trabalho, sendo que quanto menor o tempo que o trabalhador estava empregado na empresa, maior o valor do ICT ( $p<, 0,001, r=-0,17)$.

O estresse relacionado ao trabalho também esteve correlacionado à capacidade para o trabalho, sendo que quanto mais elevado o estresse, menor o valor do ICT $(\mathrm{p}<0,001, \mathrm{r}=-0,37)$. 
Tabela 15: Estatística descritiva do escore de capacidade para o trabalho segundo variáveis qualitativas relacionadas ao trabalho, Campinas e região, 2005.

\begin{tabular}{|c|c|c|c|c|}
\hline Variável & Categoria & $n^{\circ}$ & $\begin{array}{c}\text { Média (Desvio } \\
\text { padrão) }\end{array}$ & p \\
\hline $\begin{array}{l}\text { Unidade de } \\
\text { trabalho }\end{array}$ & $\begin{array}{l}\text { Valinhos/Itatiba } \\
\text { Americana } \\
\text { Sumaré } \\
\text { Itapira }^{(T)} \\
\text { Piracicaba } \\
\text { Trevo } \\
\text { Centro } \\
\text { Transmissão } \\
\text { Contabilidade } \\
\text { Recursos Humanos }\end{array}$ & $\begin{array}{l}23 \\
41 \\
50 \\
44 \\
72 \\
30 \\
56 \\
77 \\
35 \\
47\end{array}$ & $\begin{array}{l}41,6(6,7) \\
41,2(6,1) \\
42,7(3,7) \\
43,5(3,7) \\
41,8(5,0) \\
39,9(6,4) \\
50,2(6,3) \\
43,0(4,3) \\
41,8(4,6) \\
41,4(4,5)\end{array}$ & $0,036^{(\mathrm{K})}$ \\
\hline Setor & $\begin{array}{l}\text { Administrativo } \\
\text { Distribuição de energia } \\
\text { Transmissão de energia }\end{array}$ & $\begin{array}{c}82 \\
316 \\
77\end{array}$ & $\begin{array}{l}41,6(4,5) \\
41,6(5,4) \\
43,0(4,3)\end{array}$ & $0,085^{(\mathrm{K})}$ \\
\hline Cargo & $\begin{array}{l}\text { Administrativo } \\
\text { Liderança da Distribuição, Técnicos da } \\
\text { Distribuição, Técnicos da Transmissão e } \\
\text { Eletricistas da Transmissão } \\
\text { Eletricista da Distribuição } \\
\text { Eletricista de Linha Viva da } \\
\text { Distribuição e Eletricista de Linha Viva } \\
\text { da Transmissão }\end{array}$ & $\begin{array}{c}240 \\
50\end{array}$ & $\begin{array}{l}41,5(4,5) \\
42,6(4,8) \\
41,8(5,6) \\
41,0(4,9)\end{array}$ & $0,257^{(\mathrm{K})}$ \\
\hline Turno & $\begin{array}{l}\text { Diurno integral } \\
\text { Matutino ou vespertino } \\
\text { Noturno }\end{array}$ & $\begin{array}{c}346 \\
102 \\
27\end{array}$ & $\begin{array}{l}41,8(5,2) \\
41,8(5,4) \\
42,3(3,6)\end{array}$ & $0,931^{(\mathrm{K})}$ \\
\hline Conteúdo & $\begin{array}{l}\text { Mental } \\
\text { Misto }\end{array}$ & $\begin{array}{l}105 \\
370\end{array}$ & $\begin{array}{l}41,9(4,6) \\
41,8(5,3)\end{array}$ & $0,796^{(\mathrm{M})}$ \\
\hline $\begin{array}{l}\text { Faixa salarial } \\
\text { (salários mínimos) }\end{array}$ & $\begin{array}{l}<4 \\
4,0-6,9 \\
7,0-10,9 \\
11-15,9 \\
16-20,9 \\
21-25,9\end{array}$ & $\begin{array}{c}29 \\
218 \\
143 \\
36 \\
34 \\
15\end{array}$ & $\begin{array}{l}43,0(6,8) \\
41,3(5,5) \\
42,0(4,7) \\
41,9(5,1) \\
42,6(3,2) \\
43,7(3,9)\end{array}$ & $0,145^{(\mathrm{K})}$ \\
\hline
\end{tabular}

Das variáveis relacionadas ao trabalho, foram selecionadas para a análise múltipla a unidade de trabalho, o tempo na empresa e o estresse no trabalho. 


\subsection{4 - Análise do estado de saúde}

Todas as 08 dimensões do estado de saúde analisadas apresentaram correlação estatisticamente significativa com a capacidade para o trabalho $(\mathrm{p}<0,001)$, sendo que quanto melhor o estado de saúde, maior o valor do ICT (Tabela 16).

Tabela 16: Coeficientes de correlação entre variáveis relacionadas ao estado de saúde e capacidade para o trabalho, Campinas e região, 2005.

\begin{tabular}{l|ccc}
\multicolumn{1}{c|}{ Dimensão } & $\mathbf{n}^{\mathbf{0}}$ & $\mathbf{r}^{\text {(SP) }}$ & $\mathbf{p}$ \\
\hline & & & \\
Capacidade funcional & 470 & 0,442 & $<0,001$ \\
Aspecto físico & 474 & 0,317 & $<0,001$ \\
Dor & 474 & 0,479 & $<0,001$ \\
Estado geral de saúde & 473 & 0,491 & $<0,001$ \\
Vitalidade & 475 & 0,394 & $<0,001$ \\
Aspecto social & 475 & 0,334 & $<0,001$ \\
Aspecto emocional & 474 & 0,231 & $<0,001$ \\
Saúde mental & 475 & 0,395 & $<0,001$ \\
\hline (SP) = Coeficiente de correção de Spearman & & &
\end{tabular}

Das variáveis relacionadas ao estado de saúde, todas foram selecionadas para a análise múltipla.

\section{6 - Análise de regressão linear múltipla (análise conjunta dos fatores associados)}

Inicialmente, foi feita uma modelagem múltipla incluindo todas as variáveis que apresentaram valor do $\mathrm{p} \geq 0,20$ e, também, a característica demográfica sexo como variável de ajuste. A relação das variáveis, bem como a ordem de entrada no modelo múltiplo, estão apresentadas na Tabela 17. 
Tabela 17: Relação de variáveis selecionadas para a análise de regressão linear múltipla, Campinas e região,

2005.

\begin{tabular}{l|cc}
\hline \multicolumn{1}{c|}{ Variável } & p & $\begin{array}{c}\text { Ordem de } \\
\text { entrada }\end{array}$ \\
\hline Idade & $<0,001$ & $1^{\mathrm{a}}$ \\
Índice de massa corporal & $<0,001$ & $2^{\mathrm{a}}$ \\
Prática de atividade física & $<0,001$ & $3^{\mathrm{a}}$ \\
Tempo na empresa & $<0,001$ & $4^{\mathrm{a}}$ \\
Estresse no trabalho & $<0,001$ & $5^{\mathrm{a}}$ \\
Capacidade funcional & $<0,001$ & $6^{\mathrm{a}}$ \\
Aspecto físico & $<0,001$ & $7^{\mathrm{a}}$ \\
Dor & $<0,001$ & $8^{\mathrm{a}}$ \\
Estado geral de saúde & $<0,001$ & $9^{\mathrm{a}}$ \\
Vitalidade & $<0,001$ & $10^{\mathrm{a}}$ \\
Aspecto social & $<0,001$ & $11^{\mathrm{a}}$ \\
Aspecto emocional & $<0,001$ & $12^{\mathrm{a}}$ \\
Saúde mental & $<0,001$ & $13^{\mathrm{a}}$ \\
Dependência ao álcool & 0,019 & $14^{\mathrm{a}}$ \\
Unidade de trabalho & 0,036 & $15^{\mathrm{a}}$ \\
Setor & 0,085 & $16^{\mathrm{a}}$ \\
Faixa salarial & 0,145 & $17^{\mathrm{a}}$ \\
Sexo & 0,283 & $18^{\mathrm{a}}$ \\
\hline
\end{tabular}

Foram realizadas duas diferentes modelagens. Os detalhes da $1^{\mathrm{a}}$ modelagem múltipla estão descritos a seguir e apresentados na Tabela 18. Iniciou-se essa $1^{\text {a }}$ modelagem múltipla com a variável idade (modelo 1) e, em seguida, acrescentou-se o índice de massa corporal (modelo 2). Com a inclusão do IMC, a idade perdeu a significância estatística. O modelo foi refeito excluindo o IMC e incluindo o tempo na empresa e, novamente, a idade perde a significância estatística, mostrando que pode estar correlacionada com as demais variáveis. Foi calculado o coeficiente de Spearman que demonstrou que idade está correlacionada com IMC $(\mathrm{p}<0,001, \mathrm{r}=0,20)$ e com tempo na empresa $(\mathrm{p}<0,001, \mathrm{r}=0,74)$. Considerando que a forte correlação entre idade e tempo na empresa determinaria um efeito de sobreajuste caso as duas variáveis fossem mantidas no modelo, optou-se por dar preferência à permanência da variável tempo na empresa. 
Desta forma, iniciou-se outro modelo com o IMC e a inclusão da variável prática de atividade física. Houve diminuição do intervalo de confiança e melhoria do valor do coeficiente de determinação ajustado $\left(r^{2} a\right)$ e, portanto, a variável foi mantida no modelo (modelo 3 ).

Em seguida, a variável tempo na empresa foi incluída, ocorrendo diminuição do intervalo de confiança do IMC e da prática de atividade física. Houve melhoria do valor do coeficiente de determinação ajustado $\left(\mathrm{r}^{2} \mathrm{a}\right)$ e, portanto, a variável foi mantida no modelo (modelo 4).

No passo seguinte houve a inclusão da variável estresse no trabalho, com diminuição do intervalo de confiança do IMC, da prática de atividade física e do estresse no trabalho (em relação à análise univariada). Também houve melhoria do valor do coeficiente de determinação ajustado $\left(r^{2} a\right)$ e, portanto, a variável foi mantida no modelo (modelo 5). O tempo na empresa perdeu a significância estatística, mas foi mantido no modelo como variável de ajuste.

A seguir, foi incluída a variável capacidade funcional que retirou a significância estatística e alterou muito os valores dos $\beta_{1}$ do IMC e da prática de atividade física. O modelo foi refeito retirando IMC e, depois, a prática de atividade física. Como as duas variáveis continuaram sem significância estatística e como capacidade funcional é mais relevante do ponto de vista teórico, ambas foram retiradas do modelo. O modelo mantendo as variáveis tempo na empresa, estresse no trabalho e capacidade funcional apresentou diminuição do intervalo de confiança das duas últimas variáveis em relação ao modelo univariado, e proporcionou melhoria do valor do $\mathrm{r}^{2} \mathrm{a}$ (modelo 6$)$.

A inclusão da variável aspecto físico levou à diminuição do intervalo de confiança das demais variáveis (exceto tempo na empresa) e melhorou o valor do $r^{2} a$, sendo mantida no modelo (modelo 7). 
A inclusão da variável dor levou à diminuição do intervalo de confiança das demais variáveis (exceto tempo na empresa) e melhorou o valor do $\mathrm{r}^{2} \mathrm{a}$, sendo mantida no modelo (modelo 8).

A inclusão da variável estado geral de saúde levou à diminuição do intervalo de confiança das demais variáveis (exceto tempo na empresa), diminuiu o valor dos coeficientes de regressão, e melhorou o valor do $\mathrm{r}^{2} \mathrm{a}$, sendo mantida no modelo (modelo 9).

Em seguida, foi incluída a variável vitalidade que perdeu a significância estatística, não sendo mantida no modelo (modelo 10). O mesmo aconteceu com as variáveis aspecto social (modelo 11), aspecto emocional (modelo 12) e saúde mental (modelo 13).

A perda da significância estatística das quatro dimensões da saúde pertinentes a saúde mental é explicada pela correlação inversa estatisticamente significativa que elas apresentam com o estresse no trabalho, sendo que quanto menos intenso é o nível de estresse no trabalho, melhor é o estado de saúde. As correlações com o estresse no trabalho foram testadas por meio do coeficiente de Spearman: vitalidade $(\mathrm{p}<0,001$ e $\mathrm{r}=-0,97)$, aspecto social $(\mathrm{p}<0,001$ e $\mathrm{r}=-0,35)$, aspecto emocional $(\mathrm{p}<0,001$ e r=-0,24), e saúde mental ( $\mathrm{p}<0,001$ e r=-0,48).

Na continuidade da modelagem, foi incluída a variável dependência química ao álcool, que perdeu a significância estatística, não sendo mantida no modelo (modelo 14).

$\mathrm{Na}$ variável unidade de trabalho a Transmissão de Energia foi considerada a categoria de referência por ser aquela com maior média no escore do ICT (modelo 15). Como algumas categorias não foram significativas, optou-se por analisá-las em conjunto com a unidade Transmissão de Energia. 
As Unidades de Trabalho foram transformadas em novas variáveis indicadoras, com a categoria de referência sendo composta pelas unidades Americana, Trevo e Centro (unidades que não apresentaram associação com ICT). O modelo foi refeito com estas novas variáveis e apenas a unidade Trevo manteve associação estatística (modelo 16).

O modelo foi feito mais uma vez, agora somente com a variável indicadora tendo como categoria de referência a unidade Trevo, e esta variável perdeu a significância estatística, sendo a unidade de trabalho retirada da modelagem (modelo 17).

Na sequiência, a variável analisada foi o setor de trabalho, sendo que o Setor de Transmissão de Energia foi considerado como a categoria de referência (modelo 18). Pelas mesmas razões descritas na unidade, o setor foi analisado com outra categorização (modelo 19), mas, mesmo assim, esta variável foi retirada do modelo.

$\mathrm{Na}$ continuidade da modelagem, foi analisada a variável faixa salarial. A faixa de rendimentos de 21 ou mais salários mínimos foi considerada como categoria de referência, e nenhuma categoria mostrou associação estatisticamente significativa com a capacidade para o trabalho, sendo retirada do modelo (modelo 20).

Finalmente, apesar de não apresentar associação estatisticamente significativa com a capacidade para o trabalho, a variável sexo foi incluída no modelo como variável de ajuste (modelo 21). Este último modelo, composto pelas variáveis tempo na empresa, estresse no trabalho, capacidade funcional, aspecto físico, dor, estado geral de saúde e sexo, sendo o modelo múltiplo final escolhido. 
Tabela 18: Descrição das etapas de modelagem múltipla dos fatores associados à capacidade para o trabalho, $1^{\mathrm{a}}$ modelagem (incluídas as dimensões do estado de saúde), Campinas e região, 2005.

\begin{tabular}{|c|c|c|c|c|c|}
\hline Modelo & Variáveis & $\beta$ & $\mathrm{IC}_{95 \%}(\boldsymbol{\beta})$ & $\begin{array}{c}\mathbf{p} \\
(\operatorname{modelo})\end{array}$ & $\mathbf{r}^{2} \mathbf{a}$ \\
\hline 1 & Idade (em anos) & $-0,065$ & {$[-0,123 ;-0,007]$} & 0,029 & 0,08 \\
\hline \multirow[t]{2}{*}{2} & Idade (em anos) & $-0,040$ & {$[-0,098 ; 0,018]$} & 0,177 & 0,05 \\
\hline & $\operatorname{IMC}\left(\mathrm{kg} / \mathrm{m}^{2}\right)$ & $-0,271$ & {$[-0,390 ;-0,152]$} & $<0,001$ & \\
\hline \multirow[t]{2}{*}{3} & $\operatorname{IMC}\left(\mathrm{kg} / \mathrm{m}^{2}\right)$ & $-0,261$ & {$[-0,377 ;-0,144]$} & $<0,001$ & 0,08 \\
\hline & Prática de atividade física (escore) & 0,737 & {$[0,392 ; 1,082]$} & $<0,001$ & \\
\hline \multirow[t]{3}{*}{4} & $\operatorname{IMC}\left(\mathrm{kg} / \mathrm{m}^{2}\right)$ & $-0,243$ & {$[-0,377 ;-0,144]$} & $<0,001$ & 0,08 \\
\hline & Prática de atividade física (escore) & 0,725 & {$[0,392 ; 1,082]$} & $<0,001$ & \\
\hline & Tempo na empresa (em anos) & $-0,062$ & {$[-0,123 ;-0,001]$} & $<0,001$ & \\
\hline \multirow[t]{4}{*}{5} & $\operatorname{IMC}\left(\mathrm{kg} / \mathrm{m}^{2}\right)$ & $-0,195$ & {$[-0,305 ;-0,084]$} & $<0,001$ & 0,20 \\
\hline & Prática de atividade física (escore) & 0,612 & {$[0,289 ; 0,936]$} & $<0,001$ & \\
\hline & Tempo na empresa (em anos) & $-0,047$ & {$[-0,104 ;-0,010]$} & 0,104 & \\
\hline & Estresse no trabalho (escore) & $-2,442$ & {$[-3,031 ;-1,852]$} & $<0,001$ & \\
\hline \multirow[t]{3}{*}{6} & Tempo na empresa (em anos) & $-0,023$ & {$[-0,074 ; 0,028]$} & 0,381 & 0,35 \\
\hline & Estresse no trabalho (escore) & $-2,121$ & {$[-2,657 ;-1,586]$} & $<0,001$ & \\
\hline & Capacidade funcional (escore) & 0,175 & {$[0,145 ; 0,204]$} & $<0,001$ & \\
\hline \multirow[t]{4}{*}{7} & Tempo na empresa (em anos) & $-0,038$ & {$[-0,087 ; 0,011]$} & 0,381 & 0,41 \\
\hline & Estresse no trabalho (escore) & $-1,692$ & {$[-2,217 ;-1,167]$} & $<0,001$ & \\
\hline & Capacidade funcional (escore) & 0,140 & {$[0,111 ; 0,170]$} & $<0,001$ & \\
\hline & Aspecto físico (escore) & 0,059 & {$[0,042 ; 0,075]$} & $<0,001$ & \\
\hline \multirow[t]{5}{*}{8} & Tempo na empresa (em anos) & $-0,023$ & {$[-0,070 ; 0,024]$} & 0,332 & 0,46 \\
\hline & Estresse no trabalho (escore) & $-1,246$ & {$[-1,762 ;-0,730]$} & $<0,001$ & \\
\hline & Capacidade funcional (escore) & 0,112 & {$[0,083 ; 0,142]$} & $<0,001$ & \\
\hline & Aspecto físico (escore) & 0,048 & {$[0,032 ; 0,064]$} & $<0,001$ & \\
\hline & Dor (escore) & 0,067 & {$[0,048 ; 0,087]$} & $<0,001$ & \\
\hline \multirow[t]{6}{*}{9} & Tempo na empresa (em anos) & $-0,023$ & {$[-0,068 ; 0,022]$} & 0,311 & 0,51 \\
\hline & Estresse no trabalho (escore) & $-0,883$ & {$[-1,385 ;-0,381]$} & 0,001 & \\
\hline & Capacidade funcional (escore) & 0,091 & {$[0,062 ; 0,119]$} & $<0,001$ & \\
\hline & Aspecto físico (escore) & 0,044 & {$[0,029 ; 0,060]$} & $<0,001$ & \\
\hline & Dor (escore) & 0,047 & {$[0,028 ; 0,066]$} & $<0,001$ & \\
\hline & Estado geral de saúde (escore) & 0,087 & {$[0,062 ; 0,111]$} & $<0,001$ & \\
\hline \multirow[t]{7}{*}{10} & Tempo na empresa (em anos) & $-0,024$ & {$[-0,069 ; 0,021]$} & 0,294 & 0,51 \\
\hline & Estresse no trabalho (escore) & $-0,805$ & {$[-1,321 ;-0,289]$} & 0,002 & \\
\hline & Capacidade funcional (escore) & 0,088 & {$[0,059 ; 0,117]$} & $<0,001$ & \\
\hline & Aspecto físico (escore) & 0,043 & {$[0,027 ; 0,058]$} & $<0,001$ & \\
\hline & Dor (escore) & 0,044 & {$[0,025 ; 0,064]$} & $<0,001$ & \\
\hline & Estado geral de saúde (escore) & 0,080 & {$[0,054 ; 0,197]$} & $<0,001$ & \\
\hline & Vitalidade (escore) & 0,017 & {$[-0,010 ; 0,044]$} & 0,212 & \\
\hline
\end{tabular}


Tabela 18 (continuação): Descrição das etapas de modelagem múltipla dos

fatores associados à capacidade para o trabalho, $1^{\mathrm{a}}$ modelagem (incluídas as

dimensões do estado de saúde), Campinas e região, 2005.

\begin{tabular}{|c|c|c|c|c|c|}
\hline Modelo & Variáveis & $\beta$ & $\mathrm{IC}_{95 \%}(\boldsymbol{\beta})$ & $\begin{array}{c}\text { p } \\
(\text { modelo })\end{array}$ & $\mathbf{r}^{2} \mathbf{a}$ \\
\hline 11 & $\begin{array}{l}\text { Tempo na empresa (em anos) } \\
\text { Estresse no trabalho (escore) } \\
\text { Capacidade funcional (escore) } \\
\text { Aspecto físico (escore) } \\
\text { Dor (escore) } \\
\text { Estado geral de saúde (escore) } \\
\text { Aspecto social (escore) }\end{array}$ & $\begin{array}{c}-0,025 \\
-0,842 \\
0,089 \\
0,043 \\
0,045 \\
0,085 \\
0,008\end{array}$ & $\begin{array}{c}{[-0,070 ; 0,020]} \\
{[-1,353 ;-0,331]} \\
{[0,060 ; 0,118]} \\
{[0,027 ; 0,059]} \\
{[0,025 ; 0,065]} \\
{[0,060 ; 0,110]} \\
{[-0,012 ; 0,029]}\end{array}$ & $\begin{array}{c}0,274 \\
0,001 \\
<0,001 \\
<0,001 \\
<0,001 \\
<0,001 \\
0,399\end{array}$ & 0,51 \\
\hline 12 & $\begin{array}{l}\text { Tempo na empresa (em anos) } \\
\text { Estresse no trabalho (escore) } \\
\text { Capacidade funcional (escore) } \\
\text { Aspecto físico (escore) } \\
\text { Dor (escore) } \\
\text { Estado geral de saúde (escore) } \\
\text { Aspecto emocional (escore) }\end{array}$ & $\begin{array}{r}-0,026 \\
-0,835 \\
0,091 \\
0,040 \\
0,046 \\
0,085 \\
0,010\end{array}$ & $\begin{array}{c}{[-0,070 ; 0,020]} \\
{[-1,353 ;-0,331]} \\
{[0,060 ; 0,118]} \\
{[0,027 ; 0,059]} \\
{[0,025 ; 0,065]} \\
{[0,060 ; 0,110]} \\
{[-0,003 ; 0,023]}\end{array}$ & $\begin{array}{l}0,255 \\
0,001 \\
<0,001 \\
<0,001 \\
<0,001 \\
<0,001 \\
0,143\end{array}$ & 0,51 \\
\hline 13 & $\begin{array}{l}\text { Tempo na empresa (em anos) } \\
\text { Estresse no trabalho (escore) } \\
\text { Capacidade funcional (escore) } \\
\text { Aspecto físico (escore) } \\
\text { Dor (escore) } \\
\text { Estado geral de saúde (escore) } \\
\text { Saúde mental (escore) }\end{array}$ & $\begin{array}{r}-0,023 \\
-0,751 \\
0,089 \\
0,043 \\
0,044 \\
0,081 \\
0,019\end{array}$ & $\begin{array}{c}{[-0,068 ; 0,022]} \\
{[-1,282 ;-0,220]} \\
{[0,061 ; 0,118]} \\
{[0,027 ; 0,058]} \\
{[0,025 ; 0,064]} \\
{[0,055 ; 0,106]} \\
{[-0,006 ; 0,044]}\end{array}$ & $\begin{array}{c}0,308 \\
0,006 \\
<0,001 \\
<0,001 \\
<0,001 \\
<0,001 \\
0,139\end{array}$ & 0,51 \\
\hline 14 & $\begin{array}{l}\text { Tempo na empresa (em anos) } \\
\text { Estresse no trabalho (escore) } \\
\text { Capacidade funcional (escore) } \\
\text { Aspecto físico (escore) } \\
\text { Dor (escore) } \\
\text { Estado geral de saúde (escore) } \\
\text { Dependência química ao álcool (escore) }\end{array}$ & $\begin{array}{r}-0,025 \\
-0,878 \\
0,090 \\
0,044 \\
0,046 \\
0,086 \\
0,051\end{array}$ & $\begin{array}{c}{[-0,070 ; 0,020]} \\
{[-1,381 ;-0,374]} \\
{[0,061 ; 0,119]} \\
{[0,028 ; 0,059]} \\
{[0,027 ; 0,066]} \\
{[0,061 ; 0,110]} \\
{[-0,128 ; 0,026]}\end{array}$ & $\begin{array}{c}0,283 \\
0,001 \\
<0,001 \\
<0,001 \\
<0,001 \\
<0,001 \\
0,193\end{array}$ & 0,51 \\
\hline 15 & $\begin{array}{l}\text { Tempo na empresa (em anos) } \\
\text { Estresse no trabalho (escore) } \\
\text { Capacidade funcional (escore) } \\
\text { Aspecto físico (escore) } \\
\text { Dor (escore) } \\
\text { Estado geral de saúde (escore) } \\
\text { Valinhos/Itatiba } \\
\text { Americana } \\
\text { Sumaré } \\
\text { Itapira } \\
\text { Piracicaba } \\
\text { Trevo } \\
\text { Centro } \\
\text { Contabilidade } \\
\text { Recursos Humanos } \\
\text { (Unidade de referência: Transmissão) }\end{array}$ & $\begin{array}{c}-0,028 \\
-0,881 \\
0,092 \\
0,046 \\
0,041 \\
0,087 \\
-1,189 \\
-1,435 \\
-0,174 \\
-0,871 \\
-0,511 \\
-1 ., 968 \\
-1,357 \\
-0,937 \\
-0,687\end{array}$ & $\begin{array}{c}{[-0,075 ; 0,018]} \\
{[-1,385 ;-0,378]} \\
{[0,064 ; 0,121]} \\
{[0,030 ; 0,061]} \\
{[0,021 ; 0,061]} \\
{[0,062 ; 0,111]} \\
{[-2,900 ; 0,521]} \\
{[-2,812 ;-0,059]} \\
{[-1,494 ; 1,145]} \\
{[-2,275 ; 0,533]} \\
{[-1,695 ; 0,672]} \\
{[-3,523 ;-0,412]} \\
{[-2,655 ;-0,059]} \\
{[-2,403 ; 0,530]} \\
{[-2,018 ; 0,645]}\end{array}$ & $\begin{array}{l}0,232 \\
0,001 \\
<0,001 \\
<0,001 \\
<0,001 \\
<0,001 \\
0,172 \\
0,041 \\
0,795 \\
0,223 \\
0,396 \\
0,013 \\
0,041 \\
0,210 \\
0,312\end{array}$ & 0,52 \\
\hline
\end{tabular}


Tabela 18 (continuação): Descrição das etapas de modelagem múltipla dos

fatores associados à capacidade para o trabalho, $1^{\mathrm{a}}$ modelagem (incluídas as dimensões do estado de saúde), Campinas e região, 2005.

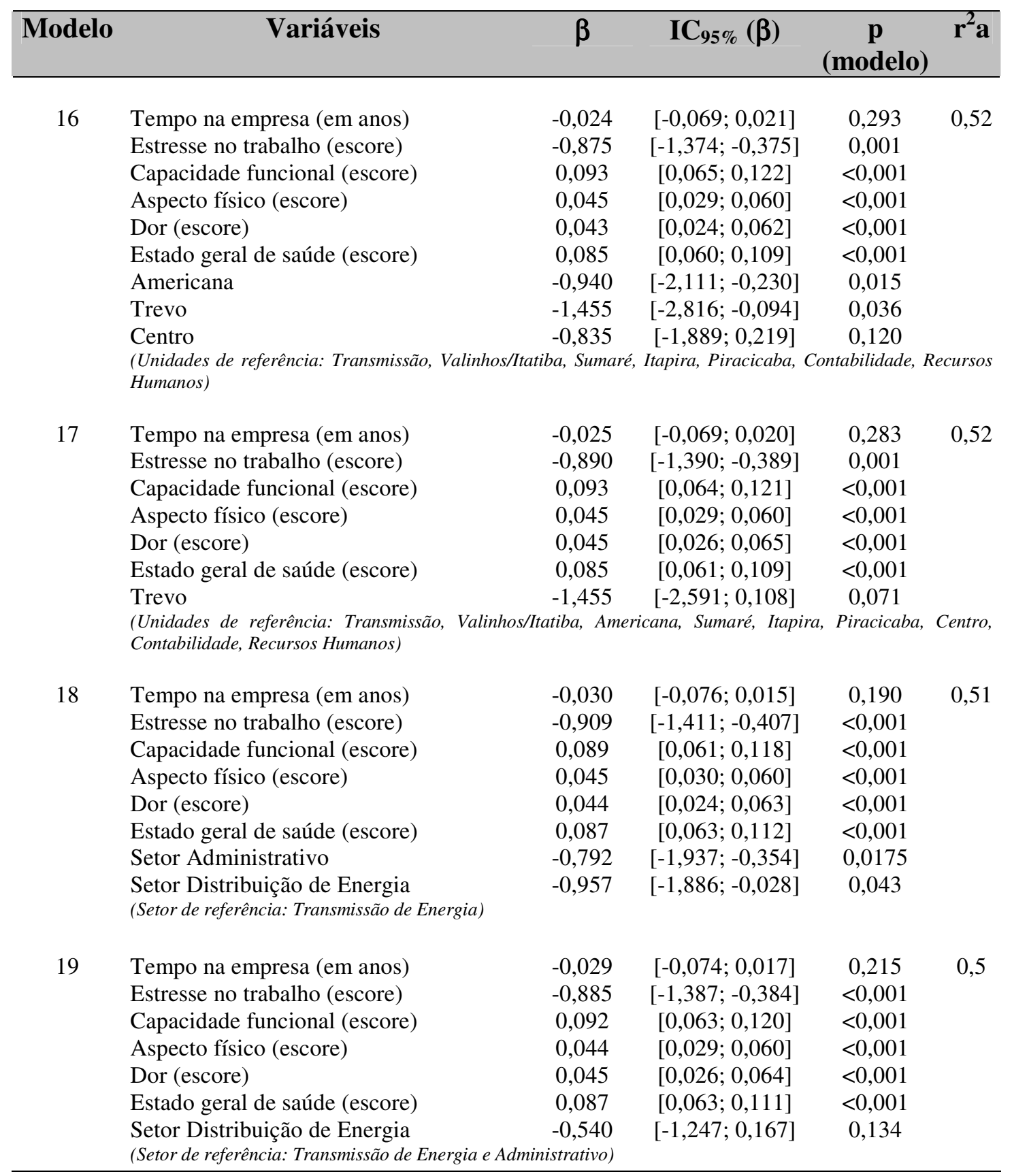


Tabela 18 (continuação): Descrição das etapas de modelagem múltipla dos fatores associados à capacidade para o trabalho, $1^{\mathrm{a}}$ modelagem (incluídas as dimensões do estado de saúde), Campinas e região, 2005.

\begin{tabular}{|c|c|c|c|c|c|}
\hline Modelo & Variáveis & $\beta$ & $\mathrm{IC}_{95 \%}(\boldsymbol{\beta})$ & $\begin{array}{c}\mathbf{p} \\
(\text { modelo) }\end{array}$ & $\mathbf{r}^{2} \mathbf{a}$ \\
\hline 20 & $\begin{array}{l}\text { Tempo na empresa (em anos) } \\
\text { Estresse no trabalho (escore) } \\
\text { Capacidade funcional (escore) } \\
\text { Aspecto físico (escore) } \\
\text { Dor (escore) } \\
\text { Estado geral de saúde (escore) } \\
\text { Menos que } 4,0 \text { salários mínimos } \\
4,0 \text { a } 10,9 \text { salários mínimos } \\
11,0 \text { a } 15,9 \text { salários mínimos } \\
16 \text { a } 20,9 \text { salários mínimos } \\
\text { (Salário de referência: } 21 \text { ou mais salários } \\
\text { mínimos) }\end{array}$ & $\begin{array}{r}-0,031 \\
-0,871 \\
0,093 \\
0,044 \\
0,046 \\
0,086 \\
-1,333 \\
-1,283 \\
-0,946 \\
-0,448\end{array}$ & $\begin{array}{c}{[-0,080 ; 0,017]} \\
{[-1,374 ;-0,368]} \\
{[0,065 ; 0,122]} \\
{[0,028 ; 0,059]} \\
{[0,026 ; 0,065]} \\
{[0,061 ; 0,110]} \\
{[-2,688 ; 1,791]} \\
{[-3,156 ; 1,264]} \\
{[-3,166 ; 0,599]} \\
{[-2,688 ; 1,791]}\end{array}$ & $\begin{array}{c}0,206 \\
0,001 \\
<0,001 \\
<0,001 \\
<0,001 \\
<0,001 \\
0,267 \\
0,181 \\
0,401 \\
0,694\end{array}$ & 0,51 \\
\hline 21 & $\begin{array}{l}\text { Tempo na empresa (em anos) } \\
\text { Estresse no trabalho (escore) } \\
\text { Capacidade funcional (escore) } \\
\text { Aspecto físico (escore) } \\
\text { Dor (escore) } \\
\text { Estado geral de saúde (escore) } \\
\text { Sexo masculino }\end{array}$ & $\begin{array}{r}-0,021 \\
-0,898 \\
0,088 \\
0,045 \\
0,047 \\
0,087 \\
0,973 \\
\end{array}$ & $\begin{array}{c}{[-0,066 ; 0,024]} \\
{[-1,399 ;-0,396]} \\
{[0,060 ; 0,117]} \\
{[0,030 ; 0,061]} \\
{[0,027 ; 0,066]} \\
{[0,063 ; 0,111]} \\
{[-0,174 ; 2,120]} \\
\end{array}$ & $\begin{array}{c}0,352 \\
<0,001 \\
<0,001 \\
<0,001 \\
<0,001 \\
<0,001 \\
0,096\end{array}$ & 0,51 \\
\hline
\end{tabular}

Concluindo, nesta modelagem estatística, os fatores independentes associados ao ICT foram: estresse no trabalho, capacidade funcional, aspecto físico, dor e estado geral de saúde. O modelo final é representado da seguinte forma:

$$
\begin{gathered}
Y=20,683-0,021(\text { tempo na empresa })-0,898(\text { estresse no trabalho })+ \\
0,088(\text { capacidade funcional })+0,045(\text { aspecto físico })+ \\
0,047(\text { dor })+0,087(\text { estado geral de saúde })+0,973(\text { sexo masculino })
\end{gathered}
$$

A interpretação do modelo é: para cada ponto do escore do estresse no trabalho, há diminuição de 0,898 pontos no índice de capacidade para o trabalho, independente das demais variáveis do modelo. Para cada ponto do escore da capacidade funcional, há um aumento de 0,088 pontos no índice de capacidade para o trabalho, ajustado pelas demais variáveis do modelo. Para cada ponto do escore do 
aspecto físico, há um aumento de 0,045 pontos no índice de capacidade para o trabalho, ajustado pelas demais variáveis do modelo. Para cada ponto do escore da dor (diminuição da limitação por dor), há um aumento de 0,047 pontos no índice de capacidade para o trabalho, ajustado pelas demais variáveis do modelo. Para cada ponto do escore do estado geral de saúde, há um aumento de 0,087 pontos no índice de capacidade para o trabalho, ajustado pelas demais variáveis do modelo. Mesmo não sendo estatisticamente significativo, para o sexo masculino, há um aumento de 0,973 pontos no índice de capacidade para o trabalho, quando comparado ao sexo feminino, e para cada ano de trabalho na empresa, há diminuição de 0,021 pontos no índice de capacidade para o trabalho.

Esse modelo apresentou coeficiente de determinação ajustado $\left(r^{2} a\right)$ de 0,51 , mostrando que $51,4 \%$ da variabilidade total do índice de capacidade para o trabalho pode ser explicado pelas variáveis que ficaram no modelo múltiplo.

No Anexo 12 está apresentada a análise dos resíduos deste modelo final. Os erros apresentam aderência à curva normal, com a seqüência esperada e presença de alguns outliers, indicando homocedasticidade. A conclusão, portanto, é que o modelo não apresenta vieses.

Observando que algumas das dimensões de saúde avaliadas por meio do SF-36 estão inclusas de forma conceitual e operacional semelhantes no ICT, e observando a significativa correlação existente entre estas dimensões e o escore do ICT (Tabela 19), considerou-se importante realizar uma segunda análise de regressão para verificar se outras variáveis não passariam a integrar o modelo final. 
Tabela 19: Coeficientes de correlação entre as dimensões da saúde e capacidade para o trabalho, Campinas e região,

2005.

\begin{tabular}{l|ccc}
\hline \multicolumn{1}{c|}{ Variável } & $\mathbf{n}^{\mathbf{0}}$ & $\mathbf{r}^{(\text {SP) }}$ & $\mathbf{p}$ \\
\hline & & & \\
Capacidade funcional & 470 & 0,44 & $<0,001$ \\
Aspecto físico & 474 & 0,32 & $<0,001$ \\
Dor & 474 & 0,48 & $<0,001$ \\
Estado geral de saúde & 473 & 0,49 & $<0,001$ \\
Vitalidade & 475 & 0,39 & $<0,001$ \\
Aspecto social & 475 & 0,33 & $<0,001$ \\
Aspecto emocional & 474 & 0,23 & $<0,001$ \\
Saúde mental & 475 & 0,36 & $<0,001$ \\
& & & \\
\hline
\end{tabular}

$(\mathrm{SP})=$ Coeficiente de correção de Spearman

Desta forma, iniciou-se outra modelagem com entrada das variáveis obedecendo a sequiência apresentada na Tabela 20, excluindo-se as dimensões da saúde. Os primeiros cinco passos da análise foram iguais aos do primeiro modelo apresentado.

Na seqüência da modelagem, foi incluída a variável dependência química ao álcool, ocorrendo diminuição do intervalo de confiança do IMC e do estresse no trabalho. Não houve alteração do valor do $r^{2}$ a e a variável continuou estatisticamente significativa, sendo mantida no modelo (modelo 6).

Na variável unidade de trabalho a Transmissão de Energia foi considerada a categoria de referência por ser aquela com maior média no escore do ICT (modelo 7). Como algumas categorias não foram significativas, optou-se por analisá-las em conjunto com a unidade Transmissão de Energia.

As Unidades de Trabalho foram transformadas em novas variáveis indicadoras, com a categoria de referência sendo composta pelas unidades não apresentaram associação com ICT (Transmissão, Valinhos/Itatiba, Americana, Sumaré, Itapira, Piracicaba e Contabilidade). O modelo foi refeito com estas novas variáveis e apenas as unidades Trevo e Centro mantiveram associação estatística (modelo 8). 
O modelo foi feito mais uma vez, incluindo também a unidade Recursos Humanos na variável indicadora. A unidade Centro perdeu a significância estatística (modelo 9).

Novamente o modelo foi refeito agora com a unidade Trevo e com a variável indicadora sendo composta pelas demais unidades. Houve pouca alteração no modelo e a variável manteve sua significância estatística sendo mantida na modelagem (modelo 10).

Na seqüência, a variável analisada foi o setor de trabalho, sendo que o Setor Transmissão de Energia foi considerado como a categoria de referência (modelo 11). O Setor Administrativo perdeu a significância estatística. Foi feita nova análise com o Setor de Distribuição sendo avaliado em relação à categoria de referência (Transmissão e Administrativo), mas, mesmo assim, esta variável foi retirada do modelo (modelo 12).

Na continuidade da modelagem, foi analisada a variável faixa salarial. A faixa de rendimentos de 21 ou mais salários mínimos foi considerada como categoria de referência, e nenhuma categoria mostrou associação estatisticamente significativa com a capacidade para o trabalho, sendo retirada do modelo (modelo 13).

Finalmente, apesar de não apresentar associação estatisticamente significativa com a capacidade para o trabalho, a variável sexo foi incluída no modelo como variável de ajuste (modelo 14). Este último modelo, composto pelas variáveis IMC, tempo na empresa, prática de atividade física, estresse no trabalho, dependência química, Unidade Trevo e sexo, sendo o modelo múltiplo final escolhido para esta segunda modelagem. 
Tabela 20: Descrição das etapas de modelagem múltipla dos fatores associados à capacidade para o trabalho, $2^{\mathrm{a}}$ modelagem (excluídas as dimensões do estado de saúde), Campinas e região, 2005.

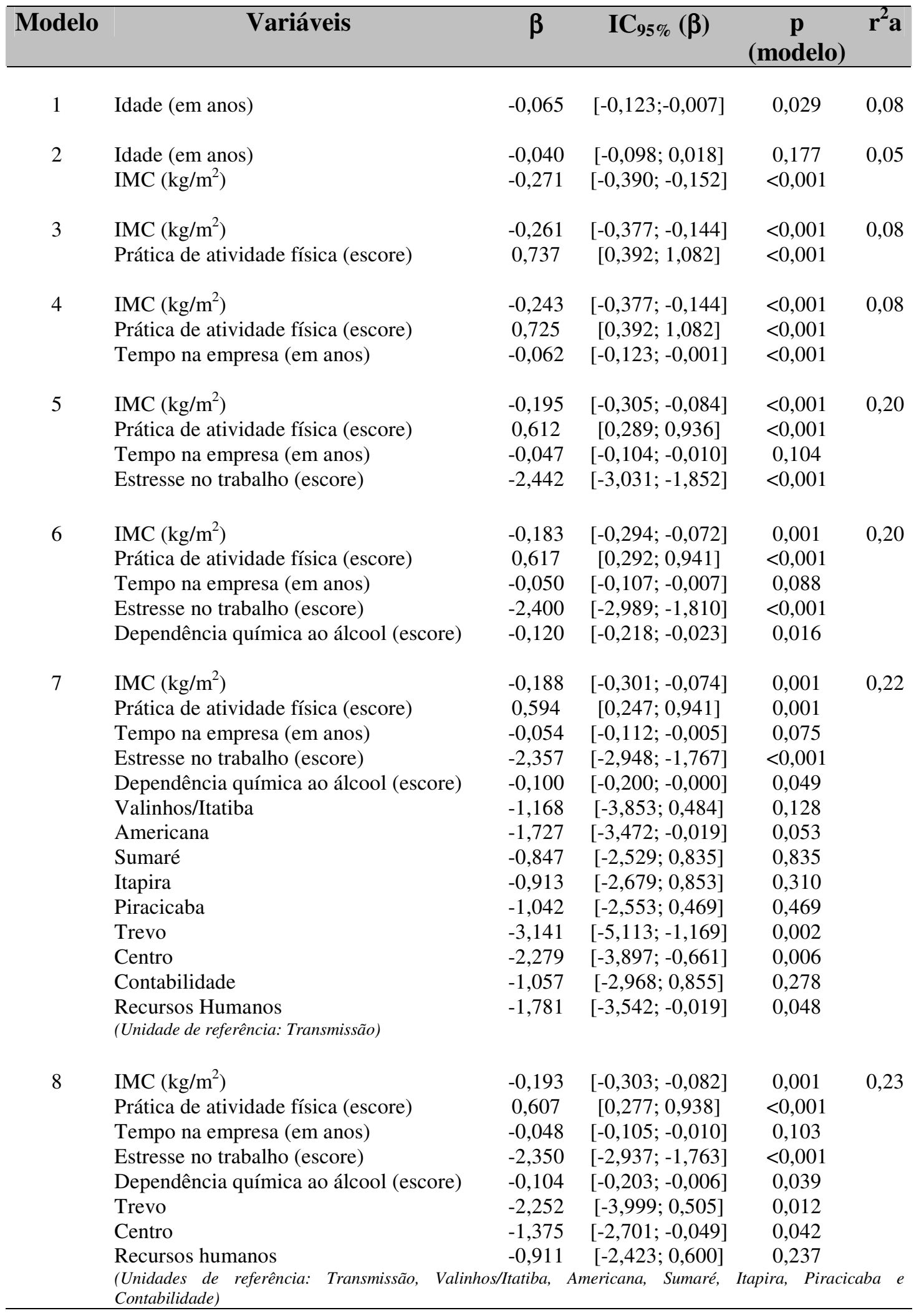


Tabela 20 (continuação): Descrição das etapas de modelagem múltipla dos fatores associados à capacidade para o trabalho, $2^{\mathrm{a}}$ modelagem (excluídas as

dimensões do estado de saúde), Campinas e região, 2005.

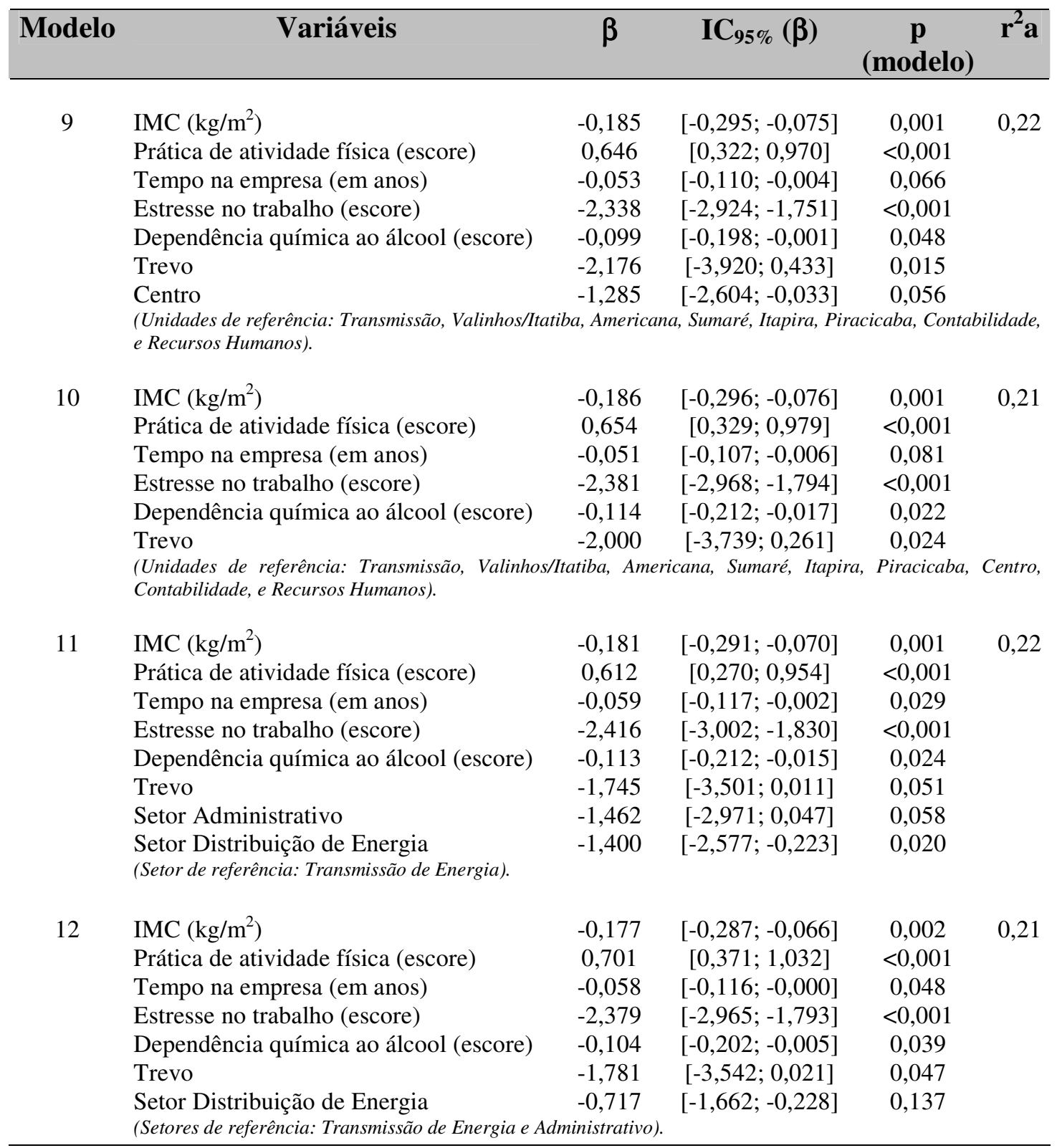


Tabela 20 (continuação): Descrição das etapas de modelagem múltipla dos fatores associados à capacidade para o trabalho, $2^{\mathrm{a}}$ modelagem (excluídas as

dimensões do estado de saúde), Campinas e região, 2005.

\begin{tabular}{clcccc}
\hline Modelo & \multicolumn{1}{c}{ Variáveis } & $\boldsymbol{\beta}$ & $\mathbf{I C 9 5 \%}(\boldsymbol{\beta})$ & $\begin{array}{c}\mathbf{p} \\
\text { (modelo) }\end{array}$ & $\mathbf{r}^{\mathbf{2}} \mathbf{a}$ \\
\hline 13 & & $-0,184$ & {$[-0,295 ;-0,073]$} & 0,001 & 0,21 \\
& IMC $\left(\mathrm{kg} / \mathrm{m}^{2}\right.$ ) & 0,750 & {$[0,415 ; 1,085]$} & $<0,001$ & \\
& Prática de atividade física (escore) & $-0,064$ & {$[-0,126 ; 0,001]$} & 0,045 & \\
Tempo na empresa (em anos) & $-2,326$ & {$[-2,914 ;-1,739]$} & $<0,001$ & \\
Estresse no trabalho (escore) & $-0,097$ & {$[-0,195 ;-0,002]$} & 0,054 & \\
Dependência química ao álcool (escore) & $-1,905$ & {$[-3,644 ;-0,166]$} & 0,032 & \\
Trevo & $-0,881$ & {$[-3,793 ; 2,031]$} & 0,552 & \\
Menos que 4,0 salários mínimos & $-1,136$ & {$[-4,015 ; 1,743]$} & 0,438 & \\
4,0 a 10,9 salários mínimos & $-2,184$ & {$[-4,676 ; 0,308]$} & 0,086 & \\
11,0 a 15,9 salários mínimos & $-1,962$ & {$[-5,036 ; 1,111]$} & 0,210 & \\
16 a 20,9 salários mínimos & & & & \\
(Salário de referência: 21 ou mais salários mínimos) & & & & \\
& & & & \\
IMC (kg/m ${ }^{2}$ ) & $-0,204$ & {$[-0,316 ;-0,092]$} & $<0,001$ & 0,22 \\
14 & 0,575 & {$[0,239 ; 0,911]$} & 0,001 & \\
Prática de atividade física (escore) & $-0,047$ & {$[-0,103 ;-0,010]$} & 0,109 & \\
Tempo na empresa (em anos) & $-2,411$ & {$[-2,998 ;-1,825]$} & $<0,001$ & \\
Estresse no trabalho (escore) & $-0,126$ & {$[-0,224 ;-0,028]$} & 0,012 & \\
Dependência química ao álcool (escore) & $-2,033$ & {$[-3,769 ;-0,298]$} & 0,022 & \\
Trevo & 1,378 & {$[-0,170 ; 2,927]$} & 0,081 & \\
Sexo masculino & & &
\end{tabular}

Concluindo, nesta modelagem estatística, onde não foram incluídas as dimensões relativas ao estado de saúde, os fatores independentes associados ao ICT foram: índice de massa corporal, prática de atividade física, estresse no trabalho, dependência química e unidade de trabalho Trevo. O modelo final é representado da seguinte forma:

$$
\begin{gathered}
\mathrm{Y}=48,024-0,204(\mathrm{IMC})+0,575(\text { atividade física })-0,047 \text { (tempo na empresa) } \\
-2,411(\text { estresse no trabalho })-0,126(\text { dependência química }) \\
-2,033(\text { Unidade Trevo })+1,378(\text { sexo masculino })
\end{gathered}
$$

A interpretação do modelo é: para cada ponto do escore do índice de massa corporal, há diminuição de 0,204 pontos no índice de capacidade para o trabalho, independente das demais variáveis do modelo. Para cada ponto do escore da prática de atividade física, há aumento de 0,575 pontos no índice de capacidade para o trabalho, independente das demais variáveis do modelo. Para cada ponto do escore 
do estresse no trabalho, há diminuição de 2.411 pontos no índice de capacidade para o trabalho, independente das demais variáveis do modelo. Para cada ponto do escore de dependência química, há diminuição de 0,126 pontos índice de capacidade para o trabalho, independente das demais variáveis do modelo. Para a unidade de trabalho Trevo, há uma diminuição de 2,033 pontos no índice de capacidade para o trabalho, quando comparada às demais unidades de trabalho. Mesmo não sendo estatisticamente significativo, para o sexo masculino, há um aumento de 1,378 pontos no índice de capacidade para o trabalho, quando comparado ao sexo feminino, e para cada ano de trabalho na empresa, há diminuição de 0,047 pontos no índice de capacidade para o trabalho.

Essa segunda modelagem realizada apresentou coeficiente de determinação ajustado ( $\mathrm{r}^{2}$ a) de 0,22 , mostrando que $22,04 \%$ da variabilidade total do índice de capacidade para o trabalho pode ser explicado pelas variáveis que ficaram no modelo múltiplo onde não foram incluídas as dimensões do estado de saúde.

No Anexo 12 está apresentada a análise dos resíduos deste segundo modelo final. Os erros apresentam aderência à curva normal, com a sequiência esperada e presença de alguns outliers, indicando homocedasticidade. A conclusão, portanto, é que o modelo não apresenta vieses. 


\section{5 - DISCUSSÃO}

Essa pesquisa analisou os fatores associados à capacidade para o trabalho em trabalhadores do Setor Elétrico no Estado de São Paulo. Sua realização se justifica pela produção restrita de estudos nacionais junto a eletricitários, e pelo atual contexto de modificação na produção e nas relações de trabalho, onde as questões da capacidade para o trabalho, apesar de ainda pouco estudadas no país, ganham relevância em função do envelhecimento da força de trabalho e da mo dificação do perfil de morbidade dos trabalhadores.

A seguir, serão discutidos os resultados desta pesquisa com foco nos aspectos metodológicos do estudo, no perfil da população de estudo e na análise dos fatores associados à capacidade para o trabalho.

\section{1 - Aspectos metodológicos}

\subsection{1 - Taxa de resposta}

A taxa de resposta consiste no percentual de indivíduos da população de estudo que participa do levantamento de dados, não havendo consenso sobre qual seja a taxa ideal de resposta. Valores acima de $75 \%$ foram considerados adequados por FOWLER JR (1990). A taxa de resposta desta pesquisa foi de 87,5\% e, portanto, acima dos padrões esperados. Essa elevada taxa de resposta pode ser atribuída aos procedimentos observados quando do planejamento e administração dos questionários para coleta de dados. Houve ampla divulgação junto às diversas instâncias hierárquicas da empresa, agendamento das atividades, horários e locais adequados às disponibilidades dos trabalhadores, fornecimento de informações sobre a pesquisa, e garantia de confidencialidade e de devolutiva dos resultados individuais. 
É recomendada a análise das perdas para se tentar determinar a extensão pela qual a taxa de não-resposta difere da taxa de resposta (FOWLER JR 1990). Esta análise identificou uma menor taxa de participação entre os trabalhadores das unidades Americana, Centro, Contabilidade e Itapira sinalizando para a possibilidade de existência de alguma característica ou situação que diferencie estas unidades das demais. Também houve diferença quanto à média da idade, sendo que ela foi maior entre os não respondentes do que entre respondentes e, embora pequena, foi estatisticamente significativa. No entanto, apesar destas diferenças, não se acredita que houvesse modificações significativas na análise dos resultados.

\subsection{2 - Validade do estudo}

Para garantir a validade interna do estudo foram observados alguns cuidados de forma a evitar erros sistemáticos. Para minimizar um viés de aferição foram utilizados questionários já adaptados e/ou validados para uso no Brasil, tomando-se os cuidados de realizar um pré-teste, de orientar os participantes da pesquisa quanto ao preenchimento dos questionários, e de verificar a confiabilidade dos questionários utilizados.

Considerando a possibilidade de erro inerente a questionários que avaliam construtos subjetivos e considerando que os questionários não haviam sido utilizados anteriormente na população de eletricitários, procedeu-se à análise da confiabilidade dos instrumentos por meio do Coeficiente alfa de Cronbach. O resultado deste coeficiente varia de 0,0 a 1,0, sendo que valores a partir de 0,7 são considerados adequados (BLAND e ALTMAN 1997).

O questionário ICT, o questionário AUDIT, a Escala Estresse no Trabalho e as 08 dimensões do SF-36 apresentaram Coeficiente alpha de Cronbach com valores acima de 0,7 e, portanto, indicando nível satisfatório de confiabilidade. Os questionários Fagerström e de Baecke apresentaram valores inferiores a 0,7 
(respectivamente 0,66 e 0,69). Nos dois instrumentos, a exclusão de um item levaria a um discreto aumento no resultado, porém ainda abaixo do valor 0,7 .

Vale ressaltar que, segundo PEREIRA (1999), cabe ao pesquisador julgar a adequação do resultado do alfa de Cronbach uma vez que, para este autor, não há um ponto de corte ideal para arbitrar o resultado e, mais importante do que julgá-lo bom ou ruim, é avaliar a complexidade do fenômeno que se pretende medir.

Quanto ao viés de seleção, para avaliar um possível efeito decorrente do levantamento de dados ter sido realizado junto a voluntários, foram analisadas as já citadas taxas de resposta e de perdas.

Para evitar possíveis vieses de confusão, as análises estatísticas foram controladas pelas variáveis sexo e tempo na empresa que são apontadas como fatores que influenciam a capacidade para o trabalho (ILMARINEN et al. 1997; PERKIÖ-MÄKELA 2000). A idade que poderia ser utilizada como variável de controle foi excluída do modelo dado que a forte correlação entre esta variável e o tempo na empresa determinaria um efeito de sobreajuste caso as duas variáveis fossem mantidas no modelo. Portanto, optou-se por dar preferência à permanência da variável tempo na empresa uma vez que, de acordo com TUOMI et al. (1997b), quanto maior o tempo em que os indivíduos permanecem ativos e expostos às exigências do trabalho, maior deverá ser o envelhecimento funcional.

Esta pesquisa foi realizada em uma empresa do Setor Elétrico do Estado de São Paulo com atuação nas áreas de geração, distribuição e comercialização de energia elétrica, e que passou por recente processo de privatização e de reestruturação produtiva. A validade externa desta pesquisa pode ser considerada para grupos de eletricitários de empresas privadas e estatais que apresentem características semelhantes quanto ao perfil demográfico, às condições e à organização do trabalho, inclusive no que diz respeito às relações trabalhistas e aos benefícios, incluindo assistência à saúde e programas relativos à saúde e segurança no trabalho. 
Para os trabalhadores de empresas terceirizadas e empreiteiras, entretanto, os resultados desta pesquisa podem ser menos aplicáveis. Isso porque, para estes trabalhadores, o processo de privatização e reestruturação produtiva do Setor Elétrico resultou em deterioração das relações de trabalho mais intensa do que para aqueles que tiveram seu vínculo empregatício preservado. Esta deterioração é caracterizada pela perda de benefícios anteriormente adquiridos, redução de salários, vínculos de trabalho informais, parciais ou temporários e, ainda, por precarização dos equipamentos de trabalho, menos treinamento e menor qualificação da mão de obra, com conseqüências negativas para a segurança, saúde e bem-estar destes trabalhadores (NOGUEIRA 1999; GUIMARÃES et al. 2002).

\subsection{3 - Efeito do trabalhador sadio}

Outro fator que deve ser considerado como uma fonte potencial de viés é o efeito do trabalhador sadio. Ele consiste em um processo de seleção progressiva dos trabalhadores, permanecendo aqueles que tendem a ser mais saudáveis, e com menores taxas de mortalidade do que a população geral, da mesma faixa etária (WEED 1986; ZAHM 1998).

O efeito do trabalhador sadio é decorrente, principalmente, do processo seletivo para admissão de trabalhadores e da exclusão daqueles que mais freqüentemente adoecem ou faltam ao trabalho por motivo de doença (WEED 1986; MENDES 1995; LI e SUNG 1999). Este efeito tende a ser mais intenso em grupos de trabalhadores com longas trajetórias de trabalho estável e tende a diminuir com a elevação da idade (STERLING e WEINKAM 1985; MENDES 1995). Ele pode sofrer influência de variáveis ocupacionais como tipo de ocupação, exposição a riscos, remuneração, políticas da empresa, programas preventivos, assistência à saúde e outros benefícios que podem condicionar mudanças no estilo de vida e no estado de saúde dos trabalhadores (WEN et al. 1983; WEED 1986; HOWE et al. 1988; LI e SUNG 1999). Esse processo pode sofrer, ainda, influência de variáveis sócio-demográficas, como a região onde está localizada a empresa, a idade de 
ingresso na força de trabalho ou o sexo com os homens sofrendo maior rejeição em função de seu estado de saúde, bem como de questões relativas à metodologia da análise, como duração do seguimento e qualidade dos dados (WEED 1986; HOWE et al. 1988; LI e SUNG 1999).

O efeito do trabalhador sadio é apontado como fator de confusão e de viés em estudos epidemiológicos de morbidade e mortalidade em saúde do trabalhador, e que não se consegue controlar na coleta e análise dos dados. É necessário cuidado ao fazer comparações entre grupos de trabalhadores e a população geral, pois se pode concluir erroneamente que trabalhadores expostos a condições e situações nem sempre favoráveis apresentam melhores perfis de saúde do que outros grupos populacionais (MENDES 1995; LI e SUNG 1999).

Esse efeito é um fenômeno complexo e difícil de ser mensurado, mas deve ser considerado quando da avaliação dos resultados de estudos em saúde do trabalhador (WEN et al. 1983; LI e SUNG 1999), em especial em um grupo de trabalhadores como os desta pesquisa que, como será discutido adiante, apresenta elevado padrão de qualidade de saúde e de capacidade para o trabalho, bem como condições sóciotrabalhistas diferenciadas em relação à grande parcela da população do país.

O efeito do trabalhador sadio é apontado em estudos sobre capacidade para o trabalho, como os de POHJONEN (2001a), BELLUSCI (2003) e COSTA (2005), como acarretando possível distorção nos perfis identificados, bem como nas associações estudadas.

\subsection{4 - Instrumentos para coleta de dados}

A capacidade para o trabalho foi avaliada por meio do Índice de capacidade para o trabalho - ICT. Trata-se de um instrumento que considera a percepção do próprio trabalhador e permite avaliar os seguintes aspectos: (a) capacidade para o trabalho atual e comparada com a melhor de toda a vida, (b) capacidade para o 
trabalho em relação às exigências do trabalho, (c) número atual de doenças autoreferidas e diagnosticadas por médico, (d) perda estimada para o trabalho devido a doenças, (e) falta ao trabalho por doenças, (f) prognóstico próprio sobre a capacidade para o trabalho, e (g) recursos mentais. Os itens recebem pontuações e fornecem um escore que varia de 7 a 49 pontos (TUOMI et al. 2005).

RADKIEWICZ e WIDERSZAL-BAZYL. (2005) avaliaram as propriedades psicométricas no ICT em uma população de cerca de 38.000 enfermeiras de 10 países europeus. Os autores identificaram que o ICT apresentou consistência interna coerente, estabilidade entre países com padrões semelhantes de confiabilidade e de estrutura fatorial, e correlações com diversas situações de bem-estar físico e mental, sinalizando que o uso do ICT pode ser generalizado, independente da cultura. Apesar destas vantagens, os autores assinalam que algumas questões podem não ter sentido ou ser desnecessárias, indicando que o questionário pode ser aprimorado.

Os resultados do ICT podem ser utilizados nos níveis individual e coletivo. Individual porque permite identificar trabalhadores com comprometimento da capacidade funcional e adotar medidas de apoio. Coletivo porque permite a identificação de um perfil geral da capacidade para o trabalho, da capacidade funcional e dos fatores que os afetam, possibilitando adoção de medidas corretivas direcionadas para estes fatores (TUOMI et al. 2005).

Uma limitação para uso do ICT no Brasil é que, apesar de traduzido e testado e de ser utilizado em pesquisas no país desde 1999, ainda não existem estudos que demonstrem as propriedades psicométricas da versão adaptada para uso em língua portuguesa, o que aponta a necessidade de estudos sobre estes aspectos do instrumento.

O estresse decorrente dos fatores psicossociais do ambiente de trabalho foi avaliado por meio da Escala de Estresse no Trabalho - EET. PASCHOAL e TAMAYO (2004) estruturaram a EET com base em referencial teórico que considera o estresse no trabalho como um processo onde as demandas do trabalho são 
percebidas pelo trabalhador como estressores que, ao exceder a capacidade de enfrentamento do indivíduo, desencadeiam reações que podem se manifestar na forma de desgaste, entendido como uma diversidade de respostas psicológicas, fisiológicas ou comportamentais negativas.

Para PASCHOAL e TAMAYO (2004), os estressores podem ser de natureza física ou decorrentes da organização do trabalho. Entre os estressores organizacionais, os autores da EET ressaltam os relacionados aos papéis, os decorrentes de fatores intrínsecos ao trabalho, os pertinentes ao relacionamento interpessoal, os relacionados ao desenvolvimento da carreira, e os referentes ao controle/autonomia no trabalho. O fenômeno do estresse no trabalho pode receber, também, influências de variáveis de natureza situacional (suporte social) e de natureza pessoal (estilo de enfrentamento, padrão de comportamento tipo A, locus de controle e auto-estima). Os autores estruturaram questões que procuravam contemplar, cada uma delas, tanto um estressor quanto a reação do trabalhador ao mesmo, reação esta resultante da percepção como mediadora do impacto do ambiente de trabalho. Após análise de juízes e análise semântica, ficou estabelecido um questionário composto por 31 questões. Esta versão do questionário foi aplicada junto a 437 trabalhadores de empresas públicas e privadas no Distrito Federal e no Estado de São Paulo. Foi realizada análise fatorial entre as 31 questões que, após eliminação de 08 questões com carga fatorial abaixo de 0,45 , revelou a existência de um único fator e confiabilidade satisfatória com coeficiente alfa de Cronbach de 0,91 .

A limitação que este questionário apresenta é que, por seu caráter de medida genérica do estresse no trabalho, podem se perder aspectos específicos de determinadas ocupações, situações, reações individuais ou outras variáveis que constituam o fenômeno em questão (PASCHOAL e TAMAYO 2004). Em contrapartida, os autores argumentam em favor deste caráter generalista, uma vez que questionários que procuram uma abordagem mais completa e complexa têm apresentado problemas de construção e de validação (PASCHOAL e TAMAYO 2004). 
A medida de saúde auto-avaliada tem demonstrado ser uma estratégia válida como representativa da saúde global havendo, inclusive, evidências de um poder preditivo da saúde auto-referida sobre a mortalidade, o indivíduo e a população geral (LUNDBERG e MANDERBACKA 1996). Considerando estes aspectos, foi utilizada a versão em português do Medical Outcomes Study 36 - Item short form health survey (SF-36) que oferece uma avaliação genérica da saúde a partir da percepção do próprio indivíduo.

Segundo CICONELLI (1997), não é utilizado um único valor que resuma toda a avaliação visando evitar o erro de não se identificar ou de subestimar problemas relacionados à saúde do indivíduo. Na versão em inglês, a análise de componentes demonstrou que existem dois conceitos distintos mensurados pelo SF-36: um físico e um mental, sendo que as 8 dimensões que compõem o questionário podem ser agrupadas em 2 medidas sintéticas chamadas componente físico e componente mental (CICONELLI 1997; HOPMAN et al. 2000; WARE e KOSINSKI 2001). O componente físico é composto pelas dimensões capacidade funcional, aspecto físico, dor e estado geral de saúde, e o componente mental é composto pelas dimensões vitalidade, aspecto social, aspecto emocional e saúde mental (WARE 2000). Embora a dimensão estado geral da saúde esteja no componente físico e a vitalidade esteja no componente mental, elas podem, indiretamente, estarem relacionadas ao outro componente (CICONELLI 1997; WARE 2000).

Como as medidas sintéticas não estão validadas para a versão brasileira, considerou-se, nesta pesquisa, que as 4 primeiras dimensões são representativas da saúde física e as 4 últimas, da saúde mental, porém cada uma das 8 dimensões foi avaliada em separado, sem configuração de uma medida síntese para saúde física ou mental. Essa opção foi baseada em CICONELLI (1997) que, comparando os resultados de pacientes brasileiros com artrite reumatóide com populações normais de outros países, verificou que os pacientes com artrite reumatóide apresentaram valores inferiores para as dimensões do componente físico, mas os valores das 
dimensões do componente mental foram semelhantes aos das populações normais, evidenciando o caráter físico da incapacidade causada pela doença.

O SF-36 possibilita uma avaliação que contempla saúde em um sentido amplo procurando abarcar não só aspectos relacionados à presença ou ausência de sintomas de disfunções ou agravos, mas também aspectos relacionados a comprometimentos que possam estar interferindo no bem-estar ou dificultando as atividades de vida do indivíduo. Neste sentido, a avaliação por meio deste instrumento considera a saúde física como a possibilidade de desempenhar atividades físicas (da vida diária, de trabalho, de lazer e sociais) sem limitações devidas à dor, à intercorrências no funcionamento do organismo ou à presença de doenças. Da mesma forma, a saúde mental pode ser entendida como uma condição na qual o indivíduo tenha a percepção de bem-estar emocional e de vitalidade, desempenhando suas atividades sem limitações decorrentes de problemas com a saúde.

O SF-36 apresenta também as vantagens de ser de fácil administração e compreensão, e de rápida aplicação. CICONELLI (1997) informa que o SF-36 foi estruturado para ser auto-administrável. Como a população junto à qual foi realizado o estudo para validação do instrumento para a língua portuguesa apresentava baixo nível sócio-econômico, cultural e de escolaridade, a autora do processo de adaptação transcultural indicou a aplicação do questionário por meio de entrevistas (CICONELLI 1997). Como a população deste atual estudo apresenta nível de escolaridade diferenciado (predominantemente com ensino de nível médio ou universitário), optou-se pela forma auto-administrável.

Para avaliação do tabagismo foi utilizado o Questionário de Tolerância de Fagerström. HALTY et al. (2002), avaliando a utilização do questionário em língua portuguesa, concluíram que sua utilização é simples, rápida e de baixo custo, e confiável na avaliação do grau de dependência nicotínica.

O consumo de bebida alcoólica pode ser avaliado por meio da informação da história sobre os hábitos de ingestão de bebidas alcoólicas, porém a obtenção de 
informações confiáveis desta história sofre influência da percepção do indivíduo sobre seu padrão de consumo, da realização de uma anamnese detalhada e cuidadosa e da condição clínica do paciente, o que torna os seus resultados sujeitos a distorções. Uma alternativa para avaliação do padrão de consumo alcoólico é o questionário $C u t$ down, Annoyed by criticism, Guilty and Eye-opener - CAGE que, embora seja amplamente utilizado e tenha níveis adequados de sensibilidade e especificidade, apresenta a limitação de identificar apenas pessoas que já apresentam sintomas de dependência alcoólica (FIGLIE et al. 2000).

Considerando estes aspectos, optou-se pela utilização do questionário Alcohol Use Disorders Identification Test - AUDIT que tem a vantagem de identificar pessoas com consumo de risco para o álcool, ou seja, tanto aquelas que têm problemas decorrentes do uso nocivo como aquelas que são dependentes do álcool, sendo relatada sensibilidade de $92 \%$ e especificidade de 93\% (FIGLIE et al. 2000, SILVA et al. 2004).

A prática de atividade física foi investigada por meio do questionário de Baecke cuja versão final para língua portuguesa foi avaliada junto a uma população de 326 homens saudáveis com idade a partir de 50 anos, mostrando consistência interna satisfatória com alpha de Cronbach de 0,76 para AFO, 0,77 para EFL e 0,71 para ALL (FLORINDO et al. 2004). Este questionário é fácil e rápido de ser aplicado e é uma medida indireta da prática de atividade física regular.

A opção pelo uso do IMC para avaliar o estado nutricional foi baseada nas vantagens que o indicador apresenta: é aplicável em estudos epidemiológicos permitindo comparações, tem baixo custo, é de fácil operacionalização, tem alta correlação com o peso e com a quantidade de gordura corporal (CERVI et al. 2005). Além disso, o peso e a estatura auto-referidos apresentam alta concordância com os valores aferidos, demonstrando a validade para o cálculo do IMC (FONSECA et al. 2004). Uma limitação do indicador é sua incapacidade de discriminar a gordura visceral, restringindo sua utilização quando da avaliação de algumas doenças 
cardiovasculares e em grupos etários específicos (COLOMBO et al. 2003; CERVI et al. 2005).

\section{2 - Perfil da população de estudo}

A população desta pesquisa apresenta um perfil sócio-ocupacional diferenciado em relação à população geral. Inicialmente deve ser apontado que o processo de privatização e de reestruturação produtiva pelo qual passou a empresa onde ocorreu esta pesquisa foi acompanhado de mudanças nas condições e na organização do trabalho destes trabalhadores. Nas atividades de conteúdo predominantemente físico, houve uma diminuição nas cargas físicas do trabalho, decorrente do aperfeiçoamento de processos de trabalho e da melhoria de equipamentos como um resultado da necessidade de adequação a parâmetros de mercado e a normas internacionais de qualidade. Por outro lado, para o coletivo destes trabalhadores, houve uma intensificação nas cargas mentais do trabalho em função, entre outros fatores, de ampliação das solicitações para análise de problemas e tomada de decisão, do uso de novas tecnologias, das pressões de prazos, de responsabilidades e de qualidade do serviço e da insegurança (instabilidade) no emprego.

Apesar destas mudanças organizacionais, ao contrário da precarização que atualmente configuram as relações trabalhistas e o mundo do trabalho, inclusive para os trabalhadores do Setor Elétrico no país, os trabalhadores da população desta pesquisa estão inseridos no mercado formal de trabalho e contam com condições trabalhistas satisfatórias. Estes trabalhadores possuem vínculo empregatício que proporciona acesso a benefícios como assistência à saúde de boa qualidade, previdência privada, programas preventivos de saúde ocupacional e segurança no trabalho, férias, $13^{\circ}$ salário e demais premissas estabelecidas na legislação trabalhista.

Além disso, estes trabalhadores apresentam melhor nível de escolaridade e melhor remuneração do que a população geral de trabalhadores. Enquanto que 6,1\% 
dos trabalhadores da população de estudo apresentaram renda inferior a 4 salários mínimos, o rendimento médio dos trabalhadores do setor privado da região metropolitana de São Paulo, em maio de 2005, foi de 3,9 salários mínimos entre os com carteira assinada, 2,3 salários mínimos entre os sem carteira de trabalho assinada e 3,0 salários mínimos entre os que trabalham por conta própria (IBGE 2006a). Quase a totalidade (91,3\%) dos trabalhadores da população de estudo tinham, pelo menos, o Ensino Médio completo e este percentual cai para 53,9\% entre os trabalhadores da população economicamente ocupada da região metropolitana de São Paulo (IBGE 2006b).

Este padrão sócio-econômico diferenciado em relação à população geral não é exclusivo da população desta pesquisa, já tendo sido relatado por MATTOS et al. (2002) ao estudar mortalidade por câncer entre eletricitários do Rio de Janeiro.

Nos aspectos pertinentes ao estilo de vida, a pesquisa evidenciou características peculiares a este grupo de trabalhadores. No que diz respeito ao tabagismo, na população geral da cidade de São Paulo a prevalência varia entre 19,9\% e 22,6\% (MS 2004; MARCOPITO et al. 2005) e entre a população desta pesquisa a prevalência identificada foi de $14,5 \%$ configurando um perfil melhor do que seria esperado.

Comparações entre populações, no que diz respeito ao consumo de bebidas alcoólicas, são difíceis em função de diferenças entre o método de coleta de dados e a conceituação de consumo e dependência ao álcool. Entretanto, se forem utilizados como parâmetros os resultados do I Levantamento domiciliar sobre o uso de drogas psicotrópicas no Brasil (CARLINI et al. 2002), observa-se que 71,5\% da população da região sudeste do País já consumiu bebidas alcoólicas e 9,2\% apresentou características compatíveis com dependência ao álcool, evidenciando um perfil mais favorável do que o dos trabalhadores desta pesquisa. Neste estudo, os resultados evidenciaram que 79,0\% dos trabalhadores fazem algum tipo de consumo de álcool. Entretanto, um aspecto importante foi a identificação de uma elevada prevalência de 
trabalhadores $(22,2 \%)$ apresentando perfil compatível com dependência ao álcool, indicando a necessidade de uma investigação diagnóstica mais detalha.

Entre os domínios da prática de atividade física que o questionário de Baecke permite avaliar, o que apareceu com escore mais elevado foi o relativo à prática de atividade física ocupacional. E esse resultado é explicado pelo fato de que 77,9\% dos trabalhadores executam atividades com conteúdo misto (físico e mental), onde algumas das tarefas podem apresentar exigências físicas bastante intensas e/ou freqüentes. Cabe lembrar que um contingente importante dos trabalhadores $(71,6 \%)$ informou alguma prática de atividade física. Este percentual é superior aos observados em estudos junto a outros grupos de trabalhadores, como por exemplo, $40,7 \%$ em trabalhadores de uma destilaria do interior paulista (SIMÃO et al. 2002), 43,8 a 49,5\% em petroleiros na Bahia (BARBERINO et al. 2005), ou 36,4\% em metalúrgicos e siderúrgicos (MARTINEZ e LATORRE 2006). O grande percentual de trabalhadores não sedentários nesta pesquisa pode estar sendo influenciado por dois fatores: (1) existe um centro de atividades físicas na sede da empresa, bem como ações de incentivo à prática de atividade física, e (2) trata-se de uma população relativamente jovem, onde a necessidade de um bom preparo físico para atender às exigências físicas do trabalho pode servir de estímulo à prática destas atividades visando preservar a qualificação para o desempenho do trabalho.

A prevalência de alterações no estado nutricional entre os trabalhadores da população de estudo foi de 42,9\% de sobrepeso e 16,8\% de obesidade. Essas prevalências são importantes quando se considera além dos prejuízos à saúde, que alterações no peso podem representar um risco ou limitação para o desempenho das atividades ocupacionais, em especial em atividade com exigências físicas importantes (LOUHEVAARA et al. 1999; POHJONEN 2001a; POHJONEN e RANTA 2001; LAITINEN et al. 2005). A comparação do estado nutricional entre grupos populacionais é difícil em função da variedade de resultados observados em diferentes estudos, podendo ser citados os de SIMÃO et al. (2002) que encontraram $23,6 \%$ de sobrepeso e $27,6 \%$ de obesidade em trabalhadores de uma destilaria do interior paulista, do Ministério da Saúde (MS 2004) que identificou 29,4\% de 
sobrepeso e 51,7\% de obesidade em São Paulo, de BARBERINO et al. (2005) com 33,2 a 40,2\% de sobrepeso e 8,0 a 11,00\% de obesidade em petroleiros na Bahia, e de MARCOPITO et al. (2005) que verificaram 13,7\% de obesidade no município de São Paulo.

Conclui-se, portanto, que a prevalência de sobrepeso dos trabalhadores aqui estudados está acima do esperado, mas a obesidade está abaixo indicando, talvez, uma tendência para o controle do peso entre os obesos. Essa tendência pode ser explicada pela necessidade de bom preparo físico para atender às exigências físicas do trabalho dos eletricistas, ressaltando-se também que as escadas utilizadas para execução das atividades em postes e torres de energia têm capacidade para suportar uma carga máxima de $100 \mathrm{~kg}$ e o trabalhador com peso acima deste limite está impedido de usar estas escadas.

A população desta pesquisa foi composta, predominantemente, pelo pessoal do Setor de Distribuição de Energia (66,5\%), conferindo ao perfil destes trabalhadores uma predominância de tarefas com conteúdo de trabalho misto (físico e mental), sobressaindo os cargos dos eletricistas. Na execução de suas atividades, os trabalhadores tiveram a percepção de um nível intermediário de estresse no trabalho, com 2,3 pontos $(\mathrm{dp}=0,7)$ em um escore de 1,0 a 5,0 pontos. Este padrão foi próximo ao encontrado por PASCHOAL e TAMAYO (2005), que identificaram pontuação de 2,6 (dp=0,8) ao avaliar um grupo de 237 funcionários de uma instituição bancária utilizando a mesma EET.

Esse perfil pode ser considerado relativamente satisfatório quando se considera o papel que o estresse no trabalho passou a representar como agente desencadeante de agravos à saúde dos trabalhadores em um cenário de globalização e de reestruturação produtiva. Esse papel está consistentemente documentado em diversos estudos que avaliam as conseqüências sobre a saúde física e mental, o bem-estar, a qualidade de vida e a produtividade dos trabalhadores (KARASEK e THEORELL 1990; LEVI 1999; COX et al. 2000). 
Entretanto, apesar deste perfil relativamente satisfatório, deve-se considerar que, além de seus efeitos agudos, o estresse traz conseqüências a médio e longo prazo, onde a exposição constante e continuada a condições adversas poderá desencadear repercussões negativas em termos de morbidade, redução da produtividade, absenteísmo e insatisfação no trabalho (KARASEK e THEORELL 1990; LEVI 1997, 1998, 1999; COX et al. 2000).

Entre os diversos fatores psicossociais do trabalho avaliados, aqueles que representaram as principais fontes de estresse entre os eletricitários foram aspectos que remetem a dificuldades no crescimento e valorização profissional (discriminação/favoritismo, pouca valorização, poucas perspectivas de crescimento na carreira, deficiência na divulgação das informações organizacionais, e forma de distribuição das tarefas). Entre os aspectos que acarretaram menos estresse aos trabalhadores, ou seja, onde eles perceberam condições mais favoráveis, estavam aqueles relativos às relações interpessoais, à jornada de trabalho e às exigências de capacitação para as tarefas. Em níveis intermediários estava o estresse decorrente de questões pertinentes à falta de autonomia e ao tipo de controle, à execução de tarefas com necessidade de pouca habilidade ou responsabilidade, e às dificuldades nas comunicações.

Os resultados desta pesquisa pertinentes ao estado de saúde mostraram valores elevados nos escores das oito dimensões analisadas, evidenciando boa qualidade do estado de saúde destes trabalhadores. As dimensões que apresentaram os escores mais baixos foram a vitalidade, a percepção de dor e a saúde mental, porém nunca inferiores a $70 \%$ do escore. Este resultado é compatível com as prevalências dos agravos à saúde identificadas por meio do ICT, onde sobressaem os agravos músculo-esqueléticos e os distúrbios emocionais leves (ver Tabela 11).

$\mathrm{Na}$ tentativa de dimensionar os resultados relativos ao estado de saúde, eles foram comparados aos de um grupo de trabalhadores de setor administrativo do município de São Paulo com conteúdo de trabalho predominantemente mental. A comparação (que está apresentada no Tabela F do Anexo 13) mostrou que, em todas 
as dimensões analisadas do estado de saúde, os eletricitários apresentaram padrão mais elevado, evidenciando a boa qualidade do estado de saúde destes trabalhadores.

Para explicar a boa qualidade de saúde destes eletricitários, é necessário lembrar o já citado efeito do trabalhador sadio, com influência da exclusão daqueles em piores condições de saúde. Essa situação que pode ser potencialmente importante em um grupo como o desta população de estudo com 77,9\% dos trabalhadores exercendo atividades com conteúdo de trabalho misto onde, para a execução de tarefas como podas de árvores ou manutenção de redes, existem importantes exigências físicas. Além disso, esse efeito também pode receber interferência do papel protetor decorrente dos benefícios relativos às condições trabalhistas, do perfil salarial e educacional, e do estilo de vida com prevalências relativamente baixas de sedentarismo e de tabagismo.

Nas bases bibliográficas consultadas, não foi possível identificar outros estudos que abordem a questão do efeito do trabalhador sadio em relação ao perfil de saúde ou de morbidade de eletricitários brasileiros. Entretanto este efeito foi citado anteriormente por KELSH e SAHL (1997) que, comparando taxas de mortalidade entre eletricitários de campo e pessoal administrativo em uma coorte da Califórnia, identificaram que os trabalhadores de campo apresentavam menores taxas de mortalidade geral e por doenças específicas, e atribuíram estes resultados ao efeito do trabalhador sadio.

MATTOS et al. (2002), estudando o padrão de mortalidade por câncer em uma coorte destes profissionais no Rio de Janeiro, identificaram que este grupo apresentava menores taxas de mortalidade geral e por diferentes grupos de causas de morte do que a população do mesmo sexo e faixa etária. Os autores atribuíram os resultados ao efeito do trabalhador sadio relacionado às condições sócio-econômicas e à inserção laboral destes trabalhadores. 
Resultados semelhantes foram encontrados por NICHOLS e SORAHAN (2005) que avaliaram uma coorte de eletricitários do Reino Unido comparando as taxas de mortalidade destes com as da população geral.

Os eletricitários apresentaram valores elevados em todas as dimensões que compõem o ICT, com um resultado final de 41,8 pontos em um escore que varia de 13,0 a 49,0, evidenciando um padrão elevado de capacidade para o trabalho, cabendo aqui as mesmas observações feitas anteriormente em relação ao efeito do trabalhador sadio.

Comparando-se estes resultados com os apresentados pelo já citado grupo de trabalhadores de área administrativa do Município de São Paulo, foi possível observar que as médias do índice de capacidade para o trabalho das duas populações foram semelhantes (Tabela G do Anexo 13). Porém, na comparação segundo faixa etária, os eletricitários apresentaram melhor perfil nas duas faixas etárias mais jovens, invertendo-se a situação nas faixas mais elevadas, o que poderia sugerir maior envelhecimento funcional entre os eletricitários.

O ICT também possibilitou identificar os agravos à saúde onde, tanto na opinião do próprio trabalhador como no relato de diagnóstico médico, os resultados são compatíveis com o perfil ocupacional e com o quadro de saúde destes trabalhadores, sobressaindo as lesões músculo-esqueléticas, os distúrbios emocionais leves, a diminuição da acuidade auditiva e, também, a obesidade, a gastrite, a hipertensão e os distúrbios da visão.

As lesões músculo-esqueléticas podem estar relacionadas tanto às exigências físicas do trabalho dos eletricistas como ao uso do computador pelo pessoal administrativo. Os distúrbios emocionais leves vêm assumindo relevância crescente desde o final dos anos 90 no país, podendo estar relacionados à organização do trabalho e às cadeias produtivas (LEVI 1997; WÜNSCH FILHO 2004). A diminuição da audição pode ser resultado da exposição a níveis de pressão sonora elevados que podem estar presentes na execução de algumas tarefas e no trânsito. 
Agravos como hipertensão, obesidade e gastrite fazem parte do perfil epidemiológico da população geral, onde as doenças crônicas ganham relevância, mas também podem guardar alguma relação com o estresse decorrente do ambiente psicossocial do trabalho (LEVI 1997; MARCOPITO et al. 2005). As alterações da visão também aparecem com prevalência elevada, mas esta pode sofrer distorção caso os distúrbios de refração corrigidos pelo uso de lentes tenham sido reportados pelos trabalhadores, apesar das orientações em contrário no ICT.

Em resumo, os resultados evidenciaram um perfil de trabalhadores com condições sócio-demográficas e estilo de vida positivamente diferenciados, com elevados padrões do estado de saúde e da capacidade para o trabalho. Apesar disso, foram observadas prevalências importantes de consumo abusivo de álcool e de excesso de peso. O perfil favorável observado pode ser conseqüência do efeito do trabalhador sadio.

\section{3 - Fatores associados à capacidade para o trabalho}

O referencial teórico adotado nesta pesquisa considera que a capacidade para o trabalho é resultante da interação das demandas do trabalho e dos recursos do indivíduo, onde situações em que as demandas sejam superiores aos recursos do trabalhador para lidar com elas, desencadeiam um processo de estresse, gerando desgaste, com conseqüente comprometimento da capacidade para o trabalho (ILMARINEN et al. 1991a; TUOMI et al. 1991a). Neste processo, além da saúde e do trabalho, as características sócio-demográficas e o estilo de vida também estão envolvidos no modelo de determinação da capacidade para o trabalho (POHJONEN 2001a; ILMARINEN 2001).

Nesta pesquisa, a única característica demográfica que apresentou associação estatisticamente significativa com a capacidade para o trabalho foi a idade. Entre as características do estilo de vida, estiveram associadas à capacidade para o trabalho as variáveis estado nutricional (expresso por meio do IMC), grau de dependência ao 
álcool e prática de atividade física. Das características do trabalho, apresentaram associação com o ICT a unidade de trabalho, o tempo na empresa e o estresse decorrente de fatores psicossociais do ambiente de trabalho. Todas as dimensões da saúde analisadas estiveram associadas à capacidade para o trabalho.

A análise dos fatores associados à capacidade para o trabalho foi feita por meio de dois modelos estatísticos. O primeiro modelo apresentou melhor poder explicativo para as relações entre as diversas variáveis. A análise conjunta das diversas características, evidenciou que a saúde física (representada pelas dimensões capacidade funcional, aspecto físico, dor e estado geral de saúde) e o trabalho (representado pelo estresse decorrente de fatores psicossociais do trabalho) foram os fatores independentes associados à capacidade para o trabalho (representada pelo ICT).

Considerou-se que este modelo poderia estar empobrecido ou sofrendo alguma distorção de seus resultados uma vez que algumas das dimensões de saúde avaliadas por meio do SF-36 estão inclusas de forma conceitual e operacional semelhantes no ICT. Isso poderia ser responsável pela significativa, embora fraca, correlação existente entre estas dimensões e o escore do ICT. Assim, optou-se por realizar um segundo modelo de análise de regressão para verificar se outras variáveis não passariam a integrar o modelo final.

No segundo modelo, onde as dimensões da saúde não foram incluídas na análise, observou-se que as características do estilo de vida (estado nutricional, prática de atividade física e dependência química) e o trabalho (representado pelo estresse decorrente de fatores psicossociais do trabalho e pela unidade de trabalho) foram os fatores independentes associados à capacidade para o trabalho (representada pelo ICT). Vale lembrar que o modelo que inclui as dimensões da saúde apresentou melhor poder explicativo $\left(\mathrm{r}^{2} \mathrm{a}=0,51\right)$ do que o modelo sem as dimensões da saúde $\left(r^{2} a=0,22\right)$.

A seguir, será discutido o papel de cada grupo de variáveis estudado. 


\subsection{1 - Características demográficas}

Nesta pesquisa, a idade esteve inversamente associada à capacidade para 0 trabalho, de maneira que o aumento da idade foi acompanhado por diminuição da capacidade para o trabalho. Esse padrão de associação que relaciona o envelhecimento funcional ao envelhecimento cronológico foi descrito em diversos estudos, entretanto ele nem sempre é linear ou pode estar ausente (ILMARINEN et al 1991b, 1997; ILMARINEN e TUOMI 1992; TUOMI et al 1997c, 2001; BELLUSCI 2003; TOBIA 2005; LIN et al. 2006).

Considera-se que o processo de envelhecimento acompanhado pelo aparecimento e/ou agravamento de doenças, seja um determinante da capacidade para o trabalho (TUOMI et al. 1997a, 1997b, ILMARINEN et al. 1997; SÖGRENRÖNKÄ et al 2002; COSTA 2005). Além disso, a deterioração da capacidade física decorrente da diminuição da capacidade cardiorrespiratória e músculo-esquelética também explicam a perda da capacidade para o trabalho (OMS 1993; SHEPHARD 1999; TUOMI 1999; ILMARINEN 2001). TUOMI et al. (1997b) consideram que, a partir dos 45 anos de idade, a capacidade funcional do trabalhador passa a apresentar deterioração de cerca de 1,5\% ao ano. Esses aspectos são especialmente relevantes em atividades com presença de demandas físicas, onde o declínio da capacidade física para o trabalho pode apresentar repercussões importantes (ILMARINEN 1991b; ILMARINEN e TUOMI 1992).

Retomando a comparação com uma população de trabalhadores administrativos citada anteriormente e apresentada no Anexo 13, os eletricitários desta pesquisa apresentaram melhores resultados no ICT nas duas faixas etárias mais jovens e piores resultados nas duas faixas etárias mais elevadas. Estes resultados podem ser entendidos à luz do referencial teórico adotado nesta pesquisa e que considera a capacidade para o trabalho como resultado das exigências do trabalho e dos recursos individuais. Os trabalhadores administrativos, que apresentam pior condição de saúde, quando chegam nas idades mais elevadas têm sua capacidade 
para o trabalho mais preservada do que os eletricitários, talvez como resultado de menor exigência de esforços físicos com maior possibilidade de adaptação na fase de envelhecimento. Já os eletricitários, apesar do melhor perfil de saúde, apresentam diminuição da capacidade para o trabalho nas faixas mais elevadas onde, possivelmente, as exigências físicas no trabalho potencializem um envelhecimento funcional mais intenso do que o envelhecimento cronológico. Essa observação é relevante quando é lembrado que o ICT avalia características principalmente físicas, em especial em atividades ocupacionais com demandas físicas (NYGÅRD et al. 1991; POHJONEN 2001b).

Esse resultado é compatível com aqueles apresentados no único estudo identificado que analisa aspectos da capacidade para o trabalho em pessoal do setor energético. Este estudo analisou a capacidade para o trabalho de 83 trabalhadores italianos do setor energético, com idade entre 45 e 65 anos, e identificou que a capacidade para o trabalho decresce com o aumento da idade, sendo este decréscimo mais evidente no grupo de 50-54 anos (TOBIA et al. 2005). Este mesmo estudo mostrou que, quando comparados a grupos de trabalhadores dos setores químico, sanitário e público, o pessoal do setor energético em fase de envelhecimento apresentou padrão intermediário do nível da capacidade para o trabalho.

Em relação à capacidade mental, ela também pode ser afetada pelo envelhecimento como conseqüência de diminuição do desempenho da memória e da capacidade de percepção e processamento rápido de informações (ILMARINEN et al. 1991b; TUOMI et al. 1997b; SEITSAMO e MARTIKAINEN 1999). Entretanto, estas mudanças não são tão sistemáticas como na capacidade física, dado que estas limitações podem ser compensadas por um aumento decorrente do conhecimento e da experiência, além da maior habilidade para trabalhar de forma independente, de maior "lealdade" ao emprego e menor absenteísmo que trabalhadores com idade mais elevada tendem a apresentar (TUOMI et al. 1997b).

Apesar da importância da questão do envelhecimento cronológico, quando da análise conjunta dos fatores associados à capacidade para o trabalho, a idade perdeu 
seu significado estatístico. Isso se deu porque esta variável estava fraca e inversamente correlacionada a uma das 4 dimensões da saúde física e que demonstrou ter maior importância para a capacidade para o trabalho, a saber, a capacidade funcional $(\mathrm{r}=-0,23, \mathrm{p}<0,001)$. Além disso, a idade também estava fortemente correlacionada ao tempo de serviço na empresa $(r=0,74, p<0,001)$, que foi priorizado na análise conjunta das variáveis.

As demais características demográficas estudadas foram sexo, estado civil e nível de escolaridade. Estas características são apontadas como fatores que exercem influência sobre a capacidade para o trabalho (TUOMI et al. 1991a, 1997b; PERKIÖ-MÄKELA 2000; BELLUSCI 2003; HOPSU et al. 2005). Entretanto, nesta pesquisa elas não demonstraram estar associadas à capacidade para o trabalho, talvez devido à homogeneidade da população de estudo.

\subsection{2 - Características do estilo de vida}

O tabagismo pode afetar indiretamente a capacidade física dos trabalhadores por sua ação como fator de risco para doenças cardiovasculares e pulmonares (OMS 1993). TUOMI et al. (1991a) identificaram que o tabagismo estava inversamente associado à capacidade para o trabalho e à capacidade física em trabalhadores finlandeses, bem como atuava como fator claramente ligado à incapacidade para os indivíduos com doenças músculo-esqueléticas.

Nesta pesquisa, o tabagismo não demonstrou ser fator associado à capacidade para o trabalho dos eletricitários, talvez pela baixa prevalência de tabagismo entre estes trabalhadores. Cabe ressaltar que o elevado padrão na prática de atividade física observado entre os trabalhadores pode, segundo SEITSAMO e ILMARINEN (1997), favorecer a confusão de resultados quando os indivíduos são simultaneamente tabagistas e praticantes de atividades físicas por causa do papel protetor destas.

O consumo de álcool apresentou associação inversa estatisticamente significativa com a capacidade para o trabalho, sendo que esta apresenta decréscimo 
à medida que aumenta o grau de dependência ao álcool. O consumo abusivo de álcool pode exercer efeitos deletérios sobre a capacidade para o trabalho por meio do comprometimento da saúde física e mental, pela queda da produtividade, pelo aumento do absenteísmo e pelo aumento do risco para acidentes de trabalho (VARGAS 1990a; OMS 1993; MARQUES e RIBEIRO 2002a).

$\mathrm{Na}$ análise conjunta dos fatores associados à capacidade para o trabalho, o consumo de álcool perdeu seu significado estatístico no modelo que incluía as dimensões da saúde porque estas variáveis mostraram ter maior importância para a capacidade para o trabalho. Já no modelo onde o estado de saúde foi excluído, a dependência ao álcool manteve seu papel como fator independente associado à capacidade para o trabalho.

Esse resultado pode ser entendido quando se considera que o consumo de álcool acarreta graves e numerosos riscos e conseqüências para a saúde, podendo ser decorrentes tanto do crônico como de intoxicações agudas (VARGAS 1990a; OMS 1993; MARQUES e RIBEIRO 2002a). Desta forma, a influência da dependência química para a capacidade para o trabalho se daria de forma indireta por meio de sua influência sobre o estado de saúde. De fato, o consumo de álcool esteve fraca e inversamente correlacionado a 5 das 8 dimensões da saúde, a saber, a capacidade funcional, estado geral de saúde, vitalidade, aspectos sociais e saúde mental (respectivamente com $r=-0,11$ e $p=0,014 ; r=-0,11$ e $p=0,015 ; r=-0,14$ e $p=0,002$; $r=-$ $0,14$ e $\mathrm{p}=0,002$; e $\mathrm{r}=-0,18$ e $\mathrm{p}<0,001)$.

O perfil de consumo de álcool identificado entre estes trabalhadores ganha relevância quando se considera que o uso abusivo de álcool traz graves prejuízos para o trabalhador, para as empresas e para a sociedade como um todo (VARGAS 1990b; AMARAL e MALBERGUIER 2004; MARQUES e RIBEIRO 2002a). O consumo alcoólico é um ato social com padrões institucionalizados no contexto de valores de cada grupo social, de tal forma que a sociedade que fomenta o consumo alcoólico é a mesma a condenar o alcoolista, sujeitando-o a contradições que, no contexto do ambiente de trabalho, levam o trabalhador a esconder seu padrão de 
consumo este se torna abusivo (VARGAS 1990b; NEVES 2004). Desta forma, a já elevada prevalência de trabalhadores com resultado compatível com consumo alcoólico abusivo deve ser observada com cautela, pois pode estar subestimada sugerindo um panorama ainda mais preocupante.

Entre os trabalhadores da população de estudo, a elevação do padrão da prática de atividade física esteve significativamente associado à elevação do índice de capacidade para o trabalho. Estudos que avaliam os efeitos da atividade física sobre diferentes grupos de trabalhadores evidenciaram benefícios para a capacidade para o trabalho por meio do aumento do consumo energético diário, redução da gordura corporal, manutenção da capacidade aeróbia, aumento da resistência e da força muscular e melhor percepção do estado de saúde (SMOLANDER et al. 2000; POHJONEN e RANTA 2001; NURMINEN et al. 2002). O declínio da capacidade para o trabalho pode ser explicada, em parte, pelo declínio da capacidade física para o trabalho, e esta pode ser intensa após os 45 anos de idade em indivíduos que não praticam atividades físicas regularmente (ILMARINEN e TUOMI 1992).

$\mathrm{Na}$ análise conjunta dos fatores associados à capacidade para o trabalho, a prática de atividades físicas perdeu seu significado estatístico no modelo que incluía as dimensões da saúde porque as variáveis que mostraram ser de maior importância para a capacidade para o trabalho, podem estar, de maneira indireta, ligadas à prática de atividade física, a saber, o estresse e as dimensões físicas da saúde. Já no modelo onde o estado de saúde foi excluído, a prática de atividade física manteve seu papel como fator independente associado à capacidade para o trabalho.

Esse resultado pode ser entendido quando se considera que a prática de atividades físicas tem importante efeito como agente de promoção e proteção da saúde (MATSUDO et al. 2001). Como apresentado acima, a prática da atividade física apresentou correlações importantes com dimensões da saúde física e mental e correlação inversa com o estresse no trabalho, com possível efeito benéfico indireto sobre a capacidade para o trabalho. Esse efeito benéfico se dá porque a prática de atividade física pode melhorar todos os aspectos da saúde (física, mental e social) por 
meio de melhoria no desempenho no trabalho e na capacidade funcional, combate ao estresse psicossocial e à depressão, proteção contra doenças e agravos à saúde, e favorecimento da redução do absenteísmo (KORHONEN 1999; SMOLANDER et al. 2000; MATSUDO et al. 2001). Esta questão merece especial atenção em uma população onde existe a necessidade de um bom preparo físico como recurso para preservar a qualificação para atender às exigências físicas nas tarefas dos eletricistas.

O estado nutricional inadequado expresso por meio do excesso de peso (sobrepeso e obesidade) esteve inversamente associado à capacidade para o trabalho dos eletricitários. Este resultado encontra respaldo nos estudos de POHJONEN e RANTA (2001) que identificaram que, após 5 anos de seguimento, houve aumento do risco para perda da capacidade para o trabalho entre os trabalhadores obesos. HOPSU et al. (2005) observaram que a obesidade demonstrou ser um preditor de aposentadoria precoce.

Assim como a prática de atividades físicas e o consumo de bebidas alcoólicas, o excesso de peso perdeu seu significado estatístico quando da análise conjunta dos fatores associados à capacidade para o trabalho no modelo que incluía as dimensões da saúde porque estas variáveis mostraram ser de maior importância para a capacidade para o trabalho. Já no modelo sem as dimensões da saúde, o estado nutricional apareceu como fator independente associado à capacidade para o trabalho. Aqui novamente pode-se considerar que o papel do excesso de peso para a capacidade para o trabalho se dê por meio de sua influência sobre o estado de saúde, em especial ao considerar que o índice de massa corporal apresentou correlação inversamente estatisticamente significativa com 6 das 8 dimensões da saúde. A saber: a capacidade funcional, aspectos físicos, dor, estado geral de saúde, vitalidade, e saúde mental (respectivamente com $\mathrm{r}=-0,29$ e $\mathrm{p}<0,001 ; \mathrm{r}=-0,11$ e $\mathrm{p}=0,017 ; \mathrm{r}=-0,12$ e $p=0,007 ; r=-0,19$ e $p<0,001 ; r=-0,11$ e $p=0,014 ; r=-0,13$ e $p=0,006)$.

O excesso de peso pode exercer impacto negativo sobre a capacidade para o trabalho também por afetar a capacidade cardiorrespiratória e músculo-esquelética e 
por favorecer o aumento da morbidade por doenças crônicas como as cardiopatias, o diabetes e a depressão (OMS 1993; LAITINEN et al. 2005; ILMARINEN 2006).

\subsection{3 - Características relativas ao estado de saúde}

No modelo estatístico que incluiu a análise do estado de saúde, todas as dimensões da saúde física mostraram ser fatores independentes associados à capacidade para o trabalho, sendo que, quanto melhor a qualidade de saúde, melhor a condição da capacidade para o trabalho. As medidas objetivas não fornecem um retrato abrangente o suficiente da saúde do indivíduo e, por isso, a percepção do estado de saúde pelo próprio trabalhador é apontada como uma medida importante (TUOMI et al. 1997a). Nesta pesquisa, onde a saúde foi avaliada através da percepção do próprio trabalhador, evidenciou-se, que a possibilidade de desempenhar atividades físicas sem limitações devidas à dor ou à alteração no funcionamento do organismo, a ausência de doenças, e o bom estado geral de saúde são atributos importantes para uma boa condição da capacidade para o trabalho.

O papel da saúde física sobre a capacidade para o trabalho está consistentemente demonstrado, em especial no que diz respeito à capacidade funcional e à presença de doenças (NYGÅRD et al. 1991; SJÖGREN-RÖNKÄ et al. 2002; BELLUSCI 2003; KARPANSALO et al. 2004; ILMARINEN et al. 1997, 2005). A capacidade cardiorrespiratória e o funcionamento músculo-esqueléticos são considerados os aspectos que maior impacto exercem sobre a capacidade funcional (ILMARINEN 1991a; RODRIGUES et al. 1999; MATSUDO et al. 2003).

A capacidade funcional pode ser considerada como a base para a capacidade para o trabalho e, de acordo com o modelo estresse-desgaste, esta característica tem um papel significativo sobre o desgaste do trabalhador, pois se relaciona ao desempenho das demandas do trabalho, sendo muito importante na regulação do desgaste (NYGÅRD et al. 1991). Essa relação pode ser entendida quando se considera que o ICT avalia características principalmente físicas, podendo ser 
considerado mais uma medida de incapacidade do que uma medida que reflita aspectos positivos da saúde, em especial em atividades ocupacionais onde existem demandas físicas (NYGÅRD et al. 1991; POHJONEN 2001b).

Para ILMARINEN et al. (2005), o estado de saúde (sintomas psicofísicos e capacidade funcional) pode ser considerado como a base para um modelo construtivo de capacidade para o trabalho, responsável pelas conexões mais significativas deste processo. Para este autor, a saúde e a capacidade funcional representam a base sobre a qual se estrutura a capacidade para o trabalho, sendo que a deterioração da saúde significa um risco e a melhoria da capacidade funcional possibilita $\mathrm{o}$ desenvolvimento da capacidade para o trabalho (ILMARINEN 2006).

Considerando estes aspectos, a identificação das dimensões da saúde física como fatores independentes associados à capacidade para o trabalho, evidenciada nesta pesquisa, expressa a relevância de uma boa qualidade do estado de saúde físico para o desempenho das atividades laborais do grupo de eletricitários estudado que, como já dito anteriormente, são caracterizadas pela presença de demandas mentais e físicas, em especial para os eletricistas e os técnicos de manutenção elétrica. Além disso, as características do estilo de vida que ganharam relevância no $2^{\circ}$ modelo estatístico realizado (consumo de álcool, prática de atividade física e estado nutricional) atuam sobre a capacidade para o trabalho por meio de seu papel reconhecidamente condicionante do estado de saúde.

A saúde mental, em geral, é apontada como menos correlacionada com a capacidade para o trabalho do que a saúde física (NYGÅRD et al. 1991), e é tida como mais relevante em trabalhos com exigências predominantemente mentais (ILMARINEN et al. 1997). Nesta pesquisa, a saúde mental foi avaliada por meio da percepção do próprio trabalhador em relação ao seu bem-estar emocional, vitalidade, limitações decorrentes de problemas emocionais ou sociais no desempenho de suas atividades, e sintomas de alteração psicológica ou comportamental. Todas as dimensões da saúde mental estiveram associadas à capacidade para o trabalho. Entretanto, na análise múltipla realizada no primeiro modelo estatístico, estas 
dimensões perderam o significado estatístico quando foi introduzida a variável estresse no trabalho, mostrando que a associação entre saúde mental e capacidade para o trabalho é dependente do estresse.

Sabe-se que o estresse decorrente de fatores psicossociais no trabalho é agente desencadeante tanto de agravos e de comprometimento da saúde mental como da capacidade para o trabalho (KARASEK e THEORELL 1990; TUOMI et al. 1991a; LEVI 1999) e, talvez por isso, na análise conjunta, o efeito da saúde mental desapareceu.

Cabe ressaltar que, apesar de não aparecer como fator independente associado à capacidade para o trabalho, as questões da saúde mental não devem ser desconsideradas uma vez que a sua importância para o bem-estar do trabalhador e para o desempenho de suas atividades está consistentemente demonstrada em literatura (DANNA e GRIFFIN 1999; FLECK et al. 2002; WHO 2005b).

\subsection{4 - Características funcionais, conteúdo e estresse no trabalho}

Ao contrário do que seria esperado, o conteúdo no trabalho não esteve associado à capacidade para o trabalho. A literatura diz que os trabalhadores com conteúdo do trabalho predominantemente físico apresentam piores condições da capacidade para o trabalho do que os trabalhadores com conteúdo de trabalho predominantemente mental, como resultado de desgaste e comprometimento da saúde em decorrência das exigências físicas do trabalho (TUOMI et al. 1997b; ILMARINEN et al. 1997; LOUHEVAARA e SMOLANDER 1997; ILMARINEN e RANTANEN 1999; LIN et al. 2005).

A divergência de resultados encontrada nesta pesquisa pode ser explicada pelo já citado efeito do trabalhador sadio que poderia estar determinando a exclusão daqueles trabalhadores que estariam com sua capacidade para o trabalho já comprometida em função de executar atividades com conteúdo físico. Outra 
justificativa que deve ser considerada é que não há, na população de estudo, trabalhos com conteúdo predominantemente físico. Mesmo os trabalhadores de campo (eletricistas, técnicos de manutenção, e outros), apesar de executarem tarefas com elevada exigência física, têm suas atividades intercaladas com outras caracterizadas por exigências mentais, sendo que algumas dessas demandas mentais, além de inerentes à profisssão, foram acentuadas com o processo de reestruturação produtiva pelo qual passou a empresa.

Esta explicação é coerente com os resultados desta pesquisa que, nos dois modelos estatísticos realizados, identificou o estresse no trabalho como fator independente associado à capacidade para o trabalho. $\mathrm{O}$ estresse decorrente dos fatores psicossociais no ambiente de trabalho é fenômeno que ganhou relevância nas últimas décadas, contribuindo para modificar o perfil de morbidade dos trabalhadores no Brasil e no mundo (HUUHTANEN et al. 1997; LEVI 1997, 1998, 1999; RIGOTTO 1998; COX et al. 2000; WÜNSCH FILHO 2004).

A globalização, a introdução das novas tecnologias, a reestruturação produtiva, a flexibilização nas relações trabalhistas trouxeram mudanças profundas nas condições e na organização do trabalho (KANTORSKI 1997; RIGOTTO 1998; LEVI 1999; TUOMI et al. 2004). Houve diminuição da importância das doenças tradicionalmente relacionadas a um agente ou grupo de agentes de risco e aumento da relevância dos agravos com etiologia multicausal, com relações causais complexas e nem sempre claras, destacando-se as doenças osteoarticulares relacionadas ao trabalho, o comprometimento da saúde mental e os sintomas inespecíficos e/ou co-existentes relacionados ao estresse no trabalho (KALIMO 1987; SPURGEON et al. 1996; LEVI 1997, 1998, 1999; WÜNSCH FILHO 2004).

A organização, os métodos, as ferramentas e as cargas de trabalho estão mudando mais rapidamente do que a capacidade de adaptação humana, representando uma das principais causas de mudanças negativas na capacidade para o trabalho (ILMARINEN 2001). Em que pese o fato de que o trabalho com esforço físico estar consistentemente demonstrado como fator de risco para a capacidade para 
o trabalho (TUOMI et al. 1991a, 2001, 2004; SAVINAINEN et al. 2004), estudos também têm identificado que o estresse decorrente de fatores da organização e do ambiente psicossocial do trabalho exercem efeitos importantes sobre a capacidade para o trabalho de trabalhadores em diferentes tipos de atividade (TUOMI et al 1997b; SJÖGREN-RÖNKA et al. 2002; GOEDHARD e GOEDHARD 2005; ILMARINEN et al. 2005).

O processo que ocorreu na empresa onde ocorreu esta pesquisa se insere no cenário de globalização e de mudanças no mundo do trabalho. Nesta reestruturação com redução do quadro de pessoal e reorganização técnica e operacional - os fatores psicossociais do trabalho ganharam relevância, com uma configuração na qual os empregados que permaneceram na empresa lidam com situações como insegurança quanto ao seu futuro na empresa, maior pressão de prazos e/ou de responsabilidade e/ou necessidade de diversidade de soluções visando realizar trabalho que atenda as demandas dos clientes internos e externos, maior volume de trabalho em decorrência da ampliação do escopo de atividades e responsabilidades e/ou da diminuição do número de pessoas disponíveis para executar as atividades, introdução de novas tecnologias e novos processos de trabalho, e necessidade de maior qualificação técnico-educacional. Embora o desenho esta pesquisa não permita comprovar tal afirmação, pode-se especular que este processo de reestruturação e a nova configuração da organização e do ambiente psicossocial do trabalho sejam os responsáveis pela relevância que o estresse no trabalho apresentou como fator independente para a capacidade para o trabalho.

Esta afirmação está de acordo com estudos que apontam variáveis pertinentes às demandas e aos fatores psicossociais do ambiente de trabalho como os fatores causais ou explicativos do padrão de capacidade para o trabalho. Entre estes estudos podem ser citados os de BELLUSCI (2003) no Brasil, ESTRYN-BEHAR et al. (2005) na França, e GOEDHARD e GOEDHARD (2005) na Holanda.

No segundo modelo estatístico, a variável unidade esteve associada à capacidade para o trabalho, com os trabalhadores da unidade Trevo apresentando 
pior condição da capacidade para o trabalho quando comparados aos trabalhadores das outras unidades. O desenho deste estudo não permitiu identificar quais os motivos que poderiam levar a esse resultado.

As variáveis cargo e setor de trabalho não estiveram associadas à capacidade para o trabalho. Aqui, novamente, pode-se especular que o efeito do trabalhador sadio contribua para manter os trabalhadores de diferentes atividades e locais de trabalho em condições semelhantes no que diz respeito à capacidade para o trabalho.

A condição sócio-econômica é apontada como fator importante na determinação do estado de saúde e da capacidade para o trabalho, e aspectos como condições de vida, nível educacional, comportamentos em saúde, e posição na estrutura hierárquica, são utilizados para operacionalizar mensurações de desigualdades sociais (GUBÉRAN e USEL 1998; AITTOMÄKI et al 2003). Nesta pesquisa a condição sócio-econômica foi mensurada por meio da faixa salarial, e não houve associação entre esta e o ICT. Talvez esse resultado possa ser explicado pelo fato de que, independentemente da faixa salarial, estes trabalhadores contam com benefícios (assistência de saúde de boa qualidade, auxílio alimentação, auxílio transporte e previdência privada) que funcionam como salário indireto, além de acesso a treinamentos, atualização profissional e programas de saúde, segurança e qualidade de vida, que poderiam atenuar o impacto das diferenças salariais.

A capacidade para o trabalho pode apresentar declínio associado ao tempo em que os indivíduos permanecem ativos em seu trabalho, uma vez que quanto maior o tempo que o trabalhador está exposto às exigências do trabalho, maior será o envelhecimento funcional (TUOMI et al. 1997b). Além disso, o tempo na empresa também pode estar correlacionado à idade, com diminuição da capacidade para o trabalho decorrente do envelhecimento cronológico. De fato, o tempo na empresa dos trabalhadores da população de estudo apresentou forte correlação com a idade ( $\mathrm{p}<0,001, \mathrm{r}=0,74)$, entretanto, perdeu a significância estatística quando da análise conjunta, evidenciando a maior importância das variáveis relativas à saúde física e ao 
estresse no trabalho no primeiro modelo estatístico, e das variáveis relativas ao estilo de vida e ao estresse no trabalho no segundo modelo estatístico.

O turno de trabalho (trabalho em turnos e noturno) é considerado fator associado à capacidade para o trabalho uma vez que ele constitui fonte de problemas para a saúde e para o bem-estar emocional e social (COSTA 2005). O trabalho em turnos e noturno provoca a dessincronização dos ritmos biológicos e a perturbação da homeostase psicofisiológica implicados na gênese de agravos à saúde (com destaque para alterações cardiovasculares, gastrointestinais e psicossomáticas), distúrbios do sono e fadiga, queda do desempenho, aumento do absenteísmo, ocorrência de acidentes e comprometimento das relações sociais e familiares (FISCHER et al. 1995; METZNER e FISCHER 2001; COSTA 2005).

Os efeitos do trabalho em turnos sobre a saúde e a capacidade para o trabalho são resultantes das interações múltiplas e complexas entre diversas variáveis relacionadas a fatores externos e internos dos indivíduos (FISCHER et al. 1995; COSTA 2005). Entre os fatores externos estão aspectos como as condições habitacionais e sociais, as características do sistema de turnos, as condições e a organização do trabalho; e entre os fatores internos estão o sexo, a idade, as características de personalidade, o ritmo biológico e o estado de saúde (FISCHER et al. 1995; COSTA 2005). Vários modelos procuram explicar estas interações, focalizando questões como as relações entre carga e desgaste no trabalho mediadas por outras variáveis independentes, a dessincronização dos ritmos biológicos, o comprometimento do equilíbrio psicofisiológico, e a adaptação ao trabalho noturno decorrente da interação de fatores biológico-comportamentais, do trabalho e psicossociais (FISCHER et al. 1995).

Nesta pesquisa, o trabalho em turnos e noturno não esteve associado à capacidade para o trabalho. Esse resultado não é facilmente explicável uma vez que esta pesquisa não contempla a análise dos diversos fatores intervenientes nesta relação. Entretanto, um aspecto importante a ser considerado é a idade relativamente jovem dos trabalhadores que compõem a população deste estudo. 
A idade é considerada como um fator de intolerância ao trabalho em turnos e noturno uma vez que o envelhecimento é acompanhado de diminuição da capacidade de adaptação do ritmo circadiano, comprometimento do sistema fisiológico, menor resistência à perda de integração à vida social e familiar e maior comprometimento da capacidade para o trabalho (FISCHER et al. 1995; METZNER e FISCHER 2001; COSTA 2005). Estas condições são acompanhados de exacerbação dos agravos à saúde, dos distúrbios do sono e de fadiga, com os conseqüentes prejuízos para o bem estar físico, emocional e social destes trabalhadores (FISCHER et al. 1995; METZNER e FISCHER 2001; COSTA 2005).

A população desta pesquisa tem média de idade de 36,8 anos ( $\mathrm{dp}=8,0$ anos), variando de 18,0 a 56 anos, com mediana de 37,0 anos e, portanto, abaixo da idade apontada por COSTA (2005) como crítica para a redução da tolerância ao trabalho em turnos, que está entre os 40 e 50 anos. Além disso, houve diferença estatisticamente significativa $(\mathrm{p}=0,003)$ na média da idade dos trabalhadores com os diferentes regimes de horários: o pessoal atuando em horário administrativo era o mais velho com (média de idade $=37,5$ anos, $\mathrm{dp}=7,8$ anos), o pessoal nos turnos da manhã e da tarde tiveram média de idade intermediária (média=35,2 anos, dp=7,9 anos), e o pessoal do horário noturno foi o mais jovem (média de idade=33,5 anos, $\mathrm{dp}=9,1$ anos $)$.

Este último resultado mostra que esta variável, apesar de não aparecer associada à capacidade para o trabalho, não deve ser desconsiderada sob o ponto de vista de potenciais comprometimentos futuros que poderão se manifestar com o envelhecimento dos trabalhadores. Além disso, deve-se destacar novamente o efeito do trabalhador sadio uma vez que, de acordo com FISCHER et al. (1995), METZNER e FISCHER (2001) e COSTA (2005), trabalhadores que não conseguem desenvolver estratégias eficientes de enfrentamento ao trabalho em turnos e noturno, podem ser precocemente excluídos da população ativa. 
Em resumo, a análise dos fatores associados identificou a relação de diversas características dos trabalhadores e do trabalho com a capacidade para o trabalho. Em um primeiro modelo, a análise conjunta destas variáveis evidenciou que as dimensões da saúde física e o estresse decorrente de fatores psicossociais do ambiente de trabalho foram os fatores independentes associados à capacidade para 0 trabalho dos eletricitários. Em um segundo modelo, excluídas as dimensões da saúde da análise, o estresse no trabalho, a unidade de trabalho e características do estilo de vida foram os fatores que melhor explicaram a capacidade para o trabalho.

Esses resultados remetem ao referencial teórico adotado nesta pesquisa no qual, tanto o conceito como o modelo causal de determinação da capacidade para o trabalho, apontam para inter-relações entre características e recursos dos trabalhadores e exigências do trabalho (OMS 1993; TUOMI et al. 1997; ILMARINEN 1997, 2001; POHJONEN 1999).

ILMARINEN (2006), propondo um modelo hierárquico de determinação da capacidade para o trabalho, assinala que a base que sustenta esse processo está na saúde e na capacidade funcional. Em um segundo nível estaria a competência profissional (conhecimentos e habilidades) e seu contínuo aperfeiçoamento para fazer frente às demandas do trabalho. Em seguida, estariam os valores, atitudes e motivação que influenciariam no equilíbrio entre os recursos pessoais e o trabalho. Por fim, em um último nível estaria o trabalho e seus fatores relacionados (condições de trabalho, conteúdo, demandas, organização, comunidade, gestão e supervisão). Para o autor, os fatores que afetam a capacidade para o trabalho estão em mudanças contínuas, e a promoção da capacidade para o trabalho deveria equilibrar os recursos individuais com as demandas do trabalho (ILMARINEN(2006).

A complexidade e as múltiplas inter-relações subjacentes à determinação da capacidade para o trabalho demonstram que, mesmo evidenciados os principais determinantes, os diversos fatores envolvidos não podem ser considerados de maneira isolada. Isso exige que a abordagem da capacidade para o trabalho, assim como o processo saúde/doença do trabalhador, se dê no contexto geral do trabalho e 
da organização do trabalho, onde o trabalhador não pode ser visto apenas como um ser biológico e sua saúde e capacidade para o trabalho são consideradas como o resultado de interações dinâmicas e complexas determinadas pelos domínios físico, mental, organizacional e social, onde o trabalho têm caráter central.

\section{4 - Considerações finais}

Considerando os resultados e as limitações desta pesquisa, e dentro de uma concepção de capacidade para o trabalho como resultado das inter-relações entre recursos dos trabalhadores e exigências do trabalho, são apresentadas algumas sugestões:

\section{- Redução do estresse no trabalho:}

Como o estresse no trabalho foi o principal fator independente associado à capacidade para o trabalho, sugere-se implementar medidas para melhoria da organização e do ambiente psicossocial do trabalho. A implementação deste tipo de medidas tanto deve atender às necessidades e expectativas dos trabalhadores como ser adequadas às necessidades e características das tarefas.

Para iniciar este tipo de medidas e direcionar prioridades, as ações podem ser focadas na melhoria dos aspectos apontados como maiores fontes de estresse pelos trabalhadores, a saber: discriminação/favoritismo no ambiente de trabalho, pouca valorização por parte dos superiores, poucas perspectivas de crescimento na carreira, deficiência na divulgação de informações sobre decisões organizacionais e forma de distribuição das tarefas.

Para embasar um trabalho mais abrangente e complexo, sugere-se a realização de análise ergonômica do trabalho com foco, não apenas nas condições físicas e da 
biomecânica do trabalho, mas priorizando as questões da organização e do ambiente psicossocial do trabalho.

\section{- Promoção, proteção e recuperação da saúde:}

As dimensões da saúde física foram fatores independentes associados à capacidade para o trabalho, o que justifica a realização de ações relativas à promoção, proteção e recuperação da saúde. Este aspecto não só justifica como reforça a importância do Programa de Controle Médico de Saúde Ocupacional PCMSO já realizado pela empresa e que procura integrar as questões ocupacionais com as questões clínico-assistenciais, visando a promoção da saúde, o diagnóstico precoce e o tratamento adequado.

Neste sentido, também deve ser mantido e incrementado o programa de incentivo à prática de atividades físicas em andamento na empresa. Estas ações se justificam pelo papel protetor que a prática de atividades físicas exerce na preservação da capacidade física, no controle da obesidade e na redução da morbidade o que, como já discutido, trará benefícios indiretos para a capacidade para o trabalho.

Sugere-se, ainda, introduzir, no PCMSO, uma estratégia para avaliação, abordagem e tratamento do uso abusivo de álcool em função da elevada prevalência de pessoas com perfil sugestivo de dependência ao álcool, bem como implementar ações de informações sobre o tema para o coletivo dos trabalhadores.

\section{- Monitoramento da capacidade para o trabalho:}

Sugere-se incluir, como rotina no PCMSO, a avaliação da capacidade do trabalho por meio do ICT de todos os trabalhadores. Essa avaliação rotineira permitiria o monitoramento da capacidade para o trabalho em dois níveis. No nível 
individual permite acompanhar cada trabalhador e identificar aqueles com comprometimento da capacidade para o trabalho e adotar medidas adequadas de apoio. No nível coletivo permite acompanhar o perfil da capacidade para o trabalho do conjunto dos trabalhadores, identificando fatores que os afetam, subsidiando a implementação de medidas corretivas, e possibilitando a avaliação e redirecionamento destas medidas.

Todas as medidas sugeridas devem ser consideradas de forma articulada no contexto do processo de trabalho, bem como contar com a participação dos trabalhadores, dos profissionais de saúde e segurança no trabalho e de recursos humanos, das lideranças e da direção da empresa. Esta participação deve ocorrer em todas as suas fases, desde a concepção até a avaliação, sob pena de não serem legitimadas e aceitas ou não serem factíveis de implementação.

\section{- Realização de novas pesquisas:}

Cabe lembrar que o desenho transversal desta pesquisa não permite estabelecer relações causais entre os diversos fatores analisados. Considerando esta limitação, a validade externa restrita desta pesquisa, bem como a escassez de estudos sobre saúde dos eletricitários e a fase ainda inicial dos estudos sobre capacidade para o trabalho no país, sugere-se a realização de novos estudos. O desenho destes estudos deve, se possível, permitir estabelecer direções causais e/ou avaliar os resultados de medidas de promoção da capacidade para o trabalho, como são consideradas as coortes de trabalhadores de diversos locais do mundo. 


\section{6 - CONCLUSÕES}

Esta pesquisa analisou os fatores associados à capacidade para o trabalho em trabalhadores do Setor Elétrico no Estado de São Paulo.

1. Entre as características do trabalhador relativas aos aspectos demográficos, a idade esteve inversa e significativamente, mas não de maneira independente, associada à capacidade para o trabalho da população de estudo, sendo que quanto mais elevada a idade, menor o valor do ICT. Entre as características do estilo de vida, o índice de massa corporal, o grau de dependência ao álcool e a prática de

atividade física apresentaram associação estatisticamente significativa com a capacidade para o trabalho. Quanto maior o IMC e o grau de dependência ao álcool, menor o valor do ICT, e quanto maior o escore da prática de atividade física, maior o valor do ICT. Estas associações não foram independentes do estresse e das dimensões físicas da saúde.

2. Entre os aspectos da saúde auto-referidos analisados, todas as dimensões da saúde física e da saúde mental estiveram positiva e significativamente associadas à capacidade para o trabalho, sendo que quanto melhor a qualidade da dimensão da saúde, maior o valor do ICT.

3. Entre as características do trabalho da população de estudo, a unidade de trabalho, o tempo na empresa e o estresse decorrente do ambiente psicossocial do trabalho estiveram significativamente associados à capacidade para o trabalho. Entre as diversas unidades de trabalho, as unidades Itapira e Transmissão apresentaram médias do ICT superiores à média da unidade Trevo. Quanto menor o tempo que o trabalhador estava empregado na empresa, maior o valor do ICT. Quanto mais elevado o estresse no trabalho, menor o valor do ICT. 
4. A análise conjunta das diversas características, ajustada por sexo e tempo na empresa, evidenciou que os fatores que melhor explicaram a variação do Índice de Capacidade para o Trabalho da população de estudo foram o estresse no trabalho e as dimensões da saúde física, a saber, capacidade funcional, aspecto físico e estado geral de saúde.

Embora não fosse um objetivo desta pesquisa, foi possível identificar que os trabalhadores da população de estudo apresentaram perfil com condições sóciodemográficas e estilo de vida positivamente diferenciados, com elevados padrões do estado de saúde e da capacidade para o trabalho. Apesar disso, foram observadas prevalências importantes de consumo abusivo de álcool e de excesso de peso. $\mathrm{O}$ perfil favorável observado pode estar recebendo influência do efeito do trabalhador sadio. 


\section{7 - REFERÊNCIAS}

Aittomäki A, Lahelma E, Roos E. Work conditions and socioeconomic inequalities in work ability. Scand J Work Environ Health. 2003;29(2):159-65.

Almeida WF. Trabalho agrícola e sua relação com saúde/doença. In: Mendes R, organizador. Patologia do trabalho. Rio de Janeiro: Atheneu; 1995. p.487-544.

Amaral RA, Malbergier A. Avaliação de instrumento de detecção de problemas relacionados ao uso do álcool (CAGE) entre trabalhadores da Prefeitura do Campus da Universidade de São Paulo (USP) - Campus Capital. Rev Bras Pisquiatr. 2004;26(3):156-63

ANATEL - Agência Nacional de Telecomunicações. Diretrizes para limitação da exposição a campos elétricos, magnéticos e eletromagnéticos variáveis no tempo (até 300GHz) [diretrizes na internet]. Brasília; 1999 [acesso em 05 mar 2005]. Disponível em: www.anatel.gov.br/radiofrequencia/diretriz_radiacao.pdf

Babor TF, Higgins-Biddle JC, Saunders JB, Monteiro MG. AUDIT - The alcohol use disorders identification test: guidelines for use in primary care. 2. ed. Geneva: WHO - World Health Organization. Department of Mental Health and Substance Dependence, 2001.

Barberino J, Carvalho F, Silvany-Neto A, Cotrim H, Góes R, Rosa H, et al. Alterações hepáticas em trabalhadores de uma refinaria de petróleo e em uma população de referência no Estado da Bahia, Brasil. Rev Panam Salud Pública. 2005;17(1):30-7.

Bellusci SM. Envelhecimento e condições de trabalho em servidores de uma instituição judiciária - Tribunal Regional Federal da $3^{\text {a }}$ Região, São Paulo [Dissertação de Mestrado]. São Paulo: Faculdade de Saúde Pública da USP; 1998. 
Bellusci SM. Envelhecimento funcional e capacidade para o trabalho em servidores forenses [Tese de Doutorado]. São Paulo: Faculdade de Saúde Pública da USP; 2003.

Bellusci SM, Barrios SRL, Fischer FM, Borges FNS. Capacidade para o trabalho de funcionários de um hospital filantrópico. In: Anais do I Encontro África-Brasil de Ergonomia, $5^{\circ}$ Congresso Latino-Americano de Ergonomia, $11^{\circ}$ Congresso Brasileiro de Ergonomia, $3^{\circ}$ Seminário de Ergonomia; 1999; Salvador, BR. Recife: ABERGO Associação Brasileira de Ergonomia; 1999. p.38-42.

Bland JMB, Altman DG. Cronbach's alpha. BMJ. 1997;314:572.

Boldori R. Aptidão física e sua relação com a capacidade de trabalho dos bombeiros militares do Estado de Santa Catarina [Dissertação de Mestrado]. Florianópolis: Faculdade de Engenharia de Produção - UFSC; 2001.

Borges FNS. Repercussões do trabalho em turnos noturnos de 12 horas de sono e bem estar em auxiliares de enfermagem e enfermeiros [Dissertação de Mestrado]. São Paulo: Faculdade de Saúde Pública da USP; 2002.

Brasil. Lei $\mathrm{n}^{\circ}$ 9.427, de 26 de dezembro de 1996. Institui a Agência Nacional de Energia Elétrica - ANEEL, disciplina o regime das concessões de Serviços Públicos de Energia Elétrica e dá outras providências. Diário Oficial da União. 27 dez 1996;Seção 1:28653.

Bugajska J, Łastowiecka E. Life style, work environment factors and work ability in different occupations. International Congress Series. 2005;1280:247-52. [Proceedings of the 2nd International Symposium in work ability: assessment and promotion of work ability, health and well-being of ageing workers; 2004; Verona, Italy]. 
Cantero MAR, Fischer FM, Sobreiro AR, Gaspar CJ, Ahuvia H. Determinação do índice de capacidade para o trabalho (ICT) em trabalhadores da área de Recursos Humanos de empresa de papel e celulose, S.P. In: Anais do $11^{\circ}$ Congresso da Associação Nacional de Medicina do Trabalho [CD-ROM]; 28 abr-03 mai 2001. Belo Horizonte, BR. Belo Horizonte: ANAMT; 2001; 2001. p.2085-89.

Carlini EA, Galduróz JCF, Noto AR, Nappo AS. I levantamento domiciliar sobre o uso de drogas psicotrópicas no Brasil: estudo envolvendo as 107 maiores cidades do país - 2001. São Paulo: CEBRID - Centro Brasileiro de Informações Sobre Drogas Psicotrópicas / UNIFESP - Universidade Federal de São Paulo; 2002.

Carvalho JAM, Garcia RA. O envelhecimento da população brasileira: um enfoque demográfico. Cad Saúde Pública. 2003;19(3):725-33.

Cervi A, Franceschini SCC, Priore SE. Análise crítica do uso do índice de massa corporal para idosos. Rev Nutr. 2005;18(6):765-75.

Chillida MSP, Cocco MIM. The workers' profile and prevalence of diseases among health care night workers at an university hospital [abstract]. Shiftwork International Newsletter 2003;20(2):52. [Presented at XVI International Symposium on Night and Shiftwork; 2003; Santos, Brazil].

Ciconelli RM. Tradução para o português do questionário de avaliação de qualidade de vida "Medical outcomes study 36 - item short-form health survey (SF-36)" [Tese de Doutorado]. São Paulo: Universidade Federal de São Paulo; 1997.

Ciórlia LAS. Intervenção dietética e níveis de colesterol plasmático em grupo de eletricitários. Arq Bras Cardiol. 1997;68(1):21-5.

Ciórlia LAS, Godoy MF. Cardiovascular risk factors and mortality. Long-term follow-up (up to 20 years) in a preventive program carried out by occupational medicine. Arq Bras Cardiol. 2005;85(1):20-5. 
Cohn A, Marsiglia RG. Processo e organização do trabalho. In: Rocha LE et al., organizadores. Isto é trabalho de gente? Vida, doença e trabalho no Brasil. Petrópolis: Vozes; 1994. p.56-75.

Colombo RCR, Aguillar OM, Gallani MCBJ, Gobatto CA. Caracterização da obesidade em pacientes com infarto do miocárdio. Rev Latino-am Enfermagem. 2003;11(4):461-7.

Colquhoun WP, Rutenfranz J, editores. Studies of shiftwork. London: Taylor \& Francis; 1980. Introduction; p. ix-xi.

Costa G. Some considartions about aging, shift work and work ability. International Congress Series. 2005;1280:67-72. [Proceedings of the 2nd International Symposium in work ability: assessment and promotion of work ability, health and well-being of ageing workers; 2004; Verona, Italy].

Costa G,Goedhard W, Ilmarinen J. Preface. International Congress Series. 2005;1280:v-viii. [Proceedings of the 2nd International Symposium in work ability: assessment and promotion of work ability, health and well-being of ageing workers; 2004; Verona, Italy].

Cox T, Griffiths A, Rial-González E. Research on work-related stress. Luxembourg: European Agency for Safety and Health at Work; 2000. Work hazards and stress; 5186.

Danna K, Griffin RW. Health and well-being in the workplace: a review and synthesis of the literature. Journal of Management. 1999;25(3):357-384.

Dellve L, Karlberg C, Allebeck P, Herloff B, Hagberg M G. Macro-organizational factors, the incidence of work disability, and work ability among the total workforce of home care workers in Sweden. Scand J Public Health. 2006;34:17-25. 
Duran ECM, Cocco MIM. Capacidade para o trabalho entre trabalhadores de enfermagem do pronto-socorro de um hospital universitário. Rev Latino-am Enfermagem. 2004;12(1):43-4.

Eskelinen L, Kohvakka A, Merisalo T, Hurri H, Wågar G. Relationship between the self-assessment and clinical assessment of health status and work ability. Scand J Work Environ Health. 1991;17(Suppl 1):40-7.

Estryn-Behar M, Kreutz G, Le Nezet O, Mouchot L, Camerino D, Salles RK, et al. Promotion of work ability among French health care workers - value of the work ability index. International Congress Series. 2005;1280:73-78. [Proceedings of the 2nd International Symposium in work ability: assessment and promotion of work ability, health and well-being of ageing workers; 2004; Verona, Italy].

Figlie NB, Pillon SC, Dunn J, Laranjeira R. The frequency of smoking and problem drinking among general hospital inpatients in Brazil - using the AUDIT and Fagerström questionnaires. Rev Paul Med. 2000;118(5):139-43.

Fischer FM, Lieber RR, Brown FM. Trabalho em turnos e as relações com a saúdedoença. In: Mendes R, organizador. Patologia do trabalho. Rio de Janeiro: Atheneu; 1995. p. 545-72.

Fischer FM, Bellusci SM, Borges FNS, Teixeira LR, Christoffolete M, Martins SE, et al. Work ability index: survey among health care shiftworkers of São Paulo, Brazil [abstract]. Shiftwork International Newsletter 1999;16(2):101. [Presented at XIV International Symposium on Night and Shiftwork; 1999; Wiesensteig, Germany].

Fischer FM. Aging and work: work ability index and self-reported diagnosed diseases, of health care shiftworkers of São Paulo. In: Proceedings of the XXVI International Congress on Occupational Health; 2000; Kent Ridge, Singapore. Kent Ridge: National University of Singapore; 2000. p.53. 
Fischer FM, Bellusci SM. Work Ability Index: survey among health care shiftworkers of São Paulo, Brazil. In: Hornberger S et al., editores. Shiftwork in th 21st Century: challenges for research and practice. Frankfurt: Peter Lang; 2000. p.195-200.

Fischer FM, Bellusci SM, Borges FNS, Teixeira LR, Christoffolete MA, Martins SE, et al. Aging at work: survey among health care shiftworkers of São Paulo, Brazil. In: Proceedings of the XIV Triennial Congress of the International Ergonomics Association, XXIV Annual Meeting of the Human Factors and Ergonomics Society; 2000; San Diego. Roma: IEA - International Ergonomics Association 2000.p.39-41.

Fischer FM. Breve histórico desta tradução. In: Tuomi et al. Índice de capacidade para o trabalho. Trad. de Fischer FM. São Carlos: EdUFScar, 2005. p. 9-10.

Fleck MPA, Lima AFBS, Louzada S, Schestasky G, Henriques A, Borges VR, et al. Associação entre sintomas depressivos e funcionamento social em cuidados primários à saúde. Rev Saúde Pública. 2002;36(4):431-8.

Florindo AA, Latorre MRDO. Validation and reliability of the Baecke questionnaire for the evaluation of habitual physical activity in adult men. Rev Bras Med Esporte. 2003;9(3):129-35.

Florindo AA, Latorre MRDO, Jaime PC, Tanaka T, Zerbini CAF. Metodologia para a avaliação da atividade física habitual em homens com 50 anos ou mais. Rev Saúde Pública. 2004;38(2):307-14.

Fonseca MJM, Faerstein E, Chor D, Lopes CS. Validade de peso e estatura informados e índice de massa corporal: estudo pró-saúde. Rev Saúde Pública. 2004;38(3):392-8. 
Fowler Jr DJ. Survey Research Methods. California: SAGE; 1990. Nonresponse: implementing a sample design; p.45-60.

Fundação SEADE - Fundação Sistema Estadual de Análise de Dados. Guia de investimentos e geração de empregos: energia elétrica [Informativo na internet]. São Paulo: 2001 [acesso em 04 fev 2005]. Disponível em: http://www.seade.gov.br/negocios/snpor_03-v2.html\#Novo

Goedhard RG, Goedhard WJA. Work ability and perceived work stress. 2005;1280:79-83. [Proceedings of the 2nd International Symposium in work ability: assessment and promotion of work ability, health and well-being of ageing workers; 2004; Verona, Italy].

Gubéran E, Usel M. Permanent work incapacity, mortality and survival without work incapacity among occupations and social classes: a cohort study of ageing men in Geneva. Int J Epidemiol. 1998;27:1026-32.

Guimarães LBM, Fischer D, Fae CS, Salis HB, Santos JAS. Apreciação macroergonômica em uma concessionária de energia elétrica. In: Anais do ABERGO 2002 - VII Congresso Latino-Americano, XII Congresso Brasileiro de Ergonomia e I Seminário Brasileiro de Acessibilidade Integral; 2002; Recife, BR. Recife: ABERGO - Associação Brasileira de Ergonomia; 2002.

Halty LS, Hüttner MD, Netto ICO, Santos VA, Martins G. Análise da utilização do Questionário de Tolerância de Fagerström (QTF) como medida da dependência nicotínica. J Pneumol. 2002;28(4):180-6.

Heatherton TF, Kozlowski LT, Frecker RC, Fagerström KO. The Fagerström test for nicotine dependence: a revision of the Fagerström Tolerance Questionnaire. Br J Addict. 1991;86:1119-27. 
Hopman WM, Towheed T, Anastassiades T, Tenenhouse A, Poliquim S, Berger C, et al. Canadian normative data for the SF-36 health survey. CMAJ. 2000;163(3):26571.

Hopsu L, Leppänen A, Ranta R, Louhevaara V. Perceived work ability and individual characteristics as predictors for early exit from working life in professional cleaners. 2005;1280:84-8. [Proceedings of the 2nd International Symposium in work ability: assessment and promotion of work ability, health and well-being of ageing workers; 2004; Verona, Italy].

Howe GR, Chiarelli AM, Lindsay JP. Components and modifiers of the healthy worker effect: evidence from three occupational cohorts and implications for industrial compensation. Am J Epidemiol. 1988;128(6):1364-75.

Huuhtanen P, Nygård C-H, Tuomi K, Martikainen R. Changes in stress symptoms and their relationship to changes at work in 1981-1992 among elderly workers in municipal occupations. Scand J Work Environ Health. 1997;23(Suppl 1):36-48.

IBGE - Instituto Brasileiro de Geografia e Estatística. Projeção da População Brasil: 1980-2050 (Projeção populacional na internet). Brasília, 2004 [acesso em 11 out 2005].

Disponível

em: http://www.ibge.gov.br/home/estatistica/populacao/projecao_da_populacao/default.s htm

IBGE - Instituto Brasileiro de Geografia e Estatística. Indicadores IBGE. Pesquisa mensal de emprego: séries históricas: tabelas completas: rendimento real habitual do trabalho principal (Indicadores na internet). Rio de Janeiro, 2006a [acesso em 02 mai 2006]. Disponível

em: http://www.ibge.gov.br/home/estatistica/indicadores/trabalhoerendimento/pme_nova/ defaulttab_hist.shtm?c=3 
IBGE - Instituto Brasileiro de Geografia e Estatística. Indicadores IBGE. Pesquisa mensal de emprego: março - 2006 (Indicadores na internet). Rio de Janeiro, 2006b [acesso em 02 mai 2006]. Disponível em: http://www.ibge.gov.br/home/estatistica/indicadores/trabalhoerendimento/pme_nova/ pmec032006.pdf

Ilmarinen J, Tuomi K, Eskelinen L, Nygård C-H, Huuhtanen P, Klockars M. Background and objectives of the Finnish research project on aging workers in municipal occupations. Scand J Work Environ Health. 1991a;17(Suppl 1):7-11.

Ilmarinen J, Tuomi K, Eskelinen L, Nygård C-H, Huuhtanen P, Klockars M. Summary and recommendations of a project involving cross-sectional and follow-up studies on the aging worker in Finnish municipal occupations (1981-1985). Scand J Work Environ Health. 1991b;17(Suppl 1):135-41.

Ilmarinen J, Tuomi K. Work ability of aging workers. Scand J Work Environ Health. 1992;18(Suppl 2):8-10.

Ilmarinen J. Aging workers. Scand J Work Environ Health. 1997;23(Suppl 1):3-5.

Ilmarinen J, Tuomi K, Klockars M. Changes in the work ability of active employees over an 11-year period. Scand J Work Environ Health. 1997;17(Suppl 1):49-57.

Ilmarinen J, Rantanen J. Promotion of work ability during ageing. Am J Ind Med. 1999;1:21-3.

Ilmarinen J. Aging and work. Occup Environ Med. 2001;58:546-51.

Ilmarinen J. What the social partners can do to improve employment opportunities for older workers. In: Final report of the Ninth EU-Japan Symposium "Improving Employment Opportunities for Older Workers" [evento na internet]; 2002; Brussels, Belgium. Brussels: European Commission, Japanese Ministry of Health, Labour and 
Welfare and Japan Institute of Labour; 2002 [acesso em 03 jan 2005]. Disponível em:

http://ec.europa.eu/employment_social/international_cooperation/japan_olderworker s_en.htm

Ilmarinen J, Tuomi K, Seitsamo J. New dimensions of work ability. International Congress Series. 2005;1280:3-7. [Proceedings of the 2nd International Symposium in work ability: assessment and promotion of work ability, health and well-being of ageing workers; 2004; Verona, Italy].

Ilmarinen J. 2006. Towards a longer worklife! Ageing and the quality of worklife in the European Union. Helsinki: FIOH; 2006. Age information through research; p.117-230.

ILO - International Labour Office. Psychosocial factors at work: recongnition and control. Report. Geneva; 1984. (ILO - Report of the Joint ILO/WHO Committee on Occupational Health - Ninth Session).

Johansen C. Electromagnetic fields and health effects: epidemiologic studies of cancer, diseases of the central nervous system and arrhythmia-related heart disease. Scand J Work Environ Health. 2004;30(Suppl 1):1-30.

Kalimo R. Psychosocial factors and worker's health: an overview. In: Kalimo R, ElBatawi MA, Cooper CL, editores. Psychosocial factors at work and their relation to the health. Geneva: WHO - W orld Health Organization; 1987. p. 3-8.

Kantorski LP. As transformações no mundo do trabalho e a questão da saúde algumas reflexões preliminares. Rev Latinoam Enfermagem. 1997;5(2):5-15.

Karasek R, Theorell T. Healthy work: stress, productivity, and the reconstruction of working life. USA: Basic Books; 1990. Health, productivity and work life; p. 01-30. 
Karpansalo M, Manninen P, Kauhanen J, Lakka TA, Salonen JT. Perceived health as a predictor of early retirement. Scand J Work Environ Health. 2004;30(4):287-92.

Kelsh MA, Sahl JD. Mortality among a cohort of electric utility workers, 1960-1991. Am J Ind Med. 1997;31:534-44.

Kiss P, Walgraeve M, Vanhoorne M. Assessment of work ability in aging fire fighters by means of the work ability index preliminary results. Arch Public Health. 2002;60:233-43.

Korhonen O. Fitness and work ability. Newsletter of the Finnish Institute [periódico na internet]. 1999 [acesso em 02 mar 2006];1(special issue):22-23. Disponível em: http://www.ttl.fi/Internet/English/Information/Electronic+journals/Tyoterveiset+jour nal/

Laitinen J, Näyhä S, Sovio U, Canoy D, Järvelin MR, Kujala V. Body size and perceived work ability - results from the Northem Finland 1966 and 1986 birth cohorts. In: Proceedings of International Symposium on Youth and Work Culture 2005; 2005; Espoo, Finland. Helsinki: FIOH - Finnish Institute of Occupational Health; 2005. p.1-6.

Laurell AC, Noriega M. Processo de produção e saúde: trabalho e desgaste operário. São Paulo: HUCITEC; 1989. Para o estudo da saúde na sua relação com o processo de produção; p.99-144.

Levi L. Psychosocial environmental factors and psychosocially mediated effects of physical environmental factors. Scand J Work Environ Health. 1997;23(3):47-52.

Levi L. Psychosocial factors, stress and health. In: ILO - International Labour Office. Encyclopedia of occupational health and safety. 4.ed. (enciclopédia na internet). Geneva: ILO; 1998. v.2 part v. chapter 34. subchapter Theories of job stress [acesso em 20 mai 2006]. Disponível em: http://www.ilo.org/encyclopedia/ 
Levi, L Guidance on Work-Related Stress. Spice of Life, or Kiss of Death? Luxembourg: European Commissio; 1999. Part 1 - The background; p. 01-34.

Leyva GV, Elio MN, Arellano OL. La producción de energía eléctrica y la salud de los trabajadores. Salud Trab (Maracay). 2005:13(1):19-36.

Li C-Y, Sung F-C. A review of the healthy worker effect in occupational epidemiology. Occup Med. 1999;(4):225-9.

Lin S, Wang Z, Wang M. Work ability of workers in western China: reference data. Occup Med. 2006;56(2):89-93.

Lindberg P, Vingård E, Josephson M, Alfredsson L. Retaining the ability to work associated factors at work. Eur J Public Health. 2005;(14). Ahead of print.

Locke EA. What is job satisfaction? Organiz Behav Human Perfom. 1969;4(4):30936.

Louhevaara V, Smolander J. Acceptable physical workload: the challenge of work physiology in ergonomics. Newsletter of the Finnish Institute [periódico na internet]. 1997[acesso em 02 mar 2006];2(special issue):20-22. Disponível em: http://www.ttl.fi/Internet/English/Information/Electronic+journals/Tyoterveiset+jour nal/

Louhevaara V, Penttinen J, Tuomi K. Work ability and job demands of aging whiteand blue-collar workers in 1981 and 1996. Exp Aging Res. 1999;25:307-11.

Lundberg O, Manderbacka K. Assessing reliability of a measure of self-rated health. Scand J Soc Med. 1996;24(3):218-224. 
Marcopito LF, Rodrigues SSF, Pacheco MA, Shirassu M, Goldfeder AJ, Moraes MA. Prevalência de alguns fatores de risco para doenças crônicas na cidade de São Paulo. Rev Saúde Pública. 2005;39(5):738-45

Marques ACPR, Ribeiro M. Álcool: abuso e dependência. In: Laranjeira R et al., coordenadores. Usuários de substâncias psicoativas: abordagem, diagnóstico e tratamento. $2^{\mathrm{a}}$ ed. São Paulo: CREMESP - Conselho Regional de Medicina do Estado de São Paulo / AMB - Associação Médica Brasileira. 2002a. p.29-47.

Marques ACPR, Ribeiro M. Nicotina: abuso e dependência. In: Laranjeira R et al., coordenadores. Usuários de substâncias psicoativas: abordagem, diagnóstico e tratamento. $2^{\mathrm{a}}$ ed. São Paulo: CREMESP - Conselho Regional de Medicina do Estado de São Paulo / AMB - Associação Médica Brasileira. 2002b. p.49-62.

Marqueze EC. Satisfação no trabalho e capacidade para o trabalho de docentes de uma instituição de ensino superior [Dissertação de Mestrado]. Tubarão: Universidade do Sul de Santa Catarina; 2005.

Martinez MC. As relações entre a satisfação com aspectos psicossociais no trabalho e a saúde do trabalhador [Dissertação de Mestrado]. São Paulo: Faculdade de Saúde Pública da USP; 2002.

Martinez MC, Latorre MRDO. Fatores de risco para hipertensão arterial e diabetes melito em trabalhadores de empresa metalúrgica e siderúrgica. Arq Bras Cardiol. 2006;87(3). No prelo.

Martins MM. Qualidade de vida e capacidade para o trabalho dos profissionais em enfermagem no trabalho em turnos [Dissertação de Mestrado]. Florianópolis: Faculdade de Engenharia de Produção da UFSC; 2002.

Matsudo SM, Matsudo VKR, Barros Neto TL. Atividade física e envelhecimento: aspectos epidemiológicos. Rev Bras Med Esporte. 2001;7(1): 02-13. 
Matsudo SM, Matsudo VKR, Barros Neto TL, Araújo TL. Evolução do perfil neuromotor e capacidade funcional de mulheres fisicamente ativas de acordo com a idade cronológica. Rev Bras Med Esporte. 2003;9(6):01-12.

Mattos IE, Koifman S. Mortalidade por câncer em trabalhadores de companhia geradora de eletricidade do Estado de São Paulo, Brasil. Rev Saúde Pública. 1996;30(6):564-75.

Mattos IE, Sauaia N, Menezes PR. Padrão de mortalidade por câncer em trabalhadores eletricitários. Cad Saúde Pública. 2002;18(1):221-33.

Mendes R. Patologia do trabalho. Rio de Janeiro: Atheneu; 1995. Detecção dos agravos à saúde relacionados com o trabalho; p. 49-58.

Metzner RJ. Trabalhadores em uma indústria têxtil: um estudo sobre fadiga e capacidade para o trabalho em turnos fixos de 12 horas em semana reduzida [Dissertação de Mestrado]. São Paulo: Faculdade de Saúde Pública da USP, 2000.

Metzner RJ, Fischer FM. Fadiga e capacidade para o trabalho em turnos fixos de doze horas. Rev Saúde Pública. 2001;35(6):548-558.

Monteiro MS. Envelhecimento e capacidade para o trabalho entre trabalhadores brasileiros [Tese de Doutorado]. São Paulo: Faculdade de Saúde Pública da USP; 1999.

MPS - Ministério da Previdência Social. Estatísticas. Anuário Estatístico de Acidentes do Trabalho 2003. Seção II - Indicadores de Acidentes do Trabalho [estatísticas na internet]. Brasília; 2003. [acesso em 06 abr 2005]. Disponível em: URL:http://www.previdenciasocial.gov.br/aeat2003/12_08_01_02.asp 
MS - Ministério da Saúde. Secretaria de Vigilância em Saúde. Secretaria de Atenção à Saúde. Instituo Nacional de Câncer. Coordenação de Prevenção e Vigilância. Inquérito domiciliar sobre comportamentos de risco e morbidade referida de doenças e agravos não transmissíveis: Brasil, 15 capitais e Distrito Federal, 2002-2003. Rio de Janeiro: INCA; 2004.

MTE - Ministério do Trabalho e Emprego. Departamento de Segurança e Saúde no Trabalho. Manual Setor Elétrico e Telefonia [Manual técnico na internet]. Brasília (DF); 2002 [acesso em 04 fev 2005]. Disponível em: http://www.mte.gov.br/Empregador/segsau/Conteudo/969.pdf

Neves DP. Alcoolismo: acusação ou diagnóstico? Cad Saúde Pública. 2004;20(1):736.

Nichols L, Sorahan T. Mortality of UK electricity generation and transmission workers, 1973-2002. Occup Med. 2005;55:541-48.

NIEHS - National Institute of Environmental Health Sciences. 1999 NIEHS Report on Health Effects from Exposure to Power-Line Frequency Electric and Magnetic Fields: technical report [relatório técnico na internet]. North Carolina; 2002 [acesso em 04 fev 2005]. Disponível em: http://www.niehs.nih.gov/emfrapid/html/EMF_DIR_RPT/Report_18f.htm

Nogueira VA. Reestruturação do Setor Elétrico: um estudo qualitativo das condições de trabalho e saúde dos eletricitários frente à privatização da CERJ [Dissertação de Mestrado]. Rio de janeiro: Escola Nacional de Saúde Pública da Fundação Oswaldo Cruz; 1999.

Nurminen E, Malmivaara A, Ilmarinen J, Ylöstalo P, Mutanen P, Ahonen G, et al. Effectiveness of a worksite exercise program with respect to perceived work ability and sick leaves among women with physical work. Scand J Work Environ Health. 2002;28(2):85-93. 
Nygård C-H, Eskelinen L, Suvanto S, Tuomi K, Ilmarinen J. Associations between functional capacity and work ability among elderly municipal employees. Scand J Work Environ Health. 1991;17(Suppl 1):122-27.

OMS - Organisation Mondiale de la Santé. Vieillissement et capacité de travail. Rapport. Genève; 1993. (OMS - rapport d'um Groupe d'étude de l'OMS).

Paschoal T, Tamayo A. Validação da Escala de Estresse no Trabalho. Estud Psicol (Natal). 2004;9(1):45-52.

Paschoal T, Tamayo A. Impacto dos valores laborais e da interferência famíliatrabalho no estresse ocupacional. Psicol Teor Pesqui. 2005;21(2):173-80.

Patarra NL. Mudanças na dinâmica demográfica. In: Monteiro CA, organizador. Velhos e novos males da saúde no Brasil. A evolução do País e de suas doenças. São Paulo: HUCITEC/NUPENS/USP; 1995. p. 61-78.

Pereira JCR. Análise de dados qualitativos: estratégias metodológicas para as ciências da saúde humanas e sociais. São Paulo: EDUSP, 1999.

Perkiö-Mäkelä MM. Finnish farmers' self-reported morbidity, work ability, and functional capacity. Ann Agric Environ Med. 2000;7:11-6.

Pohjonen T. Key components of work ability and how to maintain them. Newsletter of the Finnish Institute [periódico na internet]. 1999 [acesso em 02 mar 2006];1(special issue):4-5. Disponível em: http://www.ttl.fi/Internet/English/Information/Electronic+journals/Tyoterveiset+jour nal/

Pohjonen T. Age-related physical fitness and the predictive values of fitness testes for work ability in home care work. J Occup Environ Med. 2001a;43:723-30. 
Pohjonen T. Perceived work ability of home care workers in relation to individual and work-related factors in different age groups. Occup Med. 2001b;51(3):209-17.

Pohjonen T, Ranta R. Effects of worksite physical exercise intervention on physical fitness, perceived health status, and work ability among home care workers: five-year follow-up. Prev Med. 2001;32:465-75.

Radkiewicz P, Widerszal-Bazyl M. Psychometric properties of work ability index in the light of comparative survey study. International Congress Series. 2005;1280:3049. [Proceedings of the 2nd International Symposium in work ability: assessment and promotion of work ability, health and well-being of ageing workers; 2004; Verona, Italy].

Raffone AM, Hennington EA. Avaliação da capacidade funcional dos trabalhadores de enfermagem. Rev Saúde Pública. 2005;39(4):669-76.

Rigotto RM. Saúde dos trabalhadores e meio ambiente em tempos de globalização e reestruturação produtiva. Rev Bras Saúde Ocup. 1998;93/94(25):9-20.

Rodrigues LOC, Silami-Garcia E, Moreira MCV, Ribeiro GA. Assessment of functional capacity through oxygen consumption in patients with asymptomatic probable heart disease. Arq Bras Cardiol. 1999;73(1):6-10.

Salim CA. Doenças do trabalho: exclusão, segregação e relações de gênero. Sao Paulo Perspec. 2003;17(1):11-24.

Sauter SL, Hurrell Jr JJ, Murphy LR, Levi L. Psychosocial and organizational factors. In: ILO - International Labour Office. Encyclopedia of occupational health and safety. 4.ed. (enciclopédia na internet). Geneva: ILO; 1998. v.2 part v. chapter 34. [acesso em 20 mai 2006]. Disponível em: http://www.ilo.org/encyclopedia/ 
Savinainen M, Nygård C-H, Ilmarinen J. Workload and physical capacity among ageing municipal employees: a 16-year follow-up study. Int $\mathrm{J}$ Ind Ergon. 2004;34:519-33.

SBC - Sociedade Brasileira de Cardiologia. III Diretrizes brasileiras sobre dislipidemias e diretriz de prevenção da aterosclerose do Departamento de Aterosclerose da Sociedade Brasileira de Cardiologia. Arquivos Bras Cardiol. 2001;77 (Supl III).

SBEM - Sociedade Brasileira de Endocrinologia e Metabologia. Sobrepeso e obesidade: diagnóstico. São Paulo/Brasília, BR: AMB - Associação Médica Brasileira / CFM - Conselho Federal de Medicina; 2004. (Projeto Diretrizes).

Segovia Herrera, MLA. Fatores de risco numa empresa eletricitária: uma perspectiva cultural [Dissertação de Mestrado]. Florianópolis: Departamento de Enfermagem da UFSC, 1988.

Seitsamo J, Ilmarinen J. Life-style, aging and work ability among active Finnish workers in 1981-1992. Scand J Work Environ Health. 1997;23(Suppl 1):20-6.

Seitsamo J, Klockars M. Aging and changes in health. Scand J Work Environ Health. 1997;23(Suppl 1):27-35.

Seitsamo J, Martikainen R. Changes in capability in a sample of finnish aging workers. Exp Aging Res. 1999;25:345-52.

Seligmann-Silva E. Desgaste mental no trabalho dominado. São Paulo: Cortez; 1994. O campo da saúde mental no trabalho; p.45-90.

Seligmann-Silva E. Psicopatologia e psicodinâmica no trabalho. In: Mendes R, organizador. Patologia do trabalho. Rio de Janeiro: Atheneu; 1995. p. 545-572. 
Shephard RJ. Age and physical work capacity. Exp Aging Res. 1999;25:331-43.

Silva CJ, Castro LAPG, Laranjeira R. Diagnóstico e tratamento da dependência e uso nocivo de álcool [monografia na internet]. São Paulo: UNIFESP - Universidade Federal de São Paulo. UNIAD - Unidade de pesquisa em Álcool e Drogas; 2004 [acesso em 05 out 2004]. Disponível em: http://www.uniad.org.br/docs/alcool/DiagnosticoeTratamento.pdf

Silva NL. Eletricidade para o médico do trabalho. In: Vieira SI, coordenador. Medicina básica do trabalho. $2^{\text {a }}$ ed. Curitiba: Gênesis; 1996. v.3, p.47-90.

Simão M, Nogueira MS, Hayashida M, Cesarino EJ. Doenças cardiovasculares: perfil de trabalhadores do sexo masculino de uma destilaria do interior paulista. Revista Eletrônica de Enfermagem [periódico na internet]. 2002;4(2):27-35 [acesso em 02 maio 2006]. Disponível em: http://www.fen.ufg.br/Revista/revista4_2/pdf/perfil.pdf

Sjögren-Rönkä T, Ojanen MT, Leskinen EK, Mustalampi ST, Mälkiä EA. Physical and psychosocial prerequisites of functioning in relation to work ability and general subjective well-being among office workers. Scand J Work Environ Health. 2002;28(3):184-90.

Smolander J, Blair SN, Kohl HW. Work ability, physical activity, and cardiorespiratory fitness: 2-year results from project active. J Occup Environ Med. 2000;42(9):906-10.

Spurgeon A, Gompertz D, Harrington JM. Modifiers of non-especific symptoms in occupational and environmental syndromes. Occup Environ Med. 1996;53:361-66.

Sterling TD, Weinkam JJ. The "healthy worker effect" on morbidity rates. J Occup Med. 1985;27(7):477-82. 
Tobia L, Giammaria A, Pizzuti S, Gioia F, Lupi A, Spera G, et al. New dimensions of work ability. International Congress Series. 2005;1280:322-27. [Proceedings of the 2nd International Symposium in work ability: assessment and promotion of work ability, health and well-being of ageing workers; 2004; Verona, Italy].

Tuomi K, Eskelinen L, Toikkanen J, Jarvinen E, Ilmarinen J, Klockars M. Work load and individual factors affecting work ability among aging municipal employees. Scand J Work Environ Health. 1991a;17(Suppl 1):28-34.

Tuomi K, Luostarinen T, Ilmarinen J, Klockars M. Work load and individual factors affecting work disability among aging municipal employees. Scand J Work Environ Health. 1991b;17(Suppl 1):94-8.

Tuomi K, Ilmarinen J, Klockars M, Nygård C-H, Seitsamo J, Huuhtanen P, et al. Finnish research project on aging workers in 1981-1992. Scand J Work Environ Health. 1997a;23(Suppl 1):7-11.

Tuomi K, Ilmarinen J, Martikainen R. Aging, work, life-style and work ability among Finnish municipal workers in 1981-1992. Scand J Work Environ Health. 1997b;23(Suppl 1):58-65.

Tuomi K, Ilmarinen J, Seitsamo J, Huuhtanen P, Martikainen R, Nygård C-H, et al. Summary of the Finnish research project (1981-1992) to promote the health and work ability of aging workers. Scand J Work Environ Health. 1997c;23(Suppl 1):6671.

Tuomi K. Ageing workers and age mix at the workplace. Newsletter of the Finnish Institute [periódico na internet]. 1999[acesso em 02 mar 2006];3(special issue):11-3. Disponível em: http://www.ttl.fi/Internet/English/Information/Electronic+journals/Tyoterveiset+jour nal/ 
Tuomi K, Huuhtanen P, Nykyri E, Ilmarinen J. Promotion of work ability, the quality of work and retirement. Occup Med. 2001;51(5):318-24.

Tuomi K, Vanhala S, Nykyri E, Janhonen M. Organizational practives, work demands and the well-being of employees: a follow-up study in the metal industry and retail trade. Occup med. 2004;54:115-21.

Tuomi K, Ilmarinen J, Jahkola A, Katajarinne L, Tulkki A. Índice de capacidade para o trabalho. Trad. de Fischer FM, coordenador. São Carlos: EDUFSCAR, 2005.

Vargas HS. Repercussões do álcool e do alcoolismo. 2. ed. São Paulo: Fundo Editorial BYK; 1990a. Repercussões orgânicas do alcoolismo; p. 87-115.

Vargas HS. Repercussões do álcool e do alcoolismo. 2. ed. São Paulo: Fundo Editorial BYK; 1990b. Repercussões sociais do alcoolismo; p. 169-182.

Walsh IAP, Corral S, Franco RN, Canetti EEF, Alem MER, Coury HJCG. Capacidade para o trabalho em indivíduos com lesões músculo-esqueléticas crônicas. Rev Saúde Pública. 2004;38(2):149-56.

Ware JE. SF-36 Health Survey Update. SPINE. 2000;25(24):3130-9.

Ware JE, Kosinski M. Interpreting SF-36 Summary Health Measures: a response. Qual Life Res. 2001;10(5):405-13.

Weed DL. Historical roots of the healthy worker effect. Occup Med. 1986;28(5):3437.

Wen CP, Tsai SP, Gibson RL. Anatomy of the healthy worker effect: a critical review. J Occup Med. 1983;25(4):283-9. 
WHO - World Health organization. Healthy living. What is a healthy lifestyle? [monografia na internet]. Copenhagen; 1999 [acesso em 13 jul 2006]. Disponível em: http://www.euro.who.int/document/e66134.pdf

WHO - World Health Organization. Management of substance dependence: screening and brief intervention [informativo na internet]. Geneva; 2003 [acesso em 05 mai 2006].

Disponível

em:

http://www.who.int/substance_abuse/publications/en/SBIFactSheet.pdf

WHO - World Health Organization. What are electromagnetic fields? [monografia na internet]. Geneva; 2005a [acesso em 03 abr 2005]. Disponível em: http://www.who.int/peh-emf/about/WhatisEMF/en

WHO - World Health Organization. Regional Office for Europe. Mental health and working life. WHO European Ministerial Conference on Mental Health [evento na internet]; 2005; Helsinki. Copenhagen: WHO Regional Office for Europe; 2005b [acesso $2 \mathrm{~m} \quad 20 \quad$ ago 2006]. Disponível em http://www.euro.who.int/document/mnh/ebrief06.pdf\#search=\%22\%22mental\%20he alth\%20and\%20working\%20life\%22\%22

WHSC - The Workers Health \& Safety Centre of Ontario. Electrical Hazards: taking charge. Resource Lines [boletim na internet]. 2003 winter [acesso em 04 fev 2005]. Disponível em: http://www.whsc.on.ca/pubs/res_lines.cfm

Wünsch Filho V. Perfil Epidemiológico dos Trabalhadores. Rev Bras Med Trab. 2004;2(2):103-17.

Zahm SH. Epidemiology and statistics. Measuring effects of exposures. In: ILO International Labour Office. Encyclopedia of occupational health and safety. 4.ed. (enciclopédia na internet). Geneva: ILO; 1998. v.1 part iv. chapter 28 [acesso em 20 mai 2006]. Disponível em: http://www.ilo.org/encyclopedia/ 


\section{ANEXOS}




\section{ANEXO 01 \\ TERMO DE CONSENTIMENTO LIVRE E ESCLARECIDO}

Declaro que eu, , concordo em participar voluntariamente de uma ou mais etapas da pesquisa científica sobre capacidade para 0 trabalho, pesquisa esta que tem como objetivo estudar a capacidade para o trabalho e seus fatores determinantes, e que vem sendo realizada sob responsabilidade de MARIA CARMEN MARTINEZ, doutoranda do Departamento de Epidemiologia da Faculdade de Saúde Pública da Universidade de São Paulo.

Estou ciente de que os meus resultados pessoais são confidenciais e que serão utilizados somente para fins de pesquisa. Autorizo a divulgação do resultado individual somente para minha pessoa e o resultado coletivo para divulgação pública.

Estou ciente, também, que tenho liberdade de opção para participar ou não da pesquisa, e que posso a qualquer momento abandonar o estudo, sem qualquer prejuízo pessoal ou do trabalho.

Assinatura

São Paulo, de de 2005 . 
ANEXO 02 - CRONOGRAMA DE TRABALHO

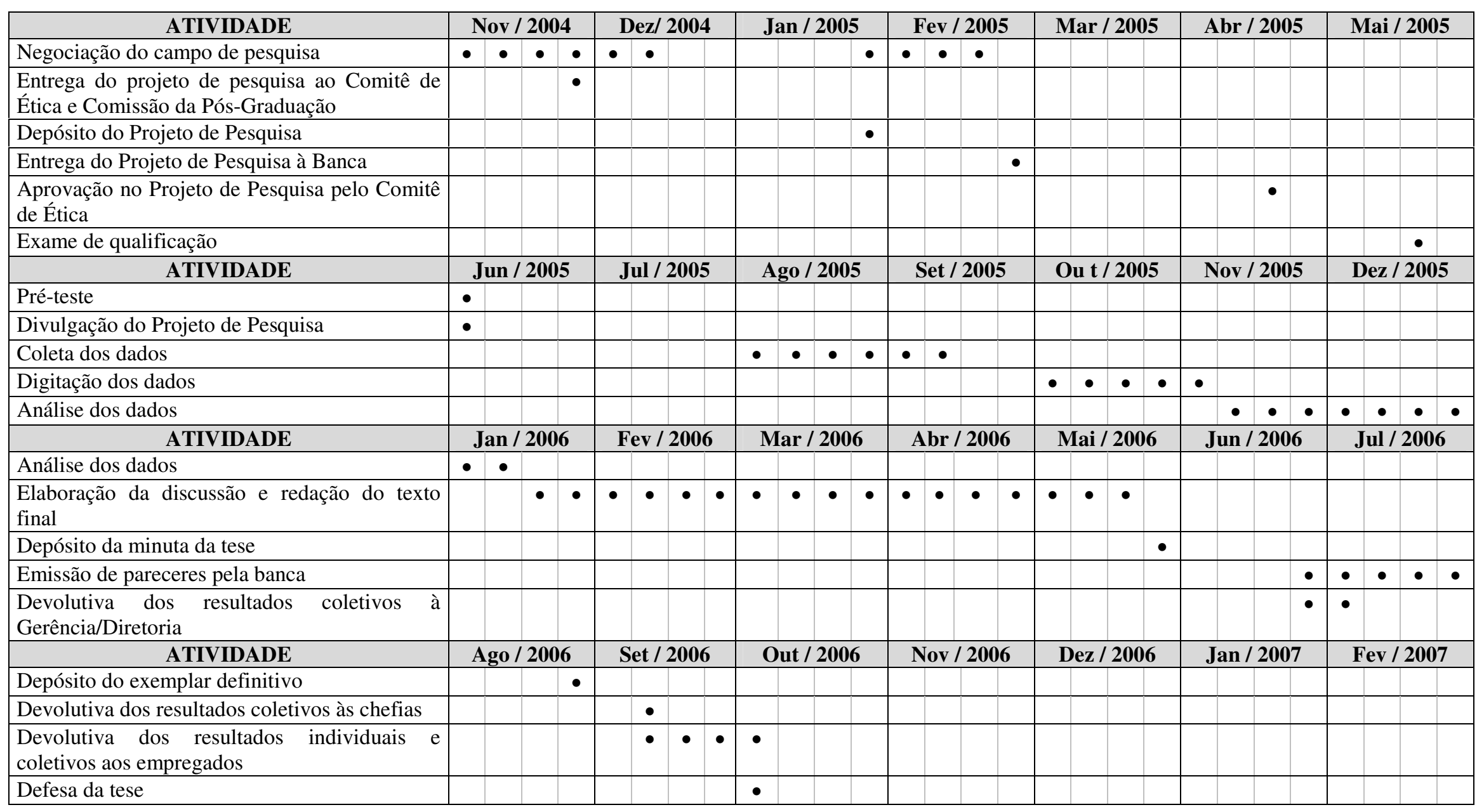




\section{INFORMAÇÕES DEMOGRÁFICAS E FUNCIONAIS}

Os resultados deste questionário serão utilizados na pesquisa "Estudo dos Fatores Associados à Capacidade para o Trabalho em Trabalhadores do Setor Elétrico".

Por favor, responda cuidadosamente todas as questões, não deixando nenhuma em branco.

\section{Código de controle}

\begin{tabular}{|c|c|c|c|}
\hline Sexo: ( ) F-1 & ()$M-2$ & Data de Nascimento: & Idade: \\
\hline
\end{tabular}

Estado civil:

( ) Solteiro(a) -1

( ) Casado(a) ou com companheira(o) - 2

( ) Separado(a) ou divorciado(a) - 3

( ) Viúvo(a) - 4

Turno de trabalho:

( ) Diurno integral - 1

( ) Manhã - 2

( ) Tarde - 3

( ) Noite - 4

Área / Depto. de trabalho: Tempo na empresa:

Profissão:

Cargo atual:

\section{Escolaridade:}

( ) Alfabetizado(a) -

( ) Completou até $4^{a}$ série do ensino fundamental (antigo primário) - 2

( ) Completou até $8^{a}$ série do ensino fundamental (antigo ginasial) - 3

( ) Completou até $3^{\mathrm{a}}$ série do ensino médio (antigo colegial) - 4

( ) Completou $3^{\circ}$ grau (nível universitário) - 5

\section{Faixa salarial:}

( ) Até $\mathrm{R} \$ 1.199,99$ - 1

( ) $R \$ 1.200,00$ até $2.099,99-2$

( ) $\mathrm{R} \$ 2.100,00$ até $3.299,99-3$

( ) $\mathrm{R} \$ 3.300,00$ até $4.799,99-4$

( ) $\mathrm{R} \$ 4.800,00$ até $6.299,99-5$

( ) $\mathrm{R} \$ 6.300,00$ até $7.799,99-6$

( ) $\mathrm{R} \$ 7.800,00$ ou mais - 7 


\section{ANEXO 04 \\ ÍNDICE DE CAPACIDADE PARA O TRABALHO}

Esse questionário foi elaborado pelo Instituto de Saúde Ocupacional da Finlândia, Helsinki; traduzido e adaptado por pesquisadores das seguintes instituições: Faculdade de Saúde Pública da Universidade de São Paulo: Departamento de Saúde Ambiental e Centro de Estudos e Pesquisas sobre o Envelhecimento; Universidade Federal de São Carlos: Departamento de Enfermagem; Fundação Oswaldo Cruz - Escola Nacional de Saúde Pública: Centro de Estudos em Saúde do Trabalhador e Ecologia Humana.

Por favor, responda cuidadosamente a todas as questões, assinalando a alternativa que você acha que melhor reflete a sua. Não deixe nenhuma questão sem responder.

1. Suponha que a sua melhor capacidade para 0 trabalho tem um valor igual a 10 pontos.

Assinale com um $X$ um número na escala de zero a dez, quantos pontos você daria para a sua capacidade trabalho atual.

$\begin{array}{ccccccccccc}0 & 1 & 2 & 3 & 4 & 5 & 6 & 7 & \begin{array}{c}8 \\ \text { Estou em minha melhor } \\ \text { Estou incapaz para o trabalho }\end{array} \\ \text { capacidade para o trabalho }\end{array}$

2. Como você classificaria sua capacidade atual para o trabalho em relação às exigências físicas do seu trabalho? (Por exemplo, fazer esforço físico com partes do corpo).

Muito boa

Boa

Moderada

Baixa

Muito baixa

3. Como você classificaria sua capacidade atual para o trabalho em relação às exigências mentais do seu trabalho? (Por exemplo, interpretar fatos, resolver problemas, decidir a melhor forma de fazer).

Muito boa

Boa

Moderada

Baixa

Muito baixa 
144

4. Na sua opinião quais das lesões por acidentes ou doenças citadas abaixo você possui atualmente. Marque também aquelas que foram confirmadas pelo médico.

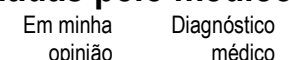

01.Lesão nas costas

02.Lesão nos braços/mãos

03.Lesão nas pernas/pés

04.Lesão em outras partes do corpo .....

Onde? Que tipo de lesão?

05.Doença na parte superior das costas

ou região do pescoço, com dores

freqüentes

06. Doença da parte inferior das costas

com dores freqüentes

07.Dor nas costas que se irradia para a perna (ciática)

08.Doença músculo-esquelética

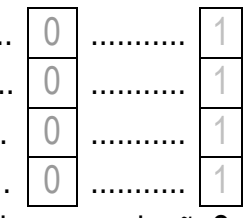

afetando os membros (braços e

pernas) com dores freqüentes

09.Artrite reumatóide

10.Outra doença músculo-esquelética..

Qual?

11.Hipertensão arterial (pressão

alta)..

12.Doença coronariana, dor no peito

durante exercício (angina pectoris)

13.Infarto do miocárdio, trombose

coronariana

14. Insuficiência cardíaca

15.Outra doença cardiovascular

Qual?

16. Infecções repetidas no trato

respiratório (incluindo amigdalite,

Sinusite aguda, bronquite aguda)

17. Bronquite crônica

18.Sinusite crônica

19.Asma

20.Enfisema

21.Tuberculose pulmonar

22. Outra doença respiratória

Qual?

23.Distúrbio emocional severo

(ex.: depressão severa)
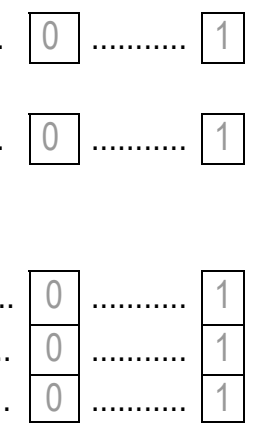

32.Gastrite ou irritação duodenal.

33.Colite ou irritação do cólon

34.Outra doença digestiva.

$$
\begin{array}{rr}
\text { Em minha } & \text { Diagnóstico } \\
\text { opinião } & \text { médico }
\end{array}
$$

26.Doença ou lesão da visão (não

assinale se apenas usa óculos e/ou

lentes de contato de grau).

27.Doença neurológica (acidente

vascular cerebral ou "derrame",

neuralgia, enxaqueca, epilepsia

28. Outra doença neurológica ou dos

órgãos dos sentidos

Qual?

29.Pedras ou doença da vesícula biliar

30. Doença do pâncreas ou do fígado.

31.Úlcera gástrica ou duodenal.

\section{Qual?}

35. Infecção das vias urinárias.

36. Doença dos rins.

37.Doença nos genitais e aparelho

reprodutor (ex.: problemas nas

trompas ou próstata).

38. Outra doença geniturinária

39.Alergia, eczema

40. Outra erupção.

Qual?

41. Outra doença de pele

Qual?

42. Tumor benigno

43.Tumor maligno (câncer)

Onde?

44. Obesidade

45. Diabetes

46. Bócio ou outra doença da tiróide.
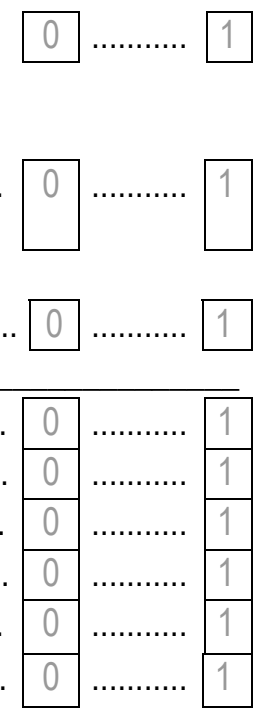

47. Outra doença endócrina ou

metabólica

Qual?

48.Anemia.

49. Outra doença do sangue.

Qual?

50.Defeito de nascimento.

Qual?

(ex.: depressão leva, tensão,

ansiedade, insônia)

25.Problema ou diminuição na audição
51.Outro problema ou doença...

Qual? 
5. Sua lesão ou doença é um impedimento para seu trabalho atual? (Você pode marcar mais de uma resposta nesta pergunta)

Não há impedimento/

Eu não tenho doenças

Eu sou capaz de fazer meu trabalho, mas ele me causa alguns sintomas

Algumas vezes preciso diminuir meu ritmo de trabalho ou mudar meus métodos de trabalho

Freqüentemente preciso diminuir meu ritmo de trabalho ou mudar meus métodos de trabalho.

Por causa de minha doença sinto-me capaz de trabalhar apenas em tempo parcial

Na minha opinião estou totalmente incapacitado para trabalhar

6. Quantos dias inteiros você esteve fora do trabalho devido a problemas de saúde, consulta médica ou para fazer exame durante os últimos 12 meses?

Nenhum

Até 9 dias

De 10 a 24 dias

De 25 a 99 dias

De 100 a 365 dias

7. Considerando sua saúde, você acha que será capaz de daqui a 2 anos fazer seu trabalho atual?

É improvável

Não estou muito certo

Bastante provável
8. Recentemente você tem conseguido apreciar suas atividades diárias?

Sempre

Quase sempre

Às vezes

Raramente

Nunca

9. Recentemente você tem se sentido ativo e alerta?

Sempre

Quase sempre

Às vezes

Raramente

Nunca

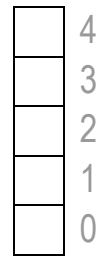

10. Recentemente você tem se sentido cheio de esperança para o futuro?

Continuamente

Quase sempre

Às vezes

Raramente

Nunca
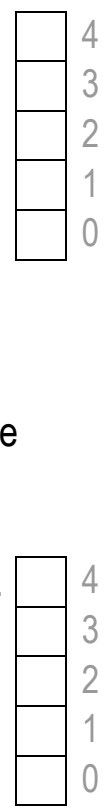


\section{ANEXO 05 \\ ESCALA ESTRESSE NO TRABALHO}

Abaixo estão listadas várias situações que podem ocorrer no dia a dia de seu trabalho. Leia com atenção cada afirmativa e utilize a escala apresentada a seguir para dar sua opinião sobre cada uma delas.

\begin{tabular}{|ccccc|}
\hline 1 & 2 & 3 & 4 & 5 \\
\hline Discordo & Discordo & $\begin{array}{c}\text { Concordo em } \\
\text { parte }\end{array}$ & Concordo & $\begin{array}{c}\text { Concordo } \\
\text { Totalmente }\end{array}$ \\
& & & & \\
\hline
\end{tabular}

\section{Para cada item, marque o número que melhor corresponde à sua resposta.}

- Ao marcar o número 1 você indica discordar totalmente da afirmativa.

- Assinalando o número 5 você indica concordar totalmente com a afirmativa.

- Observe que quanto menor o número, mais você discorda da afirmativa e quanto maior 0 número, mais você concorda com a afirmativa.

\begin{tabular}{|c|c|c|c|c|c|}
\hline 1. A forma como as tarefas são distribuídas em minha área tem me deixado nervoso & 1 & 2 & 3 & 4 & 5 \\
\hline 2. O tipo de controle existente em meu trabalho me irrita & 1 & 2 & 3 & 4 & 5 \\
\hline 3. A falta de autonomia na execução do meu trabalho tem sido desgastante & 1 & 2 & 3 & 4 & 5 \\
\hline $\begin{array}{l}\text { 4. Tenho me sentido incomodado com a falta de confiança de meu superior sobre o meu } \\
\text { trabalho }\end{array}$ & 1 & 2 & 3 & 4 & 5 \\
\hline $\begin{array}{l}\text { 5. Sinto-me irritado com a deficiência na divulgação de informações sobre decisões } \\
\text { organizacionais }\end{array}$ & 1 & 2 & 3 & 4 & 5 \\
\hline 6. Sinto-me incomodado com a falta de informações sobre minhas tarefas no trabalho & 1 & 2 & 3 & 4 & 5 \\
\hline 7. A falta de comunicação entre mim e meus colegas de trabalho deixa-me irritado & 1 & 2 & 3 & 4 & 5 \\
\hline 8. Sinto-me incomodado por meu superior tratar-me mal na frente de colegas de trabalho & 1 & 2 & 3 & 4 & 5 \\
\hline 9. Sinto-me incomodado por ter que realizar tarefas que estão além de minha capacidade & 1 & 2 & 3 & 4 & 5 \\
\hline 10. Fico de mau humor por ter que trabalhar durante muitas horas seguidas & 1 & 2 & 3 & 4 & 5 \\
\hline 11. Sinto-me incomodado com a comunicação existente entre mim e meu superior & 1 & 2 & 3 & 4 & 5 \\
\hline 12. Fico irritado com discriminação/favoritismo no meu ambiente de trabalho & 1 & 2 & 3 & 4 & 5 \\
\hline $\begin{array}{l}\text { 13. Tenho me sentido incomodado com a deficiência nos treinamentos para capacitação } \\
\text { profissional }\end{array}$ & 1 & 2 & 3 & 4 & 5 \\
\hline 14. Fico de mau humor por me sentir isolado na organização & 1 & 2 & 3 & 4 & 5 \\
\hline 15. Fico irritado por ser pouco valorizado por meus superiores & 1 & 2 & 3 & 4 & 5 \\
\hline 16. As poucas perspectivas de crescimento na carreira têm me deixado angustiado & 1 & 2 & 3 & 4 & 5 \\
\hline 17. Tenho me sentido incomodado por trabalhar em tarefas abaixo do meu nível de habilidade & 1 & 2 & 3 & 4 & 5 \\
\hline 18. A competição no meu ambiente de trabalho tem me deixado de mau humor & 1 & 2 & 3 & 4 & 5 \\
\hline $\begin{array}{l}\text { 19. A falta de compreensão sobre quais são minhas responsabilidades neste trabalho tem } \\
\text { causado irritação }\end{array}$ & 1 & 2 & 3 & 4 & 5 \\
\hline 20. Tenho estado nervoso por meu superior me dar ordens contraditórias & 1 & 2 & 3 & 4 & 5 \\
\hline $\begin{array}{l}\text { 21. Sinto-me irritado por meu superior encobrir meu trabalho bem feito diante de outras } \\
\text { pessoas }\end{array}$ & 1 & 2 & 3 & 4 & 5 \\
\hline 22. O tempo insuficiente para realizar meu volume de trabalho deixa-me nervoso & 1 & 2 & 3 & 4 & 5 \\
\hline 23. Fico incomodado por meu superior evitar me incumbir de responsabilidades in & 1 & 2 & 3 & 4 & 5 \\
\hline
\end{tabular}




\section{ANEXO 06 \\ ESTADO DE SAÚDE \\ (Medical Outcomes Study 36 - Item short form health survey - SF-36)}

Instruções: Esta parte da pesquisa questiona você sobre sua saúde. Estas informações nos manterão informados de como você se sente e quão bem você é capaz de fazer suas atividades de vida diária. Responda cada questão marcando a resposta como indicado. Caso você esteja inseguro em como responder, por favor tente responder o melhor que puder.

1. Em geral, você diria que sua saúde é:

(circule uma)

Excelente

Muito boa

Boa

Ruim

Muito ruim

2. Comparada a um ano atrás, como você classificaria sua saúde em geral, agora?

Muito melhor agora do que há um ano atrás

Um pouco melhor agora do que há um ano atrás

Quase a mesma de um ano atrás

Um pouco pior agora do que há um ano atrás 
3. Os seguintes itens são sobre atividades que você poderia fazer atualmente durante um dia comum. Devido a sua saúde, você tem dificuldade para fazer essas atividades? Neste caso, quanto?

\begin{tabular}{l|c|c|c}
\hline \multicolumn{1}{c|}{ Atividades } & $\begin{array}{c}\text { Sim. } \\
\text { Dificulta } \\
\text { muito }\end{array}$ & $\begin{array}{c}\text { Sim. } \\
\text { Dificulta um } \\
\text { pouco }\end{array}$ & $\begin{array}{c}\text { Não. Não } \\
\text { dificulta de } \\
\text { modo algum }\end{array}$ \\
\hline a) Atividades vigorosas, que exigem muito esforço, tais \\
como correr, levantar objetos pesados, participar em \\
esportes árduos
\end{tabular}


4. Durante as últimas 4 semanas, você teve algum dos seguintes problemas com o seu trabalho ou com alguma atividade diária regular, como conseqüência de sua saúde física?

(circule uma em cada linha)

\begin{tabular}{l|c|c}
\hline & Sim & Não \\
\hline a) Você diminuiu a quantidade de tempo que se dedicava ao seu & 1 & 2 \\
trabalho ou a outras atividades? & & \\
\hline b) Realizou menos tarefas do que você gostaria? & 1 & 2 \\
\hline c) Esteve limitado no seu tipo de trabalho ou em outras atividades? & 1 & 2 \\
\hline d) Teve dificuldade de fazer seu trabalho ou outras atividades (p.ex.: & 1 & 2 \\
& & \\
\hline
\end{tabular}

5. Durante as últimas 4 semanas, você teve algum dos seguintes problemas com o seu trabalho ou outra atividade regular diária, como conseqüência de algum problema emocional (como se sentir deprimido ou ansioso)?

(circule uma em cada linha)

\begin{tabular}{l|c|c}
\hline & Sim & Não \\
\hline a) Você diminuiu a quantidade de tempo que dedicava ao seu \\
trabalho ou a outras atividades?
\end{tabular}


6. Durante as últimas 4 semanas, de que maneira sua saúde física ou problemas emocionais interferiram nas suas atividades sociais normais, em relação a família, vizinhos, amigos ou em grupo?

De forma nenhuma

(circule uma)

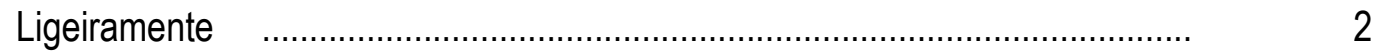

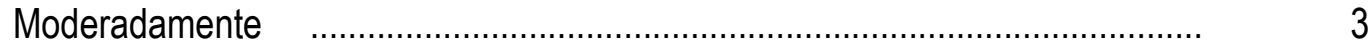

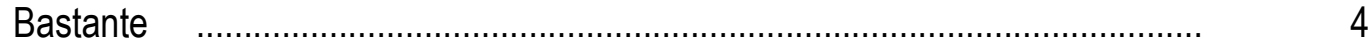

Extremamente $\quad$........................................................................................

7. Quanta dor no corpo você teve durante as últimas 4 semanas?

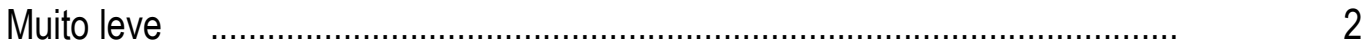

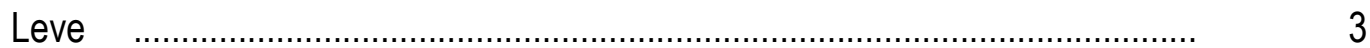

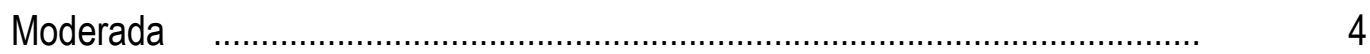

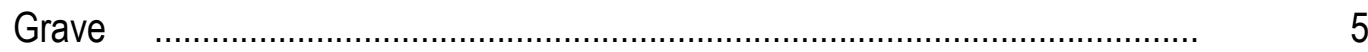

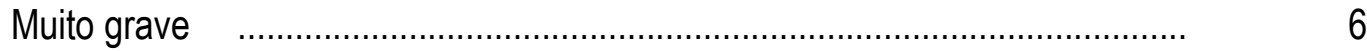

8. Durante as últimas 4 semanas, quanto a dor interferiu com o seu trabalho normal (incluindo tanto o trabalho fora de casa como dentro de casa)?

De maneira alguma

(circule uma)
...

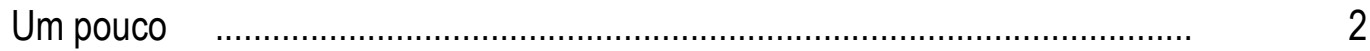

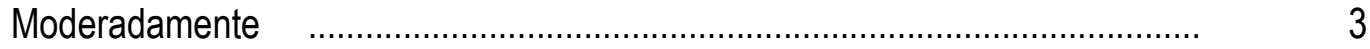

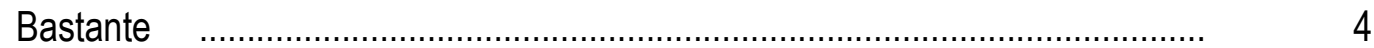

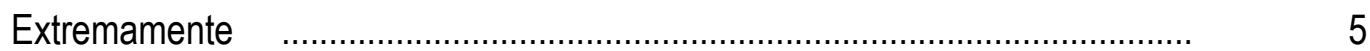


9. Estas questões são sobre como você se sente e como tudo tem acontecido com você durante as últimas 4 semanas. Para cada questão, por favor dê uma resposta que mais se aproxime da maneira como você se sente. Em relação as últimas 4 semanas.

(circule um número para cada linha)

\begin{tabular}{|c|c|c|c|c|c|c|c|}
\hline & & $\begin{array}{l}\text { Todo } \\
\text { tempo }\end{array}$ & $\begin{array}{l}\text { A maior } \\
\text { parte do } \\
\text { tempo }\end{array}$ & $\begin{array}{l}\text { Uma boa } \\
\text { parte to } \\
\text { tempo }\end{array}$ & $\begin{array}{l}\text { Alguma } \\
\text { parte do } \\
\text { tempo }\end{array}$ & $\begin{array}{l}\text { Uma } \\
\text { pequena } \\
\text { parte do } \\
\text { tempo }\end{array}$ & Nunca \\
\hline & $\begin{array}{l}\text { Quanto tempo você tem se } \\
\text { sentido cheio de vigor, cheio de } \\
\text { vontade, cheio de força? }\end{array}$ & 1 & 2 & 3 & 4 & 5 & 6 \\
\hline & $\begin{array}{l}\text { Quanto tempo você tem se } \\
\text { sentido uma pessoa muito } \\
\text { nervosa? }\end{array}$ & 1 & 2 & 3 & 4 & 5 & 6 \\
\hline & $\begin{array}{l}\text { Quanto tempo você tem se } \\
\text { sentido tão deprimido que nada } \\
\text { pode } \llbracket \text { nima-lo? }\end{array}$ & 1 & 2 & 3 & 4 & 5 & 6 \\
\hline d) & $\begin{array}{l}\text { Quanto tempo você tem se } \\
\text { sentido calmo ou tranqüilo? }\end{array}$ & 1 & 2 & 3 & 4 & 5 & 6 \\
\hline e) & $\begin{array}{l}\text { Quanto tempo você tem se } \\
\text { sentido com muita energia? }\end{array}$ & 1 & 2 & 3 & 4 & 5 & 6 \\
\hline & $\begin{array}{l}\text { Quanto tempo você tem se } \\
\text { sentido desanimado e abatido? }\end{array}$ & 1 & 2 & 3 & 4 & 5 & 6 \\
\hline & $\begin{array}{l}\text { Quanto tempo você tem se } \\
\text { sentido esgotado? }\end{array}$ & 1 & 2 & 3 & 4 & 5 & 6 \\
\hline & $\begin{array}{l}\text { Quanto tempo você tem se } \\
\text { sentido uma pessoa feliz? }\end{array}$ & 1 & 2 & 3 & 4 & 5 & 6 \\
\hline & $\begin{array}{l}\text { Quanto tempo você tem se } \\
\text { sentido cansado? }\end{array}$ & 1 & 2 & 3 & 4 & 5 & 6 \\
\hline
\end{tabular}


10. Durante as últimas 4 semanas, quanto do seu tempo a sua saúde física ou problemas emocionais interferiram com as suas atividades sociais (como visitar amigos, parentes, etc.)?

(circule uma)

Todo o tempo .....................................................................................

A maior parte do tempo

Alguma parte do tempo

Uma pequena parte do tempo

Nenhuma parte do tempo $\quad$................................................................

11. o quanto verdadeiro ou falso é cada uma das afirmações para você?

(circule um número em cada linha)

\begin{tabular}{l|c|c|c|c|c}
\hline & $\begin{array}{c}\text { Definitiva- } \\
\text { mente } \\
\text { verdadeira }\end{array}$ & $\begin{array}{c}\text { A maioria das } \\
\text { vezes } \\
\text { verdadeira }\end{array}$ & Não sei & $\begin{array}{c}\text { A maioria das } \\
\text { vezes falsa }\end{array}$ & $\begin{array}{c}\text { Definitiva- } \\
\text { mente falsa }\end{array}$ \\
\hline $\begin{array}{l}\text { a) Eu costumo adoecer um } \\
\text { pouco mais facilmente } \\
\text { que as outras pessoas }\end{array}$ & 1 & 2 & 3 & 4 & 5 \\
\hline b) Eu sou tão saudável \\
$\begin{array}{l}\text { quanto qualquer pessoa } \\
\text { que eu conheço }\end{array}$ & 1 & 2 & 3 & 4 & 5 \\
\hline c) Eu acho que a minha & 1 & 2 & 3 & 4 & 5 \\
\hline saúde vai piorar & 1 & 2 & 3 & 4 & 5 \\
\hline
\end{tabular}




\section{PRÁTICA DE ATIVIDADE FÍSICA - QUESTIONÁRIO DE BAECKE}

\section{Por favor, assinale a resposta apropriada para cada questão.}

\section{Nos últimos 12 meses:}

1) Qual tem sido sua principal ocupação (cargo / profissão)?

2) No trabalho eu sento:
( ) nunca-1
) raramente -2
( ) algumas vezes -3
( ) freqüentemente -4
( ) sempre -5

3) No trabalho eu fico em pé:
( ) nunca-1
( ) raramente -2
( ) algumas vezes -3
( ) freqüentemente -4
( ) sempre -5

4) No trabalho eu ando:
( ) nunca -1
( ) raramente -2
( ) algumas vezes -3
( ) freqüentemente -4
( ) sempre -5

5) No trabalho eu carrego carga pesada:
( ) nunca-1
( ) raramente -2
( ) algumas vezes -3
( ) freqüentemente -4
( ) sempre -5

6) Após o trabalho eu estou cansado:
( ) muito freqüentemente -5
( ) freqüentemente -4
( ) algumas vezes-3
() raramente -2
( ) Nunca-1

7) No trabalho eu suo:

$\begin{array}{lllll}\text { ( ) muito freqüentemente }-5 \quad \text { ( ) freqüentemente }-4 \quad \text { ( ) algumas vezes-3 ( ) raramente -2 } & \text { ( ) Nunca -1 }\end{array}$

8) Em comparação com outros da minha idade eu penso que meu trabalho é fisicamente:
( ) muito mais pesado-5
( ) mais pesado-4
( ) tão pesado quanto -3
( ) mais leve-2
( ) Muito mais leve -1

9) Você pratica ou praticou esporte ou exercício físico nos últimos 12 meses? （） Sim -1 （） Não -2

Qual esporte ou exercício físico você pratica ou praticou mais freqüentemente?
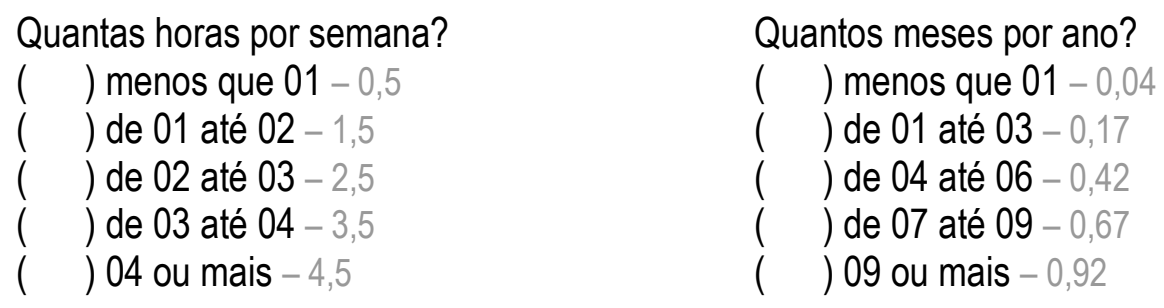
Se você faz ou fez um segundo esporte ou exercício físico, qual o tipo?
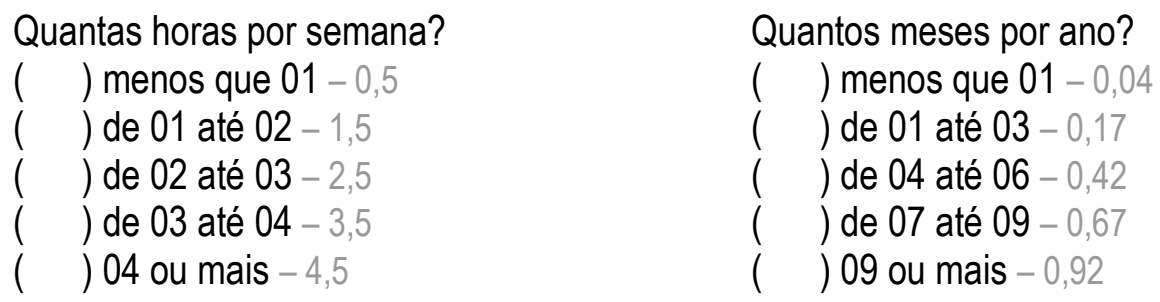

10) Em comparação com outros da minha idade eu penso que minha atividade física durante as horas de lazer é:
( ) muito maior -5
( ) Maior -4
( ) a mesma -3
( ) Menor -2
( ) muito menor -1

11) Durante as horas de lazer eu suo:
( ) muito freqüentemente -5
( ) freqüentemente -4
( ) algumas vezes-3
( ) raramente -2 ( ) Nunca-1

12) Durante as horas de lazer eu pratico esporte ou exercício físico:
( ) nunca -
) raramente -2
) algumas vezes -3
( ) freqüentemente -4
( ) Muito freqüentemente -5

13) Durante as horas de lazer eu vejo televisão:
( ) nunca -
) raramente -2
) algumas vezes -3
( ) freqüentemente -4
( ) Muito freqüentemente -5

14) Durante as horas de lazer eu ando:
( ) nunca -
) raramente -2
) algumas vezes -3
( ) freqüentemente -4
( ) Muito freqüentemente -5

15) Durante as horas de lazer eu ando de bicicleta:

$\begin{array}{llllll}\text { ( ) nunca }-1 & (\text { ( ) raramente }-2 & \text { ( ) algumas vezes }-3 & \text { ( ) freqüentemente }-4 & \text { ( ) Muito freqüentemente }-5\end{array}$

16) Durante quantos minutos por dia você anda a pé ou de bicicleta indo ou voltando do trabalho, escola ou compras?

( ) menos que $5-1$

( ) 5 a $15-2$

( ) 16 a $30-3$

( ) 31 a $45-4$

( ) mais que $45-5$

Total em minutos minutos 


\section{ANEXO 08 \\ TABAGISMO - QUESTIONÁRIO DE TOLERÂNCIA DE FAGERSTRÖM}

Você fuma?

( ) Não, nunca fumei -0
( ) Não, mas já fumei -1
( ) Sim - 2

Se você é fumante, por favor, responda às questões a seguir:

Quantos cigarros você fuma por dia?

cigarros

Há quantos anos você é fumante?

anos

1) Quanto tempo após acordar você fuma seu primeiro cigarro?

- Dentro de 5 minutos

( ) -3

- Entre 6 e 30 minutos

( ) -2

- Entre 31 e 60 minutos

- Após 60 minutos

2) Você acha difícil não fumar em lugares proibidos como igrejas, bibliotecas, etc.?

- Sim

( ) -1

- Não

3) Qual cigarro do dia que traz mais satisfação (ou que mais detestaria deixar de fumar)?

- O primeiro da manhã

- Outros

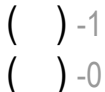

4) Quantos cigarros você fuma por dia?

- 10 ou menos

- $\quad 11$ a 21

- 21 a 30

- 31 ou mais

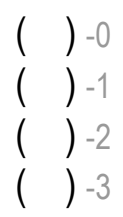

5) Você fuma mais freqüentemente pela manhã (ou nas primeiras horas do dia) que no resto do dia?
- Sim
- Não

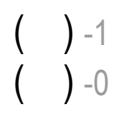

6) Você fuma mesmo quando está tão doente que precisa ficar de cama a maior parte do tempo?
- Sim
- Não 


\section{ANEXO 09 \\ CONSUMO DE BEBIDA ALCOÓLICA QUESTIONÁRIO AUDIT}

1) Qual a freqüência do seu consumo de bebida alcoólica?

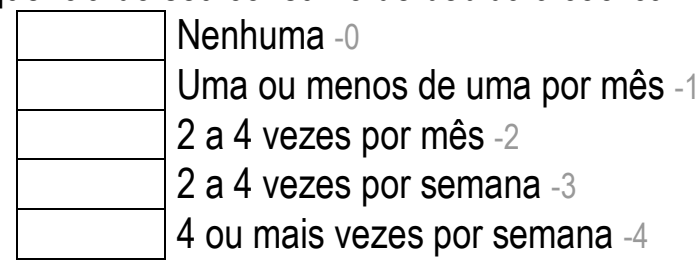

2) Quantas doses você consome num dia típico quando você está bebendo?

\begin{tabular}{|l|l|}
\hline & Nenhuma -0 \\
1 & ou $2-1$ \\
3 & ou $4-2$ \\
5 & ou $6-3$ \\
7 & ou $9-4$ \\
10 & ou mais -5
\end{tabular}

3) Qual a freqüência que você consome 6 ou mais doses numa ocasião?

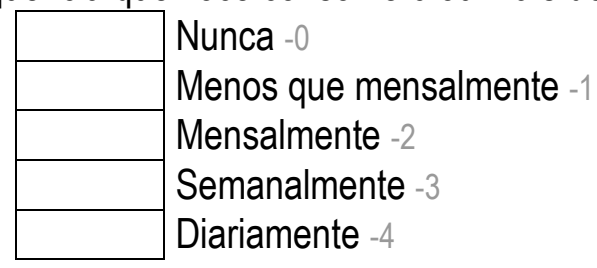

4) Com que freqüência nos últimos doze meses, você percebeu que não conseguia parar de beber uma vez que havia começado?

\begin{tabular}{|l|l|}
\hline & Nunca -0 \\
\hline & Menos que mensalmente -1 \\
& Mensalmente -2 \\
& Semanalmente -3 \\
& Diariamente -4
\end{tabular}


5) Quantas vezes nos últimos 12 meses você deixou de fazer o que era esperado devido ao uso de bebida alcoólica?

\begin{tabular}{|l|l|}
\hline & Nunca -0 \\
\hline & Menos que mensalmente -1 \\
& Mensalmente -2 \\
& Semanalmente -3 \\
& Diariamente -4
\end{tabular}

6) Quantas vezes no último mês você precisou de uma dose pela manhã para se sentir melhor depois de uma bebedeira?

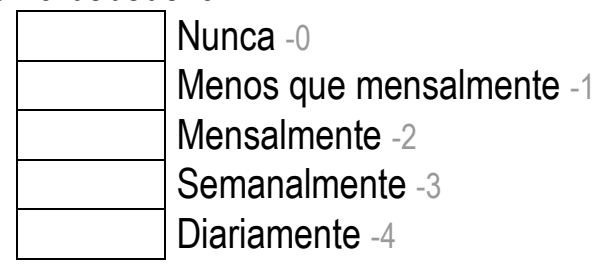

7) Quantas vezes nos últimos doze meses você se sentiu culpado ou com remorsos depois de beber?

\begin{tabular}{|l|l|}
\hline & Nunca -0 \\
\hline & Menos que mensalmente -1 \\
& Mensalmente -2 \\
& Semanalmente -3 \\
& Diariamente -4
\end{tabular}

8) Quantas vezes nos últimos doze meses você esqueceu o que aconteceu na noite anterior porque estava bebendo?

\begin{tabular}{|l|l|}
\hline & Nunca -0 \\
\hline & Menos que mensalmente -1 \\
& Mensalmente -2 \\
& Semanalmente -3 \\
& Diariamente -4
\end{tabular}

9) Você já foi criticado pelos resultados de suas bebedeiras?

\begin{tabular}{|l|l|}
\hline & Nunca -0 \\
\hline & Menos que mensalmente -1 \\
\hline & Mensalmente -2 \\
& Semanalmente -3 \\
& Diariamente -4
\end{tabular}

10) Algum parente, amigo ou medido ou outro profissional da saúde referiu-se às suas bebedeiras ou sugeriu a você parar de beber?

\begin{tabular}{|l|l}
\hline & Nunca -0 \\
\hline & Menos que mensalmente -1 \\
& Mensalmente -2 \\
& Semanalmente -3 \\
& Diariamente -4
\end{tabular}




\section{Anexo 10}

\section{PARECER DO COMITÊ DE ÉTICA DE APROVAÇÃO DA PESQUISA}

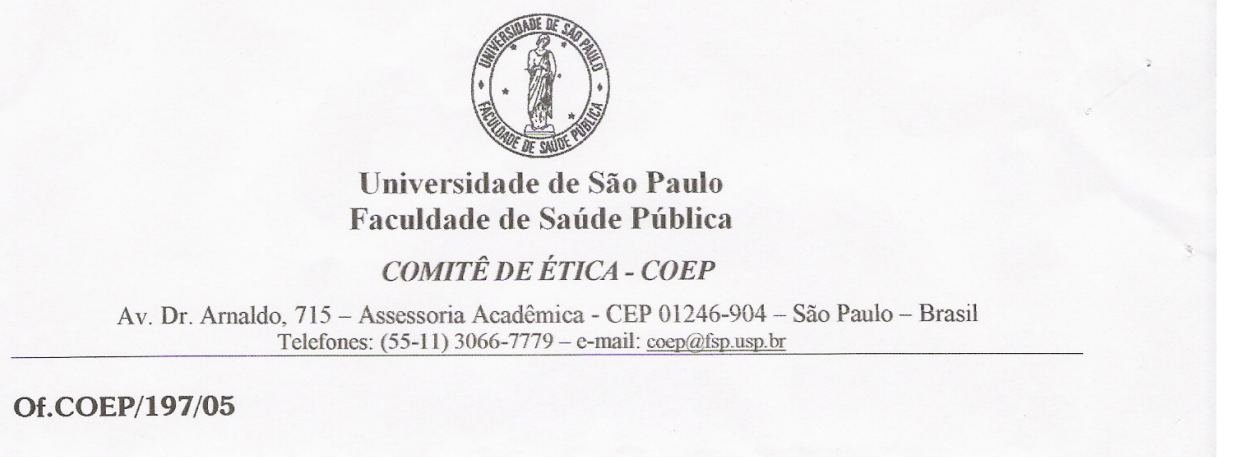

21 de setembro de 2005

Pelo presente, informo que o Comitê de Ética em Pesquisa da Faculdade de Saúde Pública da Universidade de São Paulo-COEP aprovou em sua 8. \%o5 Sessão Ordinária, realizada em 19.10 .05 e de acordo com os requisitos da Resolução CNS/196/96 e suas complementares, o adendo sobre as alterações no Protocolo de Pesquisa n. ${ }^{\circ}$ 1300, intitulado: "ESTUDO DOS FATORES ASSOCIADOS À CAPACIDADE PARA O TRABALHO”, apresentado pela pesquisadora Maria Carmen Martinez.

Atenciosamente,

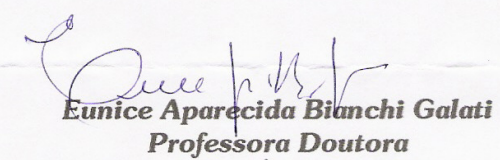

Coordenadora do Comitê de Ética em Pesquisa da FSP-COEP 


\section{Anexo 11}

\section{ANÁLISE DACONFIABILIDADE DOS QUESTIONÁRIOS}

Tabela A: Valores do Coeficiente alpha de Cronbach do Questionário de Tolerância de Fagerström, Campinas e região, 2005.

\begin{tabular}{c|c}
\hline Item & $\begin{array}{c}\text { Alpha de Cronbach se o item } \\
\text { for excluído }\end{array}$ \\
\hline 1 & 0,60 \\
2 & 0,69 \\
3 & 0,63 \\
4 & 0,58 \\
5 & 0,68 \\
6 & 0,67 \\
\hline $\begin{array}{c}\text { Dependência ao tabaco } \\
\text { (escore total) }\end{array}$ & $\mathbf{0 , 6 9}$ \\
\hline
\end{tabular}

Tabela B: Valores do Coeficiente alpha de Cronbach do Questionário AUDIT, Campinas e região, 2005.

\begin{tabular}{c|c}
\hline Item & $\begin{array}{c}\text { Alpha de Cronbach se o item } \\
\text { for excluído }\end{array}$ \\
\hline 1 & 0,75 \\
2 & 0,75 \\
3 & 0,73 \\
4 & 0,77 \\
5 & 0,78 \\
6 & 0,79 \\
7 & 0,78 \\
8 & 0,78 \\
9 & 0,77 \\
10 & 0,77 \\
\hline Dependência ao álcool \\
(escore total)
\end{tabular}


Tabela C: Valores do Coeficiente alpha de Cronbach do Questionário de Baecke,

Campinas e região, 2005.

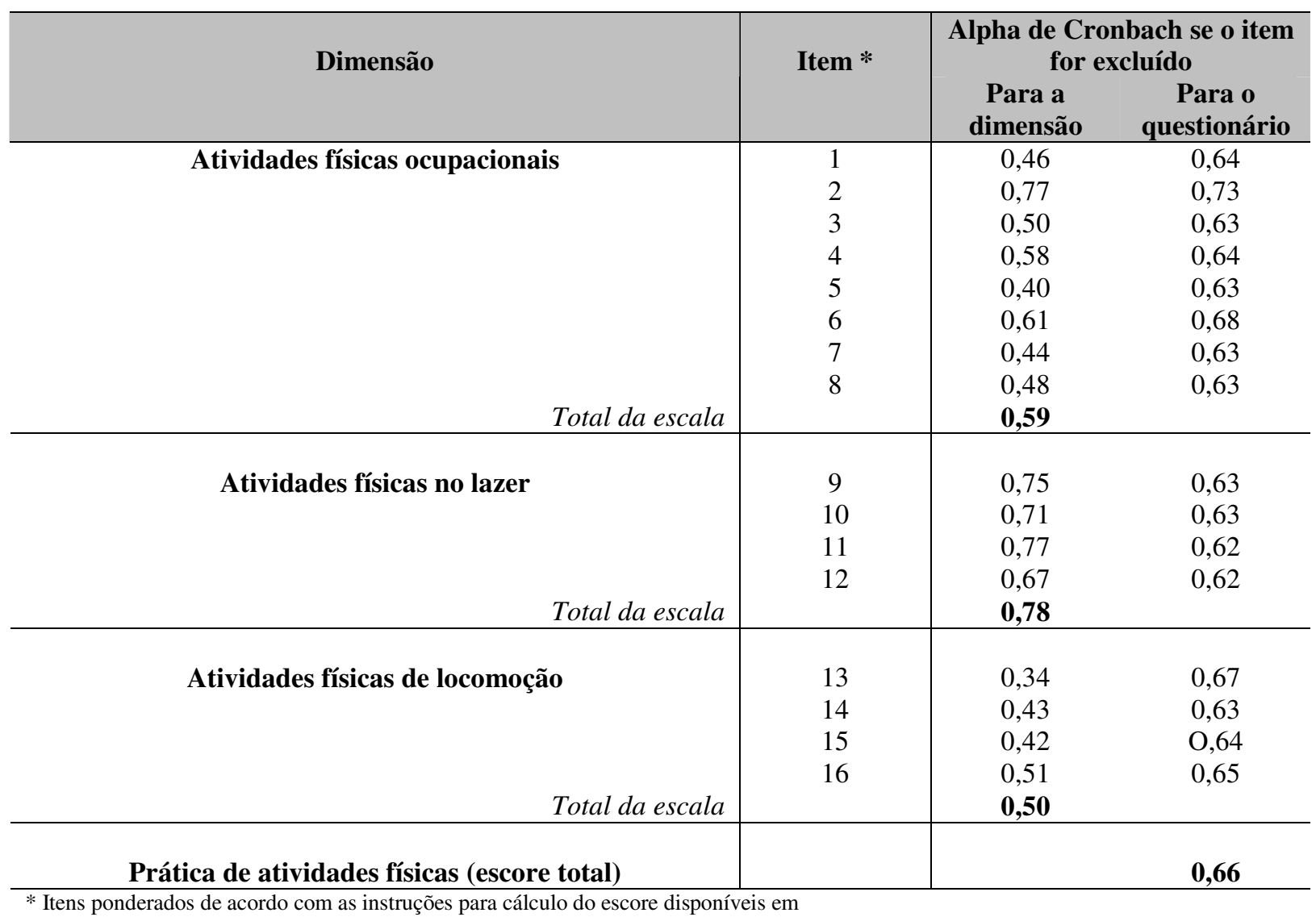
FLORINDO e LATORRE (2003) e FLORINDO et al. (2004). 
Tabela D: Valores do Coeficiente alpha de Cronbach da Escala Estresse no Trabalho, Campinas e região, 2005.

\begin{tabular}{|c|c|}
\hline Fonte de estresse & $\begin{array}{c}\text { Alpha de } \\
\text { Cronbach } \\
\text { se o item } \\
\text { for excluído } \\
\end{array}$ \\
\hline 1. A forma como as tarefas são distribuídas em minha área tem me deixado nervoso & 0,94 \\
\hline 2. O tipo de controle existente em meu trabalho me irrita & 0,94 \\
\hline 3. A falta de autonomia na execução do meu trabalho tem sido desgastante & 0,94 \\
\hline 4. Tenho me sentido incomodado com a falta de confiança de meu superior sobre o meu trabalho & 0,94 \\
\hline $\begin{array}{l}\text { 5. Sinto-me irritado com a deficiência na divulgação de informações sobre decisões } \\
\text { organizacionais }\end{array}$ & 0,94 \\
\hline 6. Sinto-me incomodado com a falta de informações sobre minhas tarefas no trabalho & 0,94 \\
\hline 7. A falta de comunicação entre mim e meus colegas de trabalho deixa-me irritado & 0,94 \\
\hline 8. Sinto-me incomodado por meu superior tratar-me mal na frente de colegas de trabalho & 0,94 \\
\hline 9. Sinto-me incomodado por ter que realizar tarefas que estão além de minha capacidade & 0,94 \\
\hline 10. Fico de mau humor por ter que trabalhar durante muitas horas seguidas & 0,94 \\
\hline 11. Sinto-me incomodado com a comunicação existente entre mim e meu superior & 0,93 \\
\hline 12. Fico irritado com discriminação/favoritismo no meu ambiente de trabalho & 0,93 \\
\hline $\begin{array}{l}\text { 13. Tenho me sentido incomodado com a deficiência nos treinamentos para capacitação } \\
\text { profissional }\end{array}$ & 0,94 \\
\hline 14. Fico de mau humor por me sentir isolado na organização & 0,93 \\
\hline 15. Fico irritado por ser pouco valorizado por meus superiores & 0,93 \\
\hline 16. As poucas perspectivas de crescimento na carreira têm me deixado angustiado & 0,94 \\
\hline 17. Tenho me sentido incomodado por trabalhar em tarefas abaixo do meu nível de habilidade & 0,94 \\
\hline 18. A competição no meu ambiente de trabalho tem me deixado de mau humor & 0,94 \\
\hline $\begin{array}{l}\text { 19. A falta de compreensão sobre quais são minhas responsabilidades neste trabalho tem causado } \\
\text { irritação }\end{array}$ & 0,94 \\
\hline 20. Tenho estado nervoso por meu superior me dar ordens contraditórias & 0,94 \\
\hline 21. Sinto-me irritado por meu superior encobrir meu trabalho bem feito diante de outras pessoas & 0,93 \\
\hline 22. O tempo insuficiente para realizar meu volume de trabalho deixa-me nervoso & 0,94 \\
\hline 23. Fico incomodado por meu superior evitar me incumbir de responsabilidades importantes & 0,94 \\
\hline Estresse no trabalho (escore total) & $\mathbf{0 , 9 4}$ \\
\hline
\end{tabular}


Tabela E: Valores do Coeficiente alpha de Cronbach do Questionário SF-36, segundo item excluído para cada dimensão em cada componente (saúde física e saúde mental),

Campinas e região, 2005.

\begin{tabular}{|c|c|c|c|c|c|}
\hline $\begin{array}{l}\text { Componente } \\
\text { Saúde Física }\end{array}$ & Item * & $\begin{array}{c}\text { Alpha de } \\
\text { Cronbach } \\
\text { se o item for } \\
\text { excluído }\end{array}$ & $\begin{array}{l}\text { Componente } \\
\text { Saúde Mental }\end{array}$ & Item * & $\begin{array}{c}\text { Alpha de } \\
\text { Cronbach se } \\
\text { o item for } \\
\text { excluído } \\
\end{array}$ \\
\hline Capacidade funcional & $\begin{array}{c}3 \mathrm{a} \\
3 \mathrm{~b} \\
3 \mathrm{c} \\
3 \mathrm{~d} \\
3 \mathrm{e} \\
3 \mathrm{f} \\
3 \mathrm{~g} \\
3 \mathrm{~h} \\
3 \mathrm{i} \\
3 \mathrm{j} \\
\text { a dimensão }\end{array}$ & $\begin{array}{l}0,87 \\
0,83 \\
0,83 \\
0,82 \\
0,84 \\
0,84 \\
0,82 \\
0,82 \\
0,84 \\
0,84 \\
\mathbf{0 , 8 5} \\
\end{array}$ & Vitalidade & $\begin{array}{c}9 \mathrm{a} \\
9 \mathrm{e} \\
9 \mathrm{~g} \\
9 \mathrm{i} \\
\text { Total da dimensão }\end{array}$ & $\begin{array}{l}0,81 \\
0,82 \\
0,84 \\
0,82 \\
\mathbf{0 , 8 6}\end{array}$ \\
\hline Aspecto físico & $\begin{array}{c}4 \mathrm{a} \\
4 \mathrm{~b} \\
4 \mathrm{c} \\
4 \mathrm{~d} \\
\text { a dimensão } \\
\end{array}$ & $\begin{array}{l}0,71 \\
0,72 \\
0,67 \\
0,73 \\
\mathbf{0 , 7 6}\end{array}$ & \multicolumn{2}{|r|}{$\begin{array}{cc}5 \mathrm{a} \\
5 \mathrm{~b} \\
5 \mathrm{c} \\
\text { Total da dimensão }\end{array}$} & $\begin{array}{l}0,53 \\
0,61 \\
0,74 \\
\mathbf{0 , 7 3}\end{array}$ \\
\hline Dor & $\begin{array}{c}7 \text { e } 8 \\
\text { a dimensão }\end{array}$ & $\mathbf{0 , 8 8}$ & $\begin{array}{l}\text { Aspecto social } \\
\qquad T \\
\end{array}$ & $\begin{array}{c}6 \text { e } 10 \\
\text { Total da dimensão }\end{array}$ & 0,74 \\
\hline Estado geral de saúde & $\begin{array}{c}1 \\
11 \mathrm{a} \\
11 \mathrm{~b} \\
11 \mathrm{c} \\
11 \mathrm{~d} \\
\text { a dimensão }\end{array}$ & $\begin{array}{l}0,65 \\
0,70 \\
0,71 \\
0,69 \\
0,61 \\
\mathbf{0 , 7 2}\end{array}$ & Saúde mental & $\begin{array}{c}9 \mathrm{~b} \\
9 \mathrm{c} \\
9 \mathrm{~d} \\
9 \mathrm{f} \\
9 \mathrm{~h} \\
\text { Total da dimensão }\end{array}$ & $\begin{array}{l}0,83 \\
0,83 \\
0,84 \\
0,83 \\
0,85 \\
\mathbf{0 , 8 6}\end{array}$ \\
\hline
\end{tabular}

* Itens ponderados de acordo com as instruções para cálculo do escore disponíveis em CICONELLI (1997). 


\section{Anexo 12}

\section{ANÁLISE DE RESÍDUOS DOS MODELOS ESTATÍSTICOS}

Gráfico A: Resíduo do modelo estatístico final 1,

Campinas e região, 2005. (Variável dependente: ICT)

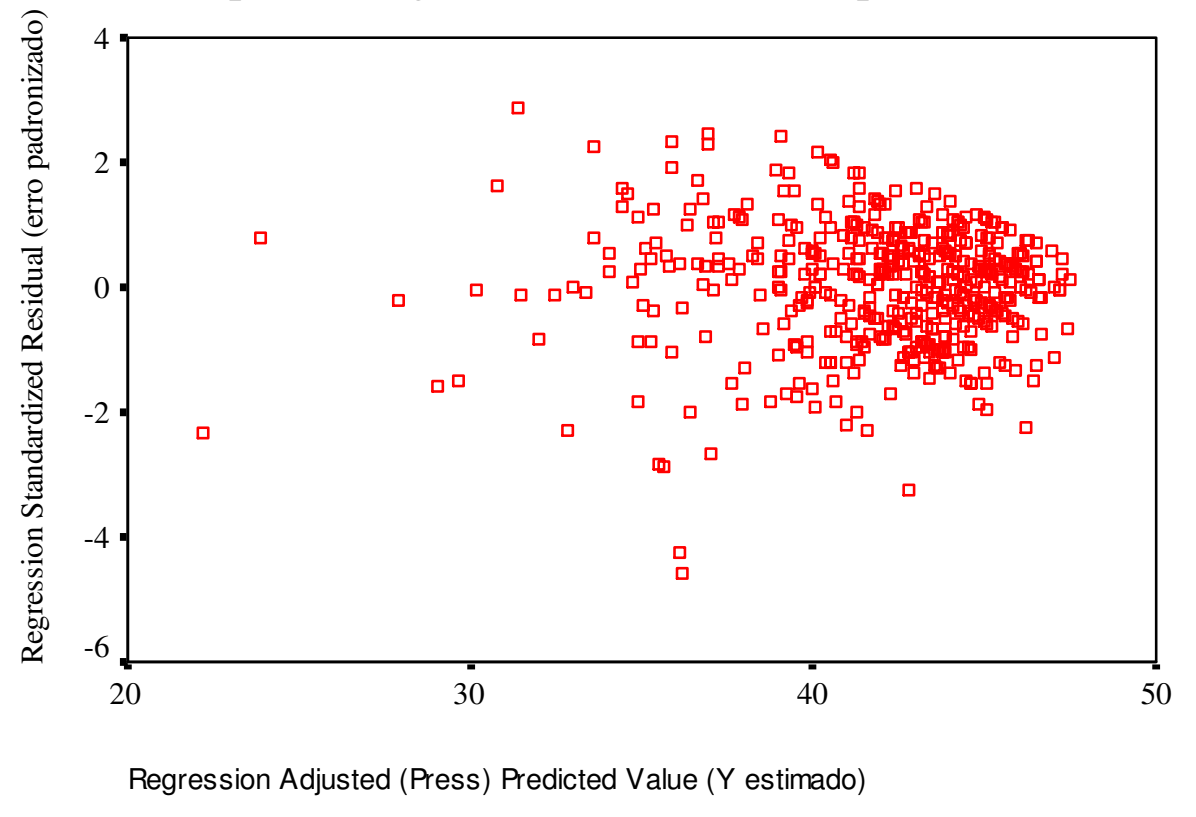

Gráfico B: Resíduo do modelo estatístico final 2,

Campinas e região, 2005 (Variável dependente: ICT)

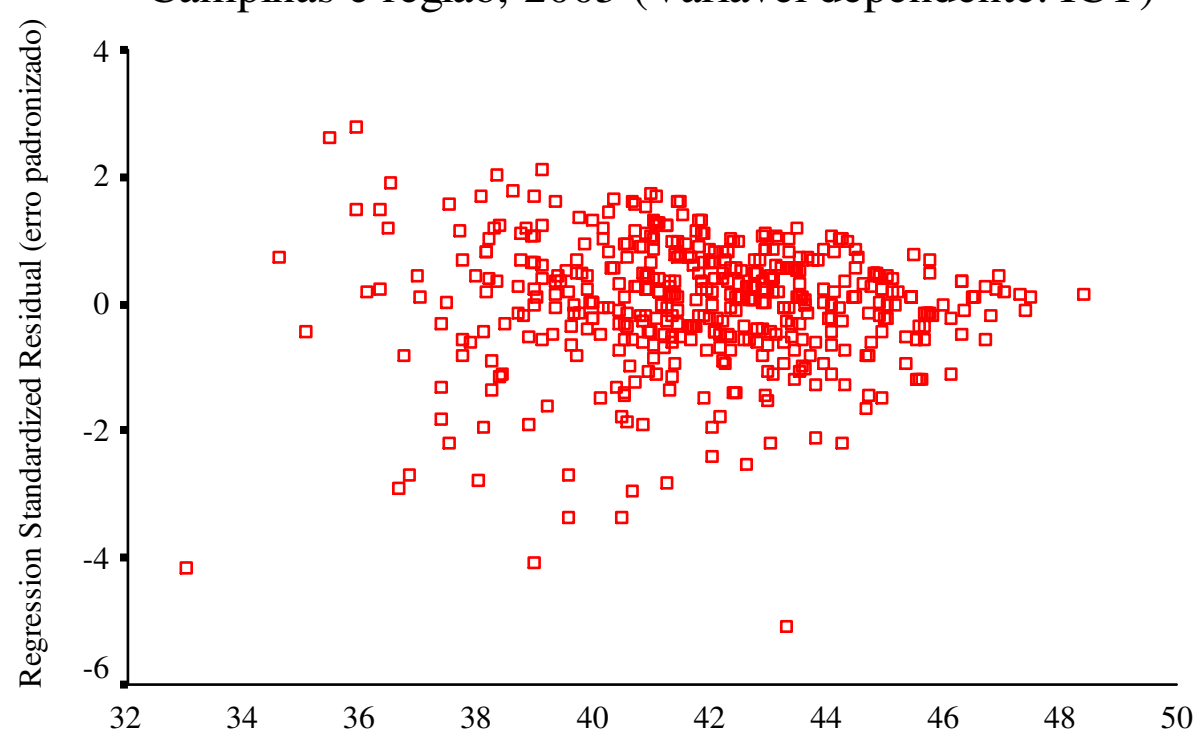




\section{Anexo 13}

\section{COMPARAÇÃO DO PERFIL DO ESTADO DE SAÚDE E DE CAPACIDADE PARA O TRABALHO COM OUTRO GRUPO DE TRABALHADORES}

Tabela F: Comparação do perfil de saúde dos eletricitários da população de estudo com trabalhadores de setor administrativo de uma empresa do município de São Paulo

(resultados padronizados por faixa etária).

Componente físico da saúde

\begin{tabular}{|c|c|c|c|c|c|c|c|c|}
\hline \multirow{2}{*}{$\begin{array}{c}\text { Dimensão } \\
\text { Faixa etária }\end{array}$} & \multicolumn{2}{|c|}{$\begin{array}{c}\text { Capacidade } \\
\text { funcional }\end{array}$} & \multicolumn{2}{|c|}{ Aspecto físico } & \multicolumn{2}{|c|}{ Dor } & \multicolumn{2}{|c|}{ Estado geral } \\
\hline & $\begin{array}{c}\text { Pop. } \\
\text { Padrão }\end{array}$ & $\begin{array}{c}\text { Pop. } \\
\text { estudo }\end{array}$ & $\begin{array}{c}\text { Pop. } \\
\text { Padrão }\end{array}$ & $\begin{array}{l}\text { Pop. } \\
\text { estudo }\end{array}$ & $\begin{array}{c}\text { Pop. } \\
\text { Padrão }\end{array}$ & $\begin{array}{c}\text { Pop. } \\
\text { estudo }\end{array}$ & $\begin{array}{c}\text { Pop. } \\
\text { Padrão }\end{array}$ & $\begin{array}{l}\text { Pop. } \\
\text { estudo }\end{array}$ \\
\hline$<30$ & 92,2 & 93,8 & 74,6 & 90,3 & 69,0 & 75,6 & 77,6 & 83,1 \\
\hline 30 a 39 & 87,3 & 91,5 & 80,3 & 85,4 & 71,3 & 77,7 & 80,7 & 80,1 \\
\hline 40 a 49 & 84,6 & 90,0 & 86,0 & 89,4 & 72,8 & 71,4 & 78,9 & 79,7 \\
\hline 50 e mais & 83,9 & 84,8 & 97,2 & 91,3 & 72,6 & 83,2 & 80,9 & 80,9 \\
\hline Total & 87,9 & 91,2 & $\mathbf{8 0 , 8}$ & 88,3 & 71,0 & 75,0 & 79,4 & 80,7 \\
\hline Padronizado & & 91,5 & & 88,1 & & 75,7 & & 80,9 \\
\hline
\end{tabular}

Componente mental da saúde

\begin{tabular}{c|cc|cc|cc|ccc}
\hline \multirow{2}{*}{ Dimensão } & \multicolumn{2}{|c|}{ Vitalidade } & \multicolumn{2}{c|}{ Aspecto social } & \multicolumn{2}{c|}{$\begin{array}{c}\text { Aspectos } \\
\text { emocionais }\end{array}$} & \multicolumn{2}{c}{ Saúde mental } \\
& Pop. & Pop. & \multicolumn{2}{c|}{ Pop. } & Pop. & Pop. & Pop. & Pop. & Pop. \\
Faixa etária & Padrão & estudo & Padrão & estudo & Padrão & estudo & Padrão & estudo \\
\hline$<30$ & 64,4 & 73,4 & 79,1 & 80,3 & 72,9 & 82,3 & 71,3 & 77,8 \\
30 a 39 & 62,7 & 73,4 & 77,7 & 81,6 & 79,4 & 83,9 & 70,3 & 75,9 \\
40 a 49 & 64,9 & 72,3 & 78,7 & 84,0 & 85,4 & 86,3 & 70,5 & 76,6 \\
50 e mais & 77,2 & 69,3 & 88,9 & 86,9 & 92,6 & 96,7 & 85,3 & 75,4 \\
\hline Total & $\mathbf{6 4 , 3}$ & $\mathbf{7 2 , 9}$ & $\mathbf{7 8 , 8}$ & $\mathbf{8 2 , 4}$ & $\mathbf{7 9 , 6}$ & $\mathbf{8 5 , 0}$ & $\mathbf{7 1 , 2}$ & $\mathbf{7 6 , 6}$ \\
\hline Padronizado & & $\mathbf{7 2 , 9}$ & & $\mathbf{8 2 , 1}$ & & $\mathbf{8 4 , 5}$ & & $\mathbf{7 6 , 6}$ \\
\hline
\end{tabular}

População padrão: 224 empregados de uma empresa de auto-gestão de planos de previdência privada e de saúde na cidade de São Paulo, dados não demonstrados da pesquisa de MARTINEZ (2002).

Tabela G: Comparação do perfil de capacidade para o trabalho dos eletricitários da população de estudo com trabalhadores de setor administrativo de uma empresa do município de São Paulo (resultados padronizados por faixa etária).

\begin{tabular}{|c|c|c|}
\hline Faixa etária & Pop. Padrão & Pop. estudo \\
\hline$<30$ & 42,2 & 42,6 \\
\hline 30 a 39 & 41,6 & 42,1 \\
\hline 40 a 49 & 41,7 & 41,3 \\
\hline 50 e mais & 44,6 & 41,4 \\
\hline Total & 41,9 & 41,8 \\
\hline Padronizado & & 42,0 \\
\hline
\end{tabular}

